University of Rhode Island

DigitalCommons@URI

Open Access Dissertations

1996

\title{
Algorithms for Missing Data Replacement in Time Series Analysis
}

Suzanne M. Colby

University of Rhode Island

Follow this and additional works at: https://digitalcommons.uri.edu/oa_diss

\section{Recommended Citation}

Colby, Suzanne M., "Algorithms for Missing Data Replacement in Time Series Analysis" (1996). Open Access Dissertations. Paper 916.

https://digitalcommons.uri.edu/oa_diss/916

This Dissertation is brought to you for free and open access by DigitalCommons@URI. It has been accepted for inclusion in Open Access Dissertations by an authorized administrator of DigitalCommons@URI. For more information, please contact digitalcommons-group@uri.edu. 


$$
\begin{aligned}
& \text { BF } 199 \\
& C 653 \\
& 19 \therefore
\end{aligned}
$$

ALGORITHMS FOR MISSING DATA REPLACEMENT IN

TIME SERIES ANALYSIS

$B Y$

SUZANNE M. COLBY

A DISSERTATION SUBMITTED IN PARTIAL FULFILLMENT OF THE REQUIREMENTS FOR THE DEGREE OF DOCTOR OF PHILOSOPHY

IN

PSYCHOLOGY

$$
\begin{gathered}
\text { UNIVERSITY OF RHODE ISLAND } \\
1996 \\
36,14,16
\end{gathered}
$$




\section{ABSTRACT}

Three simulation studies were conducted in order to compare the accuracy of two algorithms for estimating missing observations in time series data. Each study was designed to test the algorithms under conditions which are likely to occur in applied behavioral research: (1) Study 1 examined the effects of model misspecification on the accuracy of estimation; (2) study 2 examined the effects of systematically missing data (versus randomly missing data) on estimation accuracy; (3) and study 3 explored the accuracy of the algorithms under conditions of nonnormality in the data series. The two algorithms, the EM (Estimation Maximization) Algorithm and the Jones (1980) Maximum Likelihood Algorithm are compared using simulated time series with positive and negative autocorrelation, four different underlying ARIMA models, normal and lognormal distributions, and 0,20 , or $40 \%$ of data eliminated from the series. Major findings are: (1) The EM Algorithm (as currently implemented in the EMCOV2.3 program by Graham, 1995) is inaccurate under virtually all conditions tested for estimating time series data; (2) model misspecification caused only minimal problems for ML estimation; (3) systematic missing data patterns led to slightly inaccurate autocorrelation estimates, but other time series parameters could be estimated accurately when ML was used to replace missing data; and (4) neither EM nor ML performed worse under conditions of nonnormality than under conditions of normally distributed data. Findings from research on time series should also generalize to other statistical models which involve repeated measures on one or a group of individuals or units. Recommendations are made for future research in this area. 


\section{ACKNOWLEDGMENTS}

I would like to express my appreciation to my dissertation comittee. James Heltshe, Ph.D. and James Prochaska, Ph.D., have been involved throughout the course of my graduate studies, including my masters thesis committee and my comprehensive examination committee. Their insights and orientation toward the concerns of the applied researcher have contributed to the relevance of my program of research. Joseph Fava, Ph.D., and Cynthia willey, Ph.D., joined this comittee more recently; however, they have also been influential throughout much of my graduate career. Finally. I want to express my thanks to wayne F. Velicer, Ph.D., for his guidance as my academic advisor. Wayne has had substantial influence on my development as a quantitative researcher, and has served as a mentor in that domain for the past six years.

I also want to acknowledge the support of the University of Rhode Island's Academic Computing center, especially Charlene Yang, for contributing her programming expertise. I am grateful to the contribution of Patricia Foster, who prepared all of the tables and appendices for this dissertation, and to Betty Y. Abreu, who assisted with data deletion, reformatting EMcov2.3 output, and coding and entering SAS printouts.

Many thanks are extended to Peter M. Monti, Ph.D., my mentor for the past eight years at Brown University's center for Alcohol and Addiction studies. Peter has been supportive of my graduate studies and quantitative research, while providing me with the opportunity to develop my career as an applied clinical researcher. I consider myself extremely fortunate to have worked across the diverse realms of research in which I've been involved. 
Finally, I want to thank the "other Dr. Colby" of our household, who has tolerated my years of seclusion in front of a computer. Jack has served as my critic and most ardent supporter; I appreciate and have benefited from both of these roles. 
page

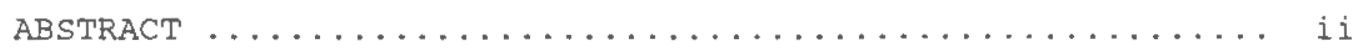

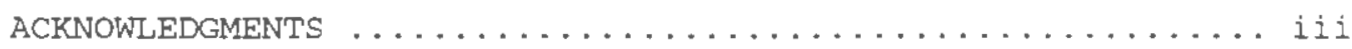

TABLE OF CONTENTS $\ldots \ldots \ldots \ldots \ldots \ldots \ldots \ldots \ldots \ldots \ldots \ldots$

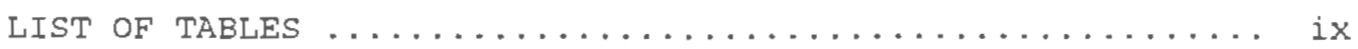

LIST OF FIGURES $\ldots \ldots \ldots \ldots \ldots \ldots \ldots \ldots \ldots \ldots \ldots \ldots \ldots \ldots \ldots \ldots \ldots \ldots$

Introduction $\ldots \ldots \ldots \ldots \ldots \ldots \ldots \ldots \ldots \ldots \ldots \ldots \ldots \ldots$

Time series Analysis: overview ............... 3

Time Series Model Identification: Overview .......... 8

Interrupted Time series Analysis $\ldots \ldots \ldots \ldots \ldots \ldots \ldots$

Alternative Analysis Approaches .............. 18

Missing Data and Time Series Analysis ............. 19

Study 1: Comparison of ML and EM Algorithms for Data

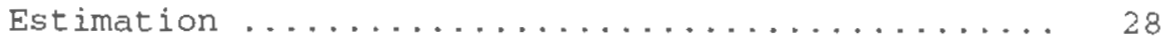

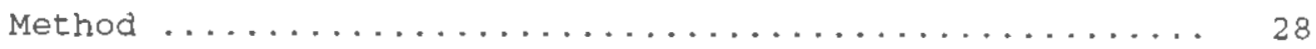

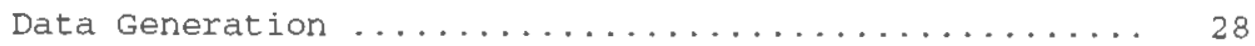

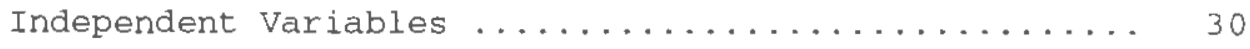

Dependent variables .................... 36

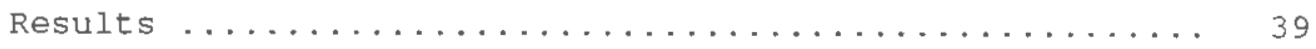

Level ............................. 40

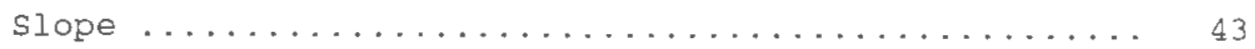

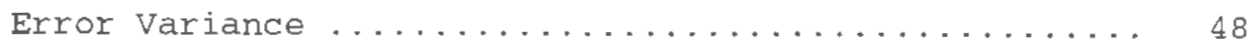

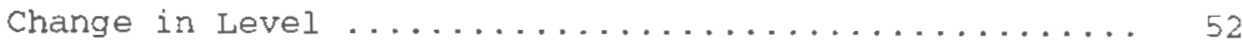

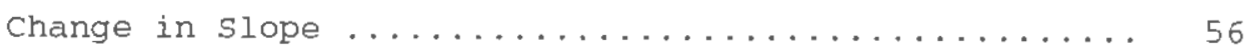

Phi (Autoregressive Models) ................. 60

Phi (Moving Averages Model) ................. 69

Theta (Moving Averages Model) ................. 71

Discussion $\ldots \ldots \ldots \ldots \ldots \ldots \ldots \ldots \ldots \ldots \ldots \ldots \ldots \ldots \ldots$ 
Study 2: The effects of systematic missing data patterns on the accuracy of missing data estimation in time

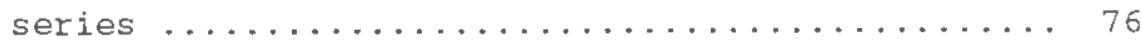

Method ........................... 76

Independent variables $\ldots \ldots \ldots \ldots \ldots \ldots \ldots \ldots \ldots \ldots . \ldots 77$

Dependent variables $\ldots \ldots \ldots \ldots \ldots \ldots \ldots \ldots \ldots \ldots . \ldots . \ldots 79$

Results ................................. 80

Leve1 .............................. 81

slope $\ldots \ldots \ldots \ldots \ldots \ldots \ldots \ldots \ldots \ldots \ldots \ldots \ldots \ldots \ldots . \ldots \ldots$

Error variance $\ldots \ldots \ldots \ldots \ldots \ldots \ldots \ldots \ldots \ldots \ldots . \ldots \ldots$

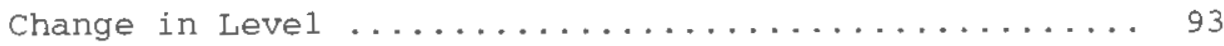

Change in slope $\ldots \ldots \ldots \ldots \ldots \ldots \ldots \ldots \ldots \ldots . \ldots \ldots$

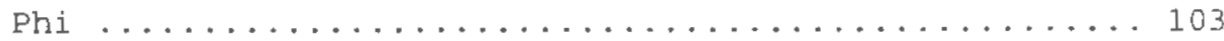

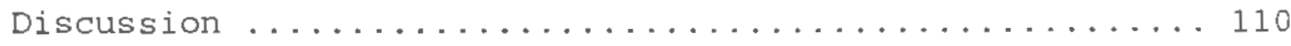

Study 3: The effects of nonnormality on the accuracy of missing data estimation in time series ........ 115

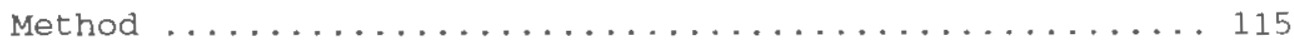

Independent variables $\ldots \ldots \ldots \ldots \ldots \ldots \ldots \ldots \ldots \ldots$

Dependent variables ..................... 117

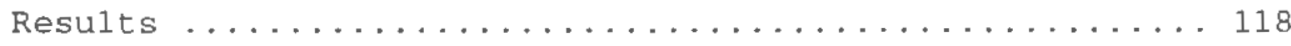

Leve1 ............................... 118

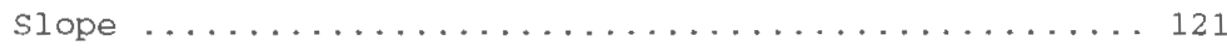

Error variance ....................... 124

Change in Level $\ldots \ldots \ldots \ldots \ldots \ldots \ldots \ldots \ldots \ldots \ldots \ldots \ldots$

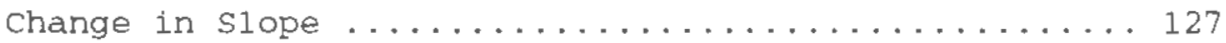

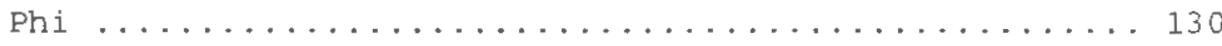

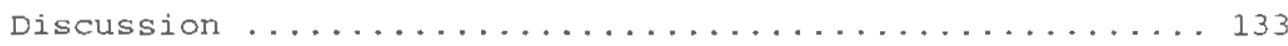

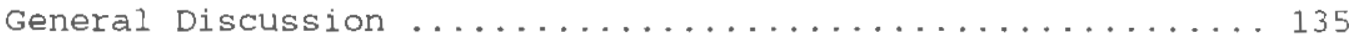




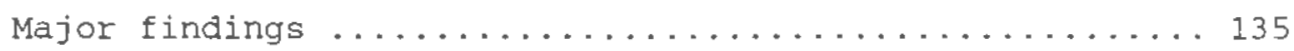

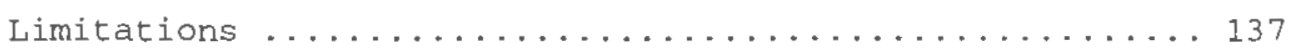

Recommendations and future directions ............. 139

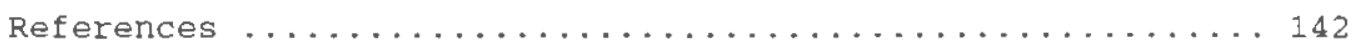

Apperdix A: ANOva summary Table for Level (study 1) ....... 149

Appendix B: ANovA sumnary Table for slope .............. 150

Appendix $C$ : ANOVA Sumary Table for variance ............ 151

Appendix D: ANOVA Sumary Table for Change in Level ...... 152

Appendix E: ANOVA Sumary Table for Change in slope ....... 153

Appendix F: ANovA Summary Table for Positive Phi

(Autoregressive Models) ............... 154

Appendix G: ANOVA Sumary Table for Negative Phi

(Autoregressive Models) ................ 155

Appendix H: ANOVA Summary Table for Positive Phi

(Moving Averages Model) .............. 156

Appendix I: ANOVA Summary Table for Negative Phi

(Moving Averages Model) ............... 157

Appendix J: ANova summary Table for positive Theta ....... 158

Appendix K: ANOVA Summary Table for Negative Theta ....... 159

Appendix L: Follow Up of $\mathrm{T} \times \mathrm{M} \times \mathrm{PM}$ Interaction in the

Estimation of Positive Phi .............. 160

Appendix M: ANOVA Summary Table for Level (study 2) ...... 161

Appendix N: ANova summary Table for slope ............ 162

Appendix 0: ANova sumary Table for variance $\ldots \ldots \ldots \ldots \ldots . .163$

Appendix P: ANOVA summary Table for Change in Level ...... 164

Appendix Q: ANOVA sumary Table for Change in slope ...... 165

Appendix R: ANova summary Table for Positive Phi ........ 166

Appendix S: ANOVA Summary Table for Negative Phi ........ 167 
Appendix $\mathrm{T}$ : Follow Up of $\mathrm{T} \times \mathrm{P} \times \mathrm{PM}$ Interaction in the Estimation of Level ................. 168

Appendix U: Follow Up of $\mathrm{T} x \mathrm{P} x$ PM Interaction in the Estimation of slope ................... 169

Appendix V: Follow Up of $\mathrm{T} \times \mathrm{P} \times \mathrm{PM}$ Interaction in the

Estimation of variance .............. 170

Appendix $\mathrm{W}$ : Follow up of $\mathrm{T} x \mathrm{P} \times \mathrm{PM}$ Interaction in the Estimation of Change in Level ............ 171

Appendix $\mathrm{X}$ : Follow Up of $\mathrm{T} x \mathrm{P} x$ PM Interaction in the

Estimation of Change in slope .......... 172

Appendix $\mathrm{Y}$ : Follow Up of $\mathrm{T} \mathrm{x} \mathrm{P} \mathrm{x}$ PM Interaction in the

Estimation of Positive phi ............ 173

Appendix $\mathrm{z}$ : Follow Up of $\mathrm{T} x \mathrm{P} x \mathrm{PM}$ Interaction in the

Estimation of Negative Phi ............ 174

Appendix AA: ANOVA Summary Table for Level (Study 3) . .... 175

Appendix BB: ANOVA sumary Table for slope ............ 176

Appendix cC: ANova summary Table for variance ......... 177

Appendix DD: ANovA summary Table for change in Level ..... 178

Appendix EE: ANovA summary Table for change in slope ...... 179

Appendix FF: ANOVA summary Table for Phi ............. 180

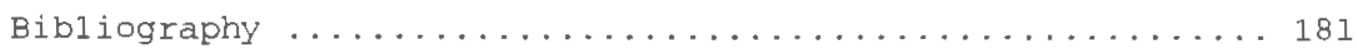




\section{LIST OF TABLES}

Table 1

Means and Standard Deviations of Estimated Level. Criterion

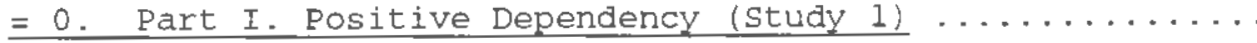

Table 2

Means and Standard Deviations of Estimated Leve1. Criterion

$\equiv$. Part II. Negative Dependency (Study 1) ...........

Table 3

Means and standard Deviations of Estimated Tangent of Slope.

Criterion $=.27$. Part I. Positive Dependency (Study 1) $\cdots$

Table 4

Means and Standard Deviations of Estimated Tangent of Slope.

Criterion $=.27$. Part II. Negative Dependency (Study 1) $\cdots$

Table 5

Means and Standard Deviations of Estimated Error Variance.

Criterion $=1.0$. Part I. Positive Dependency (Study 1) ... 50

Table 6

Means and standard Deviations of Estimated Error variance.

Criterion $=1.0$. Part II. Negative Dependency (Study 1) $\cdots$

Table 7

Means and Standard Deviations of Estimated Change in Level.

Criterion $=1.5$. Part I. Positive Dependency $($ Study 1$) \cdots 54$

Table 8

Means and Standard Deviations of Estimated Change in Level.

Criterion $=1.5$. Part II. Negative Dependency (Study 1) $\cdots 55$ 
Table 9

Means and standard Deviations of Estimated Change in slope. Criterion $=0$, Part I. Positive Dependency (study 1) $\ldots .558$

Table 10

Means and Standard Deviations of Estimated Change in slope. Criterion $=0$. Part II. Negative Dependency (Study 1) ... 59

Table 11

Means and Standard Deviations of Estimated Phi. Criterion

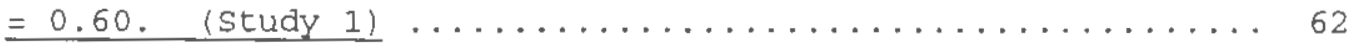

Table 12

Means and Standard Deviations of Estimated Phi. Criterion

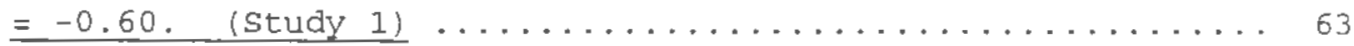

Table 13

Means and Standard Deviations of Estimated Autocorrelation in Autoregressive Model. (study 1) .............. 70

Table 14

Means and Standard Deviations of Estimated Level. Criterion $=0$. Part I. Positive Dependency (study 2) $\ldots \ldots \ldots \ldots$.

Table 15

Means and Standard Deviations of Estimated Level. Criterion =0. Part II. Negat ive Dependency (study 2) $\ldots \ldots \ldots \ldots \ldots$ Table 16

Means and Standard Deviations of Estimated Tangent of slope. Criterion $=.27$. Part I. Positive Dependency (study 2 ) $\ldots 86$ 
Table 17

Means and Standard Deviations of Estimated Tangent of slope. Criterion $=.27$. Part II. Negative Dependency (Study 2) $\cdots \quad 87$

Table 18

Means and Standard Deviations of Estimated Error Variance. Criterion $=1.0$. Part I. Positive Dependency (Study 2) $\cdots 91$

Table 19

Means and Standard Deviations of Estimated Error Variance. Criterion $=1.0$. Part II. Negative Dependency (Study 2) $\ldots 92$ Table 20

Means and Standard Deviations of Estimated Change in Level. Criterion $=1.5$. Part I. Positive Dependency (Study 2) $\ldots 95$ Table 21

Means and Standard Deviations of Estimated Change in Level. Criterion $=1.5$. Part II. Negative Dependency (Study 2) $\ldots 96$ Table 22

Means and Standard Deviations of Estimated Change in Slope.

Criterion $=0$. Part I. Positive Dependency (Study 2) … 100

Table 23

Means and Standard Deviations of Estimated change in slope. Criterion $=0$. Part II. Negative Dependency (Study 2) $\ldots 101$ Table 24

Means and Standard Deviations of Estimated Positive Phi.

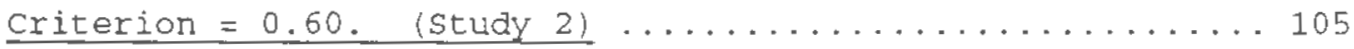


page

Table 25

Means and Standard Deviations of Estimated Negative Phi.

Criterion $=-0.60 . \quad($ study 2$) \ldots \ldots \ldots \ldots \ldots$

Table 26

Means and Standard Deviations of Estimated Level. Criterion

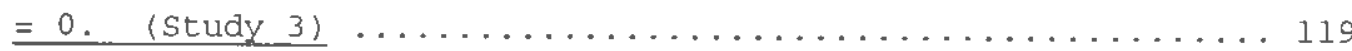

Table 27

Means and Standard Deviations of Estimated Tangent of slope.

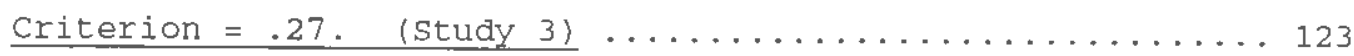

Table 28

Means and Standard Deviations of Estimated Error Variance.

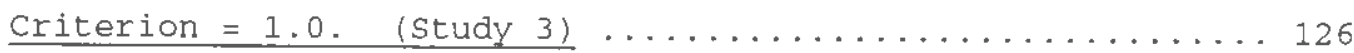

Table 29

Means and Standard Deviations of Estimated Change in Level.

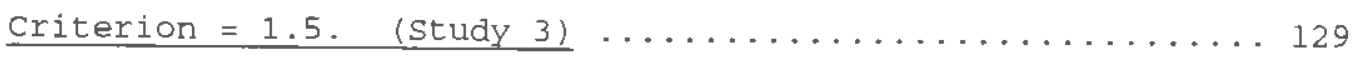

Table 30

Means and Standard Deviations of Estimated Change in S1ope.

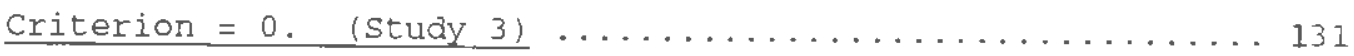

Table 31

Means and Standard Deviations of Estimated Phi. Criterion

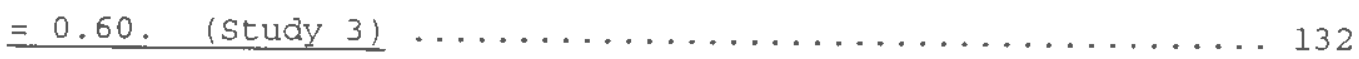




\section{LIST OF FIGURES}

page

Figure 1.

Illustrations of our time series using computer generated

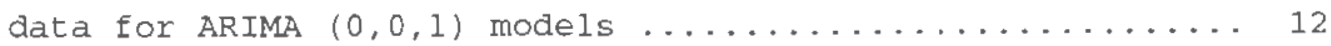

Figure 2.

Technique by percent missing interaction for level ...... 44

Figure 3.

Technique by percent missing interaction for slope ....... 49

Figure 4.

Technique by percent missing interaction for variance ..... 53

Figure 5.

Technique by percent missing interaction for change in

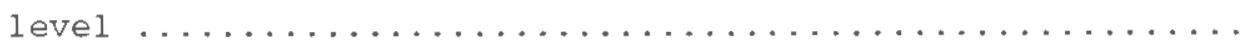

Figure 6.

Technique by percent missing by model interaction for phi . 65

Figure 7.

Technique by model interaction for negative phi ........ 67

Figure 8.

Technique by percent missing interaction for negative phi . 68

Figure 9.

Technique by percent missing by pattern interaction for

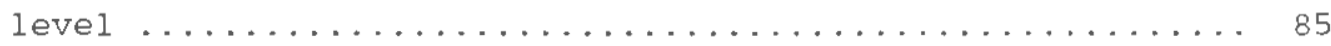

Figure 10.

Technique by percent missing by pattern interaction for

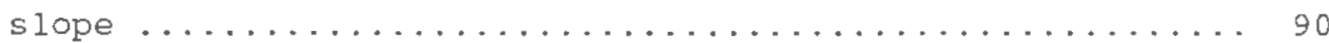


Figure 11.

Technique by percent missing by pattern interaction for variance $\ldots \ldots \ldots \ldots \ldots \ldots \ldots \ldots \ldots \ldots \ldots \ldots \ldots \ldots . \ldots \ldots$

Figure 12 .

Technique by percent missing by pattern interaction: Change

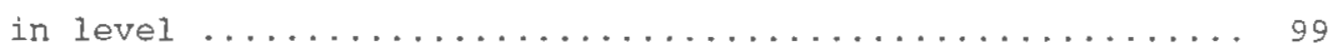

Figure 13.

Technique by percent missing by pattern interaction: Change

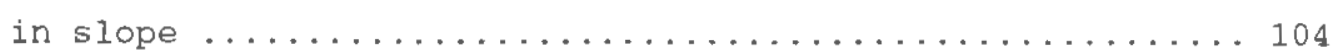

Figure 14.

Technique by percent missing by pattern interaction: Positive phi ...................................

Figure 15.

Technique by percent missing by pattern interaction:

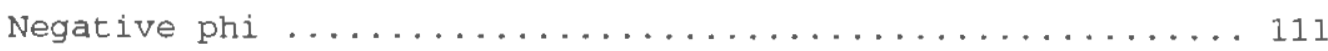

Figure 16.

Technique by percent missing interaction for level ...... 122

Figure 17.

Technique by percent missing interaction for slope ..... 125

Figure 18.

Technique by percent missing interaction for variance .... 128 Figure 19.

Technique by percent missing interaction for phi ....... 134 


\section{Algorithms for Missing Data Replacement in Time Series Analysis}

Time series analysis is a statistical procedure appropriate for repeated observations on a single subject or unit, A practical advantage of the procedure is that it is highly appropriate for the type of data available in applied settings. A theoretical strength is that the method emphasizes the nature of the change process and is appropriate for assessing the pattern of change over time. The goal of the analysis may be to determine the nature of the process that describes an observed behavior or to evaluate the effects of a treatment or intervention. Time series designs also share relevant characteristics with other statistical models which involve repeated measures on one or a group of individuals or units, e.g., longitudinal data procedures such as repeated measures analysis of variance designs and lagged parel designs in structural equation modeling. Thus, findings based on time series designs are expected to generalize to these other related statistical models.

In the first section of this paper, an overview of time series design and analysis methods is provided, with an emphasis on practical issues of application. This section begins with an explanation of model identification, a central issue in time series analysis. Since time series involves repeated observations on the same unit, the data are likely to have dependency across the observations. Dependency is the extent to which a subject's for any experimental unit's) behavior at time $\underline{t}$ is predicted by that subject's behavior at time $t-1$. The terms "dependency" and 
autocorrelation" are used interchangeably. Models which account for dependency in the data are available. Model identification involves specifying which of several alternative Autoregressive Integrated Moving Average (ARIMA) models best describes the series and may be used to investigate basic processes.

The second section describes intervention analysis, the analysis used to determine if an intervention results in a change in the series. This could be either a change in level or a change in the direction (i.e., slope) of the series. Applications of intervention analysis include the evaluation of the effects of a treatment program on a single individual, and the evaluation of organizational-level changes (i.e., program or policy evaluation). The overview section will subsequently review the problem of missing data in time series analysis and will conclude with a rationale for the three studies performed as part of this dissertation. These three simulation studies examine the accuracy of two algorithms for estimating missing observations in time series data. Each study was designed to test the algorithms under conditions which are likely to occur in applied behavioral research: (1) Study 1 examined the effects of model misspecification on the accuracy of estimation; (2) study 2 examined the effects of systematically missing data (versus randomly missing data) on estimation accuracy; (3) and study 3 explored the accuracy of the algorithms under conditions of nonnormality in the data series. The two algorithms, the EM (Estimation Maximization) Algorithm and the Jones (1980) Maximum Likelihood Algorithm were also compared at 
different levels of missing data and positive versus negative autocorrelation in the series. Although simulated time series data were used for these studies, results of these studies do have implications for all time-ordered data.

\section{Time Series Analysis: overview}

Time series analysis involves repeated observations on a single unit (often a single subject) over time. In the area of the clinical psychology, the analysis of interest is often an interrupted time series analysis. The interruption corresponds to the occurrence of an intervention and the goal is to evaluate its effect. Traditional between-groups statistical procedures cannot be employed because repeated observations on the same unit cannot be assumed to be independent. The presence of dependency may substantially bias a statistical test that does not take it into account. The direction of the bias will depend on the direction of the dependency. If the dependency is positive, apparent variability in the data is decreased (i.e., error variance is artificially decreased), and the probability of a Type I error increases. If the dependency is negative, apparent variability is increased, and the probability of a Type II error increases. This phenomenon has been demonstrated using simulation studies (crosbie, 1993; Padia, 1975). The major unique feature of time series analysis is that it takes dependency into account, and therefore yields more accurate parameter estimates and significance tests than if it were ignored. The most widely employed methods of analysis for time series designs are based on the ARIMA (Autoregressive Integrated Moving Average) models (Box \& Jenkins, 
1976; Box \& Tiao, 1965). These procedures permit the effects of dependency to be statistically removed from the data (Glass, Willson, \& Gottman, 1975; Gottman, 1973; Gottman \& Glass, 1978).

Time series analysis has generated widespread interest for a number of reasons. First, time series designs are particularly applicable to the study of problems in applied settings where more traditional between-subject designs are often impossible or very difficult to implement. Second, time series designs can make a compelling case regarding causality because of the temporal occurrence of both the intervention and effect of the intervention. Third, time series designs possess the additional advantage of permitting the study of the pattern of intervention effects (i.e., temporary effects vs. permanent effects, changes in slope as well as changes in level) over and above the usual question of the existence of a mean treatment effect.

The employment of time series methods also suffers from several drawbacks. First, generalizability cannot be inferred from a single study; only through systematic replication. second, traditional measures may be inappropriate for time series designs; measures are required which can be repeated a large number of times on a single subject, usually at short intervals. Third, a large number of observations is required for accurate model identification. Model identification is a necessary step in order to remove the dependency present in the data. Advances in methods of analysis in the last decade have provided partial solutions to the generalizability issues and the sample size issues. Finally, time series analysis requires 
complete data for analysis. Researchers must handle missing data problems prior to analysis. It is the objective of the current program of research to provide a better empirical basis upon which to make decisions related to handling missing data in time series designs.

Time series design examole. To illustrate the use of time series analysis, consider the following hypothetical example. A time series design was used to evaluate the effects of a brief motivational intervention in a physician's office on smoking behavior. During the baseline phase $(20$ days prior to the office visit) subjects were asked to monitor their daily smoking behavior. The baseline phase (i.e., pre-intervention series) consists of tabulations of number of cigarettes smoked per day for 20 days. The intervention occurred during the office visit and consisted of feedback to the patient on the impact smoking was having on them, based on various biological measures, and a motivational intervention to attempt to elicit a commitment to behavior change on the part of the patient. Following the intervention, an additional 20 days of observation (i.e., the post-intervention series) occurred.

The analysis estimates two parameters for each phase, level and slope. Conceptually, we are fitting a straight line to each series of data, with the level referring to the intercept of the line and the slope referring to the rate of increase or decrease of the series over time. A slope near 0.0 would be presented graphically as a nonincreasing line parallel to the time axis. In the case of a nearzero slope, the level can be also interpreted as the mean of the 
series. The intervention can be evaluated in terms of the significance of the changes that occur in the level and slope of the series from pre-to post-intervertion. A positive outcome of this study would be represented by a significant decrease in the level of smoking behavior, and either a near-zero or decreasing slope.

This example illustrates several of the strengths and weaknesses of time series analysis. First, this design illustrates how time series could be incorporated into an applied setting. second, the evaluation of an abrupt change in the level of the series, if it occurred at the same point in time when the intervention occurred, permits a strong causal inference about the relation between intervention and the outcome (avoiding for the purposes of this discussion the problems with demand characteristics and validity of self report). Third, a change in slope provides additional information about the nature of the intervention effect. The drawbacks of time series analysis are also illustrated by this example. The issue of generalizability could be addressed by employing multiple subjects to replicate the effect. The dependent measure used in this example was appropriate for repeated observations, but the length of the series was too short to permit model identification.

The most widely used time series analysis procedure is described by Glass, Willson, and Gottman (1975; Gottman, 1973; Gottman \& Glass, 1978), following Box and Jenkins (1976; Box \& Tiao, 1965). It involves a two step process: first, the researcher identifies which of a family of ARIMA (p, d, q) models is appropriate 
for the data; and then the researcher employs a specific transformation appropriate to the identified model to transform the dependent observed variable $\left(z_{j}\right)$ into a serially independent variable $\left(Y_{i}\right)$. Intervention effects can then be evaluated by a generalized least squares estimate of the model parameters. This procedure suffers from a number of drawbacks including: (a) the requirement of a large number of data points for accurate model identification; mathematical complexity; and (c) problems with accurately and reliably performing the model identification task, even when the recommended minimum number of observations are obtained (Velicer a Harrop, 1983). Alternative procedures that avoid model identification have been proposed (Simonton, 1977; Algina \& Swaminathan, 1977, 1979; Swaminathan \& Algina, 1977; Velicer \& McDonald, 1984; 1991).

A key concept for time series aralysis is dependence. This is assessed by calculating the autocorrelations of various lags. A typical correlation coefficient estimates the relation between two variables measured at the same time. An autocorrelation estimates the relation between the same variable measured on two occasions. For example, if we have a series of observations and we pair the second observation with the first, the third observation with the second, and so on, until the last observation is paired with the second from the last observation and we then calculate the correlation between the paired observations, we have calculated the lag one autocorrelation. If we pair the third with the first and each subsequent observation with the observation two occasions behind 
we have calculated the lag two autocorrelation. The lag of an autocorrelation refers to how far in the past you go. Typically, autocorrelations are between 1.00 and -1.00 . In the behavior sciences, the size of the autocorrelation will typically decrease as the lag increases. The exception is seasonal or cyclic data, which is sometimes found in the study of addictive behaviors such as alcohol abuse. The pattern of the autocorrelation and the related partial-autocorrelations at each lag are employed as the basis for identifying the specific ARIMA model. These plots are provided in the printed output of most time series analysis programs. (Partialautocorrelations are mathematically complex and won't be defined here; see Box and Jenkins, 1976, for detailed description). A white noise model is one where there is no dependency in the data, i.e., the autocorrelations and partial-autocorrelations for all lags are zero.

Time Series Model Identification: Qverview

In interrupted time series analysis, model identification often represents a first step, preliminary to the goal of the analysis, i.e. the estimating and testing of the pre- and post-intervention parameters (Box \& Jenkins, 1976; Box \& Tiao, 1965, 1975; Glass, Wilson, \& Gottman, 1975; Mccleary \& Hay, 1980; Velicer \& McDonald, 1984, 1991). Model identification can also be the primary goal of a time series analysis. Determining the specific ARIMA model can identify a basic process underlying a particular behavior, thereby addressing important theoretical and etiologic issues. However, model identification can be a difficult and problematic procedure. 
While an extensive variety of procedures have been developed to identify the model (Glass, Willson, \& Gottman, 1975; Mccleary \& Hay, 1980; Akaike, 1974; Beguin, Courieroux, \& Monfort, 1980; Bhansali \& Downham, 1977; Gray, Kel1y, \& McIntire, 1978; Hannan \& Rissanen, 1982; Kashyap, 1977; Parzen, 1974; Pukkila, 1982; Rissanen, 1978; 1986a, 1986b; Schwartz, 1978; Tsay, 1984; Tsay \& Tiao, 1984), no clear consensus as to which method is best has emerged. Model identification has also been problematic because of the large number of data points required for accurate identification, the complexity of the procedures, and problems with accuracy and reliability of some methods, even under ideal circumstances (Velicer \& Harrop, 1983). In this section, some procedures and inherent problems in model identification will be described.

\section{Definition of Model Identification. The ARIMA (D, d,g) model} represents a family of models with the parameters designating which specific model is involved. The first parameter ( $D$ ) is the order of the autoregressive parameter and the last parameter ( $g$ ) is the order of the moving average parameter. The middle parameter (d) represents the presence of instability or stochastic drift in the series. Each of the parameters of the model may be of order $0,1,2,3$ or more, although higher order models are unusual in the behavioral sciences (Glass, et al., 1975). A parameter equal to zero indicates the absence of that term from the model.

Model identification involves a number of aspects which can be determined with varying degrees of accuracy. Selection of the Model involves determining which specific model from the ARIMA (D, d, g) 
family of models most parsimoniously describes the data. This is a difficult task to accomplish accurately because the different models, under certain conditions, can appear very similar. For example, a first order moving average model, i.e., a $(0,0,1)$ model is confusable with an autoregressive model of high order, e.g., a $(5,0,0)$ model. order refers to how many preceding observations must be considered in order to account for the dependency in the series. Accuracy is difficult because higher order autocorrelation terms are typically closer to zero than first order terms and, therefore, are more likely to be included within the bounds for any error estimate. order reflects how far into the past one must go to predict the present observation.

Degree of dependency refers to how large the autocorrelations are on a scale between 0.0 and 1.0. As with other dependency indicators, this can be interpreted as the strength of relationship between consecutive measurements. The accuracy of estimation is largely a function of number of observations with numbers of observations over 100 providing reasonably accurate estimates (Glass, Willson, \& Gottman, 1975; Ljung \& Box, 1978; Box \& Pierce, 1970). The degree of dependency indicates the extent to which an observation at any point in time is predictable from one or more preceding observations. For example, if smoking data were collected daily, then finding an order 1 model would suggest that the previous observation $(t-1=1$ day ago) was more important than the and previous observation $(t-2=2$ days ago) in predicting the level of the series at time $t$. 
Autocorrelation coefficients. Autocorrelation in the moving average component of a time series (ARIMA) model is represented by the coefficient theta $a_{i}\left(\theta_{i}\right)$ where $i$ refers to the lag of the autocorrelation. In the autoregressive component of an ARIMA model, autocorrelation is represented by the coefficient $2 \mathrm{phi}_{\mathrm{i}}\left(\phi_{\mathrm{i}}\right)$.

Direction of Dependency refers to whether the autocorrelation is positive or negative. This can be determined with a high degree of accuracy when the dependency is clearly non-zero. The direction is of less interest as the degree of dependency approaches zero. The direction of dependency has clear implications. When the sign of the autocorrelation is negative, a high level for the series on one occasion predicts a low level for the series on the next occasion. When the sign is positive, an above average level of the series on one occasion predicts a higher than average level on the next occasion.

Ilustrations of Alternative Time series. Figure I illustrates four different types of models with computer-generated data $\left(N_{1}=N_{2}\right.$ $=50)$ for an ARIMA $(0,0,1)$ model, i.e., an order 1 moving averages model. The first graph (A) represents an ideal interrupted time series example with no error and an immediate change in level of one unit at the time of intervention. The second graph (B) is the same model with the same change in level but with a random error component added. The variance or the random error is 1.00 . There is no autocorrelation in this model. The third graph (C) is a model with the same change in level and error variance but with a large negative autocorrelation (theta $=-.80$ ). The fourth graph (D) is a model with 
Figure 1. Illustrations of four time series using computer-generated data for ARIMA $(0,0,1)$ mode1s.
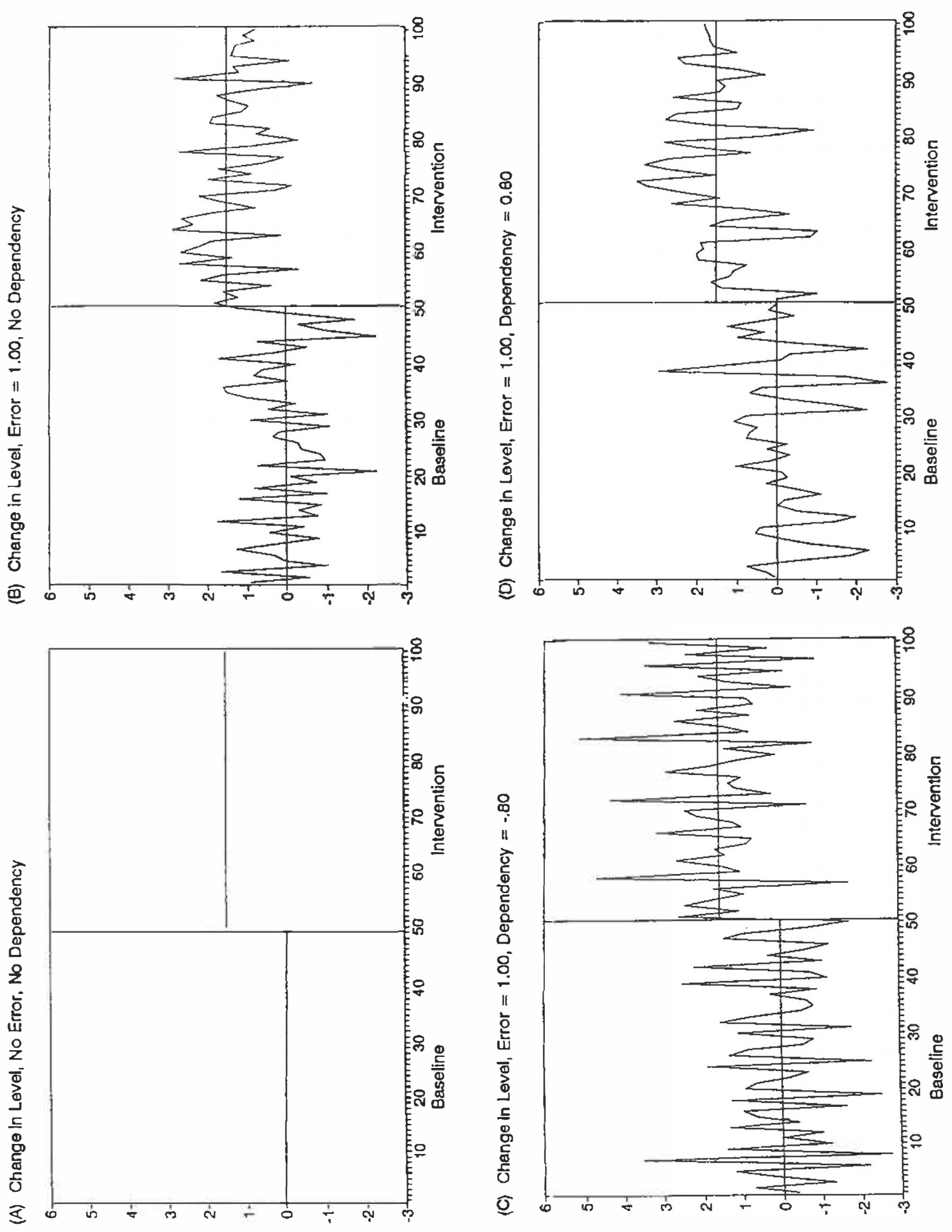
the same change in level and error variance as (B) but with a large positive autocorrelation (theta $=0.80$ ). The impact of dependency can be easily observed. The negative dependency results in an exaggerated "sawtooth" graph with increased apparent variability. The positive dependency results in a smoother graph with decreased apparent variability. The inclusion of an intervention effect (the change in level) illustrates how difficult it is to determine if an intervention had an effect by visual inspection alone.

There are a few recent examples in the applied behavioral research literature which demonstrate the utility of model identification in time series analysis for theory testing le.g., see Rosel đe Elósegui, 1994; Velicer, Redding, Richmond, Greeley, \& Swift, 1992). These studies are designed to determine which of various competing theoretical models are best represented by the time series data. The velicer et al. (1992) study is a comparison of three models of nicotine regulation. These models seek to explain the mechanism that determines how smokers increase or decrease their level of smoking in order to maintain a certain level of nicotine in their systems. Each of the three models was identified with one of three broad classes of time series (ARIMA) models: (1) a positive dependency model, (2) a white noise model (no dependency), and (3) a negative dependency model. By determining which model best represented smokers' time series data, empirical support for each of the models could be evaluated. In the next section, the model identification procedures used in the velicer et al. (1992) study 
will be described as they are illustrative of the approach that may be used in applied research.

Model Identification Procedures. Model identification involves determining if autoregressive terms or moving average terms must be included to fully describe the data. The distribution of the autocorrelations and partial autocorrelation provides the basis for making such decisions. For an autoregressive component, the autocorrelations will decay slowly to zero for increasing lags and the partial autocorrelations will drop abruptly to zero when the appropriate lag (p) is reached. For the moving averages component, the autocorrelations will drop abruptly to zero when the appropriate lag (p) is reached, and the partial autocorrelations will drop slowly to zero. Velicer et al. (1992) used a procedure that is consistent with current practice, which is to restrict model identification to autoregressive models (Djuric \& Kay, (1992); Gottman, 1981; Velicer \& McDonald, 1984, 1991). Diagnostic checks on the residuals were performed to test the appropriateness of this procedure. A third component, drift, was set equal to zero a priori for all identification problems based on preliminary evaluation of the data. Models that demonstrate no dependence are called white noise models and are described as ARIMA $(0,0,0)$ models.

Five different procedures were employed for model identification. First, traditional visual analysis of the autocorrelations and partial autocorrelations was performed. The visual analysis required the consensus of three raters. Then four different automated methods for order identification of 
autoregressive models were employed: (1) PMDL (predictive minimum descriptive length; Rissanen, 1986a); (2) PLS (predictive least squares; Rissanen, 1986b) ; (3) PLAV (predictive least absolute value; Djuric \& Kay, 1992); and (4) PDC (predictive density criterion; Djuric \& Kay, 1992). Two additional methods were considered and rejected: (1) AIC (Akaike information criterion; Akaike, 1974); and (2) MDL (minimum descriptive length; Rissanen, 1978; Schwartz, 1978). A simulation study evaluating these six criteria (Djuric \& Kay, 1992) found that the AIC and MDL tended to overestimate the order of series. In this study, these two criteria were inconsistent with either visual analysis or the other four criteria, typically finding a much higher order, so they were eliminated from consideration.

For the majority of model identification, all five procedures converged on the same answer. When disagreement occurred, it was typically a difference of one in order and all models were reviewed. Disagreements typically involved a low autoregressive coefficient that was approximately equal to the critical value for statistical significance. The more parsimonious fit (lower order) was employed when the evidence for the higher order model was weak and the inclusion of the additional term would not result in a change in interpretation.

Results of the study were as follows. Seven of the subjects were described by a first order autoregressive model with a moderate to high degree of negative dependence (i.e., phi $i_{1}=-.30$ to -.80 ). All subjects reported on their smoking behavior in the morning and afternoon. The data resulted in a very clear, easily identified 
model with a high degree of autocorrelation. This pattern is consistent with the multiple regulation model and the study was interpreted as supporting that model. This study provides an excellent illustration of the potential contribution that can be made by the time series approach to understanding the processes underlying behavior.

\section{Interrupted Time Series Analysis}

The simplest interrupted time series analysis is a design which involves repeated observations on a single unit followed by an intervention followed by additional observations of the unit. The purpose of the analysis is to determine if the intervention had an effect. The hypothetical example presented earlier illustrates this approach. The analysis involves some preprocessing of the data to remove the effects of dependence. Several alternative procedures will be described below. The analysis then involves a general linear model analysis using a generalized least squares or Aitken estimator (Aitken, 1934; Morrison, 1983). The intervention can be an experimental manipulation such as the implementation of some kind of treatment, or it can be a naturally occurring event such as a change in policy or funding for a public program. If the intervention effect is significant, it is of interest to evaluate the nature of the effect. One of the advantages of time series analysis is the ability to assess the nature of change over time. The next section will describe the Box-Jenkins procedure. Several variations on this procedure have been proposed to eliminate the problematic model 
identification step; these will be described following the next section.

Box-Jenkins Intervention Analysis. An intervention with a single subject or experimental unit can be evaluated using a BoxJenkins analysis. The Box-Jenkins procedure (Box \& Jenkins, 1976), as adapted by Glass et al. (1975), is a two-step process. As described above, the autocorrelations and partial autocorrelations are calculated for various lags. This information is the basis for identifying the specific ARIMA model, i,e., specifying the value for ㄱ. $\mathrm{g}$, and $\mathrm{g}$. Model identification determines the specific transformation matrix to be used. The purpose of this distributional transformation is to remove the dependence from the data so that the data series meets the assumptions of the general linear model (GLM). The GLM is the general analytic procedure that includes multiple regression, analysis of variance, and analysis of covariance as special cases. Once transformed, the data are analyzed with a modified GLM program and the parameters are estimated and tested for significance. With the dependence in the data accounted for, the analysis follows standard estimation and testing procedures.

The Box-Jenkins approach to intervention analysis has several disadvantages. First, the number of observations required for model identification is often prohibitive for research in applied settings. second, even when the required number of observations has been attained, correct identification is problematic (Velicer \& Harrop, 1983). Third, the method is complex, making applications by the mathematically unsophisticated researcher difficult. Three 
alternative approaches are described in the next section, all of which attempt to avoid the problematic model identification step.

\section{Alternative Analysis Approaches}

Simonton (1977) proposed a procedure that avoids the problem of model identification by using an estimate of the variance-covariance matrix based on a pooling of the observations across all subjects observed. This approach, however, requires the basic assumption that all series are fit $(1,0,0)$ ARIMA models. While the assumption is theoretically indefensible, empirical investigations indicate that this procedure works well in a wide variety of cases (Harrop \& Velicer, 1985).

Algina and Swaminathan 1979; Algina \& Swaminathan, 1977; Swaminathan \& Algina, 1977) have proposed an alternative to Simonton's statistical analysis, employing a profile analysis. The sample variance-covariance matrix is employed as an estimator for the transformation matrix used to remove dependence from the data in the modified least squares solution. This approach, however, requires the assumption that the number of subjects is greater than the number of observations per subject. This is not a condition that is likely to be met in most applied research settings where time series approaches are most appropriate.

Instead of trying to determine the specific transformation matrix (i.e., the one matrix uniquely appropriate for the specific underlying ARIMA model of a series), Velicer and McDonald (1984) propose a general transformation matrix, $\mathbf{T}$, with the numerical values of the elements of $\mathbf{T}$ being estimated for each problem. The rationale 
for a general matrix is that all transformation matrices have an identical form - a lower triangular matrix with equal subdiagonals. Weight vectors with five non-zero weights are accurate for most cases. A greater number of weights can be employed where indicated by appropriate diagnostics (Velicer \& McDonald, 1984). The accuracy of this approach has been supported by two simulation studies (Harrop \& Velicer, 1985; 1990b).

The previous section illustrates some of the advances that have been made in the approaches to time series analysis during the last decade. A combination of computational advances and alternative statistical procedures have increased the ease of application and the range of potential applications. One of the early drawbacks, the large sample size required for model identification, has been largely overcome.

There do remain some practical barriers to the use of time series designs that have been less well addressed to date, although attention to them is increasing. Specifically, the problem of missing data is still prohibitive to a broader application of time series designs in applied behavioral research. Since implementation of time series analysis requires complete data, it is necessary to correct for missing data prior to analysis.

\section{Missing Data and Time Series Analysis}

The problem of missing data is almost unavoidable in time series analysis and presents a number of unique challenges. Life events will result in missing data even for the most conscientious researchers. Missing data is known to be a common problem when 
studies are characterized by repeated observations on the same experimental unit, particularly when the experimental unit is a person (Laird, 1988). Thus, time series designs in applied behavioral sciences research are particularly susceptible to missing data problems.

Available methods for handling missing data in time series analysis vary in terms of their ease of implementation and their appropriateness for time-ordered data, i.e., the extent to which they address the special characteristics of time-ordered data. Although the problem of handing missing data in time series is the specific focus of this dissertation, it is expected that findings from research on time series will also generalize to other statistical models which involve repeated measures on one or a group of individuals or units, e.g., longitudinal procedures such as repeated measures analysis of variance designs and lagged panel designs in structural equation modeling.

The problem of missing data in time series designs has received little attention in the applied behavioral sciences area. Rankin and Marsh (1985) assessed the impact of different amounts of missing data for 32 simulated time series, modeled after sixteen real world data examples. In this study, missing observations were deleted from the series rather than estimated. The authors concluded that with up to 20 missing data there was little impact on model identification but the impact was pronounced when more than $40 \%$ were missing. In an extensive simulation study, colby and velicer (in submission) compared four different techniques of handling missing 
data: deletion of missing observations from the analysis;

substitution of the mean of the series; interpolation (i.e.. substitution of the mean of the two adjacent observations); and a maximum likelihood estimation (Jones, 1980) available in SAS/ETS. These methods were tested using generated time series data with varying levels of autocorrelation, slope, and missing data. Overall, the maximum likelihood approach was the most accurate; it led to accurate time series parameter estimates in every condition with up to 40 or missing data (the highest level of missing data tested). Imputing the mean of the series was judged unacceptable; use of this technique resulted in huge overestimates of the variance and the level of the series, and led to inaccurate estimation of autocorrelation parameters. These effects were apparent even at low levels of missing data (e.g., 108). Interpolation of missing data, while intuitively appealing, led to the least accurate estimates of the autocorrelation parameter. Deletion was an acceptable method at low levels of missing data (e.g., 10\%), but was consistently less accurate than maximum likelihood.

While the Colby and Velicer (in submission) study supported the accuracy of maximum likelihood estimation of missing data in time series analysis, the study was limited by the fact that it estimated data under ideal circumstances. First, correct underlying model specification was provided in all cases. When using the Jones (1980) ML algorithm available in SAS/ETS, it is necessary to specify the type of model that underlies the series of data. This model specification is used for both ML estimation of missing values and 
the time series analysis itself. In the simulation study, the model specification issue was circumvented by generating only ARIMA ( 1,0 , 0) series, and then correctly specifying the model for the SAS/ETS program. (All missing data methods compared in this study had the benefit of correct model identification for time series analysis . Second, data were eliminated from the time series in a random pattern; the remaining data set was a completely random subset of the total data set. This is a stringent assumption for missing data patterns not often met in the real world. Third, all simulated time series data were sampled from normally distributed data distributions; this is an assumption of maximum likelihood estimation. The critical issue subsequent to that study is to determine what happens to the accuracy of ML estimation when these ideal circumstances and assumptions are violated.

In addition, an alternative data estimation method not studied by the Colby and Velicer (in submission) study is the recently developed application of the EM (Expectation Maximization) algorithm (see Little \& Rubin, 1987). The EM algorithm is a general iterative procedure for maximum likelihood estimation in missing data problems. Although it is considered appropriate for use with time series data (Little \& Rubin, 1987), it was not developed specifically for use with time series. Indeed, its appeal is based on its generality and applicability to a broad range of problems (Dempster, Laird, \& Rubin, 1977).

Until recently, disadvantages of the EM approach were: it was fairly difficult to implement and it could be very slow to converge 
if there was a substantial amount of missing data (Colby \& Velicer, in submission). However, a method for easy implementation of the EM algorithm was developed in 1993 by Graham and Hofer (EMCOV.EXE). This interactive program can be run in IBM DOS; it is compared to the Jones (1980) ML algorithr in this dissertation.

An obvious distinction between the two algorithms to be tested is the extent to which they were developed specifically for timeordered data problems. The following sections discuss some aspects of missing data estimation that are specific to time series designs.

Model identification and handling missing data. As described above, there are several methods of performing time series analysis without model identification. Several of these approaches have been shown to be effective in sufficiently removing the dependence from time series data (e.g., Harrop \& Velicer, 1985, 1990b; Simonton, 1977; Velicer \& McDonald, 1984). However, the necessity of correct model specification for ML estimation of missing data points is unknown. Since the underlying model of a time series cannot be known a priori, except in simulation research, it is important to know the effects of model misspecification on ML estimation of missing data and subsequent time series analysis. It is plausible that the same approaches used to analyze time series data without model identification (e.g., specifying a $1,0,0$ model for all series or specifying a higher order autoregressive model for all series) may also work for estimating missing time series observations. This is one of the issues which will be addressed in this dissertation (see Study 1 below). The Jones (1980) ML algorithm will be tested under 
conditions of correct and incorrect model specifications. These results will be contrasted with those derived from implementation of the EM algorithm, which does not require model specification.

Pattern of missing data. The choice of an appropriate method for handing missing data depends in part on the characteristics of the missing data pattern. The following classifications were developed by Rubin (1976).

Data are Missing Completely at Random (MCAR) if the observations with missing values are a random subsample of the full sample of observations. In this case the missing data mechanism (i.e., the reason the data are missing) is unrelated to the model and is therefore ignorable. Missing data estimation can proceed without taking the missing data mechanism into consideration. In both the Rankin and Marsh (1985) study and the colby and velicer (in submission) study, missing data were MCAR.

Data are Missing at Random (MAR) if the pattern of missingness for a variable is not a function of its observed variables, but it may be a function of other variables in the model. For example, the scheduling constraints of either experimenter or subject may preclude daily attendance at the laboratory according to a specific pattern (e.g., one consecutive week during a vacation; or alternating days due to class schedule). The pattern of missingness is not completely random, it is related to some variable $(e . g .$, class schedule). As long as the values of the missing observations are unrelated to the missing data mechanism, in other words the reason the data are missing (e.g., class schedule), data can be considered to be MAR. 
Values are classified as "not MAR" when the values are a function of the missing data pattern or mechanism. For example, if a study which requires daily self-monitoring of alcohol consumption results in missing values on days when subjects consume so much alcohol that they cannot recall how much they drank, the missing data mechanism (i.e., intoxication) and the value of the missing observations (i.e., amount of alcohol consumed) are related. These values would be described as "not $\mathrm{MAR}^{n}$.

The Colby and velicer (in submission) study provides empirical support for the accuracy of ML estimation of missing data under the ideal condition of data MCAR. This dissertation tests the accuracy of ML and EM estimation under more the common condition of data that are MAR. Missing data patterns in study 2 are either MCAR or systematic (i.e., missing in a consecutive or alternating pattern) but independent of the values of the missing observations. The ML and EM algorithms will again be compared; both should perform best when data are MCAR, since missing data mechanisms are not explicitly modeled in order to estimate missing values.

Nonnormality. It is common in applied behavioral research for time series data to violate the assumption of normally distributed error distributions. For example, human addictive behavior is often characterized by long periods of moderate behavior followed by brief periods of extreme (e.g., binge) behavior (velicer \& colby, in press). Such patterns of behavior result in data distributions that are characterized by positive skew and kurtosis. Since the general linear model and maximum likelihood (including EM) approaches to 
estimation assume normally distributed data, it is important to test missing data estimation algorithms under conditions of nonnomality. study 3 of this dissertation provides a comparison of the accuracy of the the Jones (1980) ML algorithm and the Graham and Hofer (1993) application of the EM algorithm under conditions of nonnormality. The decision to simulate data. Comparisons of missing data estimation methods could have either been done using well-known data sets or simulated data. The former approach would be considered a reliability study while the latter approach provides a study of validity. While actual data sets are limited to the accidental sample of behavior previously obtained, simulated data enable the experimenter to study data which meet population criteria of interest. Simulated data are generated to represent population parameter values (criterion values) against which estimates can be compared. This methodology made it possible to determine the accuracy of two algorithms for handing missing time series observations under specific conditions of interest which were manipulated by the experimenter.

summary of the research completed for this dissertation. The Jones (1980) maximum likelihood algorithm in SAS/ETS is remarkably accurate in estimating data when the underlying ARIMA model is a $(1,0,0)$ model, and that underlying model is correctly specified, and data are missing completely at random from the series, and conditions of normality are met. It has been recommended as the method of choice for handing missing data for time series analysis (Colby belicer, 1995) but its limitations must be delineated. 
The EM algorithm is a general iterative procedure for handling missing data. It provides an alternative to the Jones (1980) ML algorithm. Obvious advantages include the EM algorithm's established applicability to a broad range of missing data problems (see Baum, Petrie, soules, \& Weiss, 1970; Beale \& Little, 1975; Dempster, Laird, \& Rubin, 1977; Hartley, 1958) and the fact that use of the EM algorithm does not require model specification or normality assumptions for its use. The concern that must be addressed regarding the EM algorithm is whether it is too general. In other words, it must be established whether EM can address the special characteristics of time series data.

These two missing data algorithms were tested in this dissertation under various commonly-encountered conditions: without correct model identification; (2) with systematically missing data; and (3) with time series data that are nonnormally distributed. It is important for researchers to explore and understand the limitations of approaches to handling missing data in time series. This research represents an attempt to delineate some of these limitations. This comparison of two viable methods of missing data replacement under problematic but realistic conditions determines the strengths and weaknesses of each approach, in an attempt to extend the utility of time series designs beyond applications under ideal conditions. 
Study 1: Comparison of $\mathrm{ML}$ and EM Algorithms for Data Estimation.

\section{Method}

study 1 was designed to test the effects of model

misspecification on the accuracy of the Jones (1980) MI algorithm for estimating missing time series data, and to contrast this approach with an application of the EM algorithm which does not require model specification. The algorithms will be compared using time series data with various underlying ARIMA models, different levels of missing data, and positive versus regative dependency.

simulated time series data representing four common ARIMA models had various levels of data points randomly eliminated from the series. Next, ML estimation of the missing data was performed under conditions of correct and incorrect model specifications and EM estimation was performed (no model specification necessary for EMCov2.3, but time series analysis had correct model specification). Resulting parameter estimates were compared across these conditions, as well as with criterion values, and analyses based on the original, complete data.

\section{Data Generation}

All time series data generation was performed on an IBM 4381 mainframe computer. Data were generated using the most recent version of a FORTRAN computer program that was originally developed by Padia (1975), revised by Harrop and velicer (1985), and revised again by colby and velicer (in submission). This program generates time series data according to a specified underlying ARIMA model and 
criterion values of series length, level, change in level, slope, change in slope, error variance, and phi.

Number of observations $(\mathbb{N})$. Generated time series had $N_{1}=N_{2}$ $=50$ data points (i.e., 50 observations at pre-intervention and 50 observations post-intervention). This is considered the minimum amount required for accurate model identification with complete data. While shorter series are often found in the applied behavioral literature, such series were not examined in this study, as the focus of this study was data estimation in time series that meet general requirements for accurate analysis in respects other than the missing data.

Number of replications. Ten replications (samples) in each of the conditions were generated. This is the same as the $s$ (subjects) factor in an ANOVA design. Ten replications were chosen based on Harrop and velicer (1990). In a simulation study which evaluated computer programs for analyzing interrupted time series data, some preliminary runs were done to decide between 5, 10, and 20 replications. It was found that 10 and 20 replications yielded estimates that were more accurate and stable than estimates from 5 replications, but there was little or no improvement in the estimates when using 20 replications as opposed to 10 . Ten simulated replications per condition were used for all three studies in this series. 
Independent Variables Manipulated

There were four independent variables manipulated, resulting in a total of 96 conditions $(4 \times 4 \times 3 \times 2)$ with 10 replications in each condition. The independent variables were:

I. Underlying Time Series Model. Underlying model was manipulated as a between-groups factor. This factor in the design is sometimes referred to as "model" in the interest of brevity in the results section. Four different types of underlying ARIMA models were simulated:

a. An autoregressive $(1,0,0)$ model. This was chosen because it is the most common ARIMA model encountered in the behavioral sciences. This condition served as a basis for comparison for the series with misspecified models, described below. This condition also allowed a test of the effects of misspecifying a higher order autoregressive model for data estimation and analysis of a $(1,0,0)$ series.

b. An autoregressive $(2,0,0)$ model. This condition provided a test of which model specification for ML estimation (1, 0, 0$)$ vs. $(5,0,0)$ results in more accurate parameter estimates. It also tested whether the EM algorithm can successfully be applied to a higher order autoregressive model.

c. An autoregressive $(3,0,0)$ model. This was chosen to provide the same tests described in (b.) above, under slightly more extreme conditions. One might predict that missing data in series with significant autocorrelation at three lags may be easier to estimate than in series with autocorrelation at only one or two lags. 
In the former case, each observation has three predictor variables in the series (t-1, $t-2$, and $t-3$ ) which can estimate the missing observation at time $t$; the latter cases only have one or two predictive observations, respectively. Following this reasoning, one would also expect that the $\mathrm{ML}$ approach with correct or $(5,0,0)$ model specification should estimate missing values better than EM or ML with (1, 0, 0) specification, which would not take advantage of these additional predictors.

d. A moving averages $(0,0,1)$ model. This was chosen because it is sometimes encountered in the behavioral sciences, and it can be demonstrated that a higher order autoregressive model of infinite length can be substituted for it. This condition provided a partial test of that assumption, with a more limited series $(5,0,0)$ employed. This condition also tested the practical effects of applying the EM algorithm to a non-autoregressive (i.e., moving averages) model.

Comment. A "white noise" $(0,0,0)$ model was considered for inclusion in this study for comparison purposes, but was rejected primarily because it does not represent a compelling comparison. First, a time series with no dependence among the observations meets the assumptions of the General Linear Model, and therefore can be analyzed with an analysis of variance. Under these conditions, missing data techniques employed do not have to meet the special constraints imposed by the time series models. The more appropriate comparison in this design was the analysis of original complete time series data with dependence in the series. This comparison isolated 
the effects of increasing proportions of missing data and of the estimation method used.

II. Proportion of Missing Data. Data were randomly eliminated from the time series in varying proportions. In the colby and velicer (1995) simulation study, 108, 20\%, 30\%, and 40\% of the data were eliminated, with complete data (0\% eliminated) used for purposes of comparison. Effects of proportion of data missing were linear, with accuracy decreasing steadily as proportion of missing data increased. Because no curvilinear relationships between proportion of missing data and accuracy of data estimation were found, it was decided that in this study only two proportions of data would be eliminated (20\% versus $40 \%$ ), and these would be compared to complete data $10 \%$ eliminated). This variable was manipulated as a within-groups factor.

III, Data Estimation Technique. Randomly eliminated time series observations were estimated using two separate algorithms: EM and ML. The EM algorithm does not require model specification. The ML algorithm does, and was tested under various conditions of model specification and misspecification, described below.

Model specification in this study was mostly restricted to autoregressive models, as is consistent with current practice (Djuric E KaY, 1992; Gottman, 1981; Velicer \& McDonald, 1984, 1991; Velicer, Redding, Richmond, Greeley, \& Swift, 1992). The exception to this restriction occurred in the condition of the $(0,0,1)$ model underlying the simulated data, when data estimation was performed with the EM algorithm or the ML algorithm with correct model 
specification. This condition provided a limited but interesting empirical test of the current practice of specifying only autoregressive models for time series analysis. This independent variable was manipulated as a between-groups factor, and is sometimes referred to in the results section as "technique". In all, four data estimation techniques were compared:

a. Jones (1980) ML algorithm specifying a first order autoregressive model $(1,0,0)$. Specification of a $(1,0,0)$ model was selected because simonton (1977) has suggested that specifying a $(1,0,0)$ autoregressive model is appropriate for analyzing all time series. The utility of this approach is supported by Marsh and Shibano (1984), who reanalyzed 70 clinical series published in journal articles over a four year period. The authors found that specification of a (1, 0, 0) model proved satisfactory with 80 percent of the series tested (i.e., even when a $(1,0,0)$ model did not underlie the data). The $(1,0,0)$ model is also the most commonly encountered model in the behavioral sciences (Marsh \& Shibano, 1984; Rankin 5x Marsh, 1985; Revenstorf et al., 1980). Glass, Willson, and Gottman (1975) state that higher order models are unusual in the behavioral sciences. It's important to note that the model specification described in this section refers to specifying an underlying ARIMA model in order to perform time series analysis (i.e., in order to transform the original time series data to meet the assumptions of the General Linear Model), while this study tested the effects of model specification for data estimation. However, the practical implications of model specification are intertwined to some 
extent, since data estimation with the Jones (1980) ML algorithm and data analysis occur within the same SAS/ETS routine. The fact that there is a complete data comparison condition provides a means of distinguishing effects of model identification for time series analysis from the effects for data estimation.

b. Jones (1980) ML algorithm specifying a higher order (5, 0, 0) autoregressive model. This model was used based on velicer and MCDonald's (1984) suggestion to specify a higher order autoregressive model for all time series analysis. Theoretically, the higher order model provides a generalized transformation matrix, rather than a transformation specific to the ARIMA model that underlies the series. Additionally, higher order autoregressive models look like lower order moving averages models (Velicer, Redding, Richmond, Greeley, \& Swift, 1992), so this specification was posited to be more appropriate for $(0,0,1)$ models than the $(1,0,0)$ specification. When used for estimating missing data, a higher order model specification was expected to result in more accurate estimates of data points, especially in higher order series, since more observations could be used to estimate a given observation.

\section{c. Jones (1980) ML algorithm specifying the correct underlying} ARIMA model. This condition tested whether there is any meaningful difference between applying the ML algorithm under ideal conditions of correct model specification versus its use under more realistic conditions of generic model specification.

d. EMCOV Version 2.3 (1995) application of the EM algorithm. In this condition, missing data were estimated using the most recent 
version of the EMcov computer program, originally developed by Graham \& Hofer (1993). This FORTRAN computer program is invoked from the MS-DOS command line and then runs interactively. The program prompts for the name of the raw data file, the sample size (in this case the number of observations, 100), the number of variables (1), and other parameters. Two of EMCov's output files were used to produce the input to SAS for time series analysis. EMCOV generates: (1) a full data matrix with missing values imputed by regression imputation using the b-weights obtained from EM; and (2) a data matrix of residuals for use in subsequent multiple imputation procedures. The program ADDRESID. EXE (part of EMCOV 2.3) is designed to correct the regression-estimated missing values in the data matrix by adding residuals to them. The data output from ADDRESID.EXE was used as input to SAS.

EMCOV.EXE does not require model specification for missing data estimation. In this condition, correct model specification was used for SAS/ETS time series analysis.

IV. Direction of dependence in the data. Positive and negative dependency in the time series were compared, based on findings by colby and velicer (in submission), which suggest that these conditions are differentially affected by various methods of data estimation, and result in differences in data estimation and parameter estimation accuracy.

a. Positive dependence:

i. In the $(1,0,0)$ model, $\phi=0.60$.

ii. In the $(0,0,1)$ model, $\theta=0.60$. 
iii. In the $(2,0,0)$ model, $\phi_{1}=0.60$, and $\phi_{2}=$ 0.30.

iv. In the $(3,0,0)$ model, $\phi_{1}=0.60, \phi_{2}=0.30$, and $\phi_{3}=-0.15$.

The magnitude of the autocorrelation parameters was selected in order to have a detectable level of dependence for all parameters, yet to remain within the bounds of stationarity which constrain the values of autocorrelation coefficients. In the $(3,0,0)$ model, $\phi_{3}$ was given a negative value in order to ensure a stationary series. For a detailed description of the bounds of stationarity, see Glass, Willson, and Gottman (1975). Autocorrelation in the lower order models was selected to match that of the corresponding higher order models' parameters. The absolute values of autocorrelations in the negative dependence series were the same, as described below.

b. Negative dependence:

i. In the $(1,0,0)$ model, $\phi=-0.60$.

ii. In the $(0,0,1)$ model, $\theta=-0.60$.

iii. In the $(2,0,0)$ model, $\phi_{1}=-0.60$, and $\phi_{2}=-0.30$

iv. In the $(3,0,0)$ model, $\phi_{1}=-0.60, \phi_{2}=-0.30$, and $\phi_{3}=0.15$.

\section{Dependent Variables}

Nine hundred sixty series (4 underlying models $x 4$ missing data methods $\mathrm{x} 3$ proportions of missing data $\mathrm{x} 2$ directions of dependence in the series $x 10$ replications of each) were input to sAs/ETS for time series analysis. Six dependent variables were obtained, 
corresponding to the parameters of ARIMA interrupted time series models (level, slope, error variance, change in level, change in slope, and autocorrelation).

Time series analyses were performed by Proc ARIMA, version 6.06, of SAS/ETS (SAS Institute, 1988). SAS/ETS uses a nonlinear algorithm for its solution. Analyses used default values for starting estimates and stopping criterion. The maximum number of iterations was set at 100 . The conditional least squares (CLS) method of estimation was used.

I. Level (L). Level was calculated for each series. This statistic is equal to the intercept of the best-fitting straight line through the plotted observations of a series. The criterion value of $I$ was 0 in all series.

II. Slope (S). Slope was also calculated for each series. The slope parameter of a series is often of clinical interest: the presence of slope in a series may change interpretations of results or speculations about processes of change. The population value of $s$ was 15 degrees at both pre- and post-intervention. A moderate positive slope was chosen based on evidence that a slope of zero can be accurately estimated in time series analysis under almost all conditions, while a slope of 15 degrees is more suited to highlighting conditions which are problematic for slope estimation (Colby \& Velicer, in submission). Although the criterion value of slope was 15 degrees, SAS provides an estimate of the tangent of the slope, which is equal to 0.27 . It is the tangent of the slope which is used in analyses and presented in figures and tables. 
III. Minimum Residual Error Variance. This is a measure of error variation in a transformed time series, i.e., calculated after the dependency has been removed from the data. Residual error variance should be uncorrelated (i.e., not significantly different from a series of random errors) with a mean of zero. This parameter estimate was obtained from the SAS/ETS analysis, to demonstrate the extent to which each method of data estimation affected subsequent estimates of error variance. In interrupted time series designs, this term is critical in the calculation of tests of significance. The criterion value of error variance was 1,0 . IV. Change in Level (DL). Change in level is one of the two parameters which measures intervention effects in an interrupted time series design. The criterion value of $\mathrm{DL}$ was 1.5 in ald series. v. Change in slope (DS). Change in slope is the second parameter which measures intervention effects in an interrupted time series design. However, in these series there was no significant change in slope from pre- to post-intervention. The criterion value of DS was 0 in all series.

VI. Autocorrelation coefficients (phi and theta). Phi ( $\phi)$ represents the degree of dependency in the data when the underlying model is autoregressive. Theta $(\theta)$ represents the degree of dependency in the data when the underlying model is moving averages. In this study, autocorrelation was analyzed as a dependent variable, although conceptually this is somewhat problematic since the underlying models do not all have the same autocorrelation coefficient (phi vs. theta). This dependent variable is complicated 
in the case where a moving averages model underlies a series, but an autoregressive model is specified. The dependency parameter is theta, but the time series analysis will yield an estimate of phi. However, this must happen in practice, because: (1) specification of exclusively autoregressive models has become common; and (2) models may also be misspecified when model identification is attempted. This study condition demonstrated the practical results of these common occurrences in terms of the information about dependency obtained by the researcher.

\section{Results}

For each condition, the mean and standard deviation of the ten replications were calculated for estimates of level, slope, error variance, change in level, change in slope, and phi or theta. Five separate $4 \times 4 \times 3 \times 2$ (type of underlying model $\times$ missing data estimation technique $\mathrm{x}$ percent data missing $\mathrm{x}$ direction of dependence) analyses of variance (ANOVAs) were used to examine mean differences for level, slope, error variance, change in level, and change in slope. In this design, the first and last factors were between-subjects factors; the remaining two factors were withinsubjects factors. Significant effects $(p<.01)$ were followed up with simple effects tests and Tukey tests. Follow-up tests were not performed for any analysis for which the overall F-ratio was nonsignificant.

Autocorrelation analyses. Analyses of variance were performed on nested models within the design, so that inappropriate comparisons of a completely mixed design could be avoided. Because direction of 
dependence was also an independent variable in this study, each level of autocorrelation (positive vs. negative) was analyzed separately. Analyses of theta estimates were necessarily limited to conditions in which the underlying model in the series was moving averages and the appropriate model was specified. Analyses of phi were performed across all conditions which yielded phi estimates. As described above, significant effects were followed up with simple effects tests and Tukey tests. Follow-up tests were not performed for any analysis for which the overall F-ratio was non-significant.

Source tables summarizing all ANOVAs performed for study 1 are presented in Appendices A - K.

Leve1: Overview.

A $4 \times 4 \times 3 \times 2$ (Model $\times$ Technique $\times$ Percent Missing $\mathrm{x}$ Direction of Dependency) ANOva was used to compare estimates of leve1. Model, Direction of Dependency, and Technique were manipulated as between-subjects factors; Percent Missing was manipulated as a within-subjects factor. The means and standard deviations for level are presented in Tables 1 and 2 .

Significant overall effects. There were significant main effects for Direction of Dependency $(\underline{F}(1,72)=13.83, \mathrm{p}<.001)$, Percent Missing ( $\underline{F}(2,144)=170.70, \underline{P}<.001)$, and Technique ( $(3,216)=175.12, \mathrm{p}<.001)$. There was one significant 2 -way interaction effect: Percent Missing by Technique $(\underline{F}(6,432)=$ 170.73, $P<.001)$. No other effects in the analysis were significant. 
Table 1

Means and Standard Deviations of Estimated Level.

Criterion $=0$.

Part I. Positive Dependency.

\begin{tabular}{|c|c|c|c|c|c|c|}
\hline $\begin{array}{l}\text { Model of } \\
\text { Series }\end{array}$ & $\begin{array}{l}\text { Percen } \\
\text { Missin }\end{array}$ & & $\begin{array}{l}\text { EM } \\
\text { Algorithm }\end{array}$ & $\begin{array}{c}M L \\
(1,0,0)\end{array}$ & $\begin{array}{c}M L \\
(5,0,0)\end{array}$ & $\begin{array}{c}\text { ML } \\
\text { (correct) }\end{array}$ \\
\hline \multirow[t]{3}{*}{$(1,0,0)$} & 08 & $\begin{array}{r}M \\
S D\end{array}$ & $\begin{array}{r}-.273 \\
.902\end{array}$ & $\begin{array}{r}-.167 \\
.496\end{array}$ & $\begin{array}{r}-.200 \\
.708\end{array}$ & $\begin{array}{r}-.363 \\
.844\end{array}$ \\
\hline & 208 & $\stackrel{M}{S D}$ & $\begin{array}{l}2.936 \\
2.049\end{array}$ & $\begin{array}{r}-.152 \\
.551\end{array}$ & $\begin{array}{r}-.285 \\
.686\end{array}$ & $\begin{array}{r}-.490 \\
.887\end{array}$ \\
\hline & 408 & $\stackrel{M}{S D}$ & $\begin{array}{l}4.977 \\
1.563\end{array}$ & $\begin{array}{r}-.186 \\
.532\end{array}$ & $\begin{array}{r}-.295 \\
.679\end{array}$ & $\begin{array}{r}-.291 \\
.658\end{array}$ \\
\hline \multirow[t]{3}{*}{$(2,0,0)$} & 0 용 & $\begin{array}{r}M \\
S D\end{array}$ & $\begin{array}{l}-.672 \\
1.367\end{array}$ & $\begin{array}{r}.118 \\
2.108\end{array}$ & $\begin{array}{l}-.535 \\
1.765\end{array}$ & $\begin{array}{r}.117 \\
1.826\end{array}$ \\
\hline & 208 & $\stackrel{M}{S D}$ & $\begin{array}{l}1.578 \\
2.980\end{array}$ & $\begin{array}{l}-.158 \\
1.957\end{array}$ & $\begin{array}{l}-.473 \\
1.872\end{array}$ & $\begin{array}{r}-.019 \\
1.875\end{array}$ \\
\hline & 408 & $\stackrel{M}{S D}$ & $\begin{array}{l}3.440 \\
2.384\end{array}$ & $\begin{array}{r}.144 \\
2.243\end{array}$ & $\begin{array}{r}-1.041 \\
1.298\end{array}$ & $\begin{array}{r}.188 \\
1.865\end{array}$ \\
\hline \multirow[t]{3}{*}{$3,0,0$} & 08 & $\begin{array}{l}M \\
\text { SD }\end{array}$ & $\begin{array}{r}-.771 \\
.985\end{array}$ & $\begin{array}{r}-.680 \\
.706\end{array}$ & $\begin{array}{l}-.122 \\
1.477\end{array}$ & $\begin{array}{r}-.770 \\
.782\end{array}$ \\
\hline & 208 & $\stackrel{M}{\mathrm{SD}}$ & $\begin{array}{l}2.598 \\
2.401\end{array}$ & $\begin{array}{l}-.876 \\
1.154\end{array}$ & $\begin{array}{r}-.189 \\
1.242\end{array}$ & $\begin{array}{r}-.671 \\
.806\end{array}$ \\
\hline & 408 & $\begin{array}{l}M \\
\text { SD }\end{array}$ & $\begin{array}{l}3.808 \\
1.237\end{array}$ & $\begin{array}{r}-.523 \\
.751\end{array}$ & $\begin{array}{l}-.348 \\
1.249\end{array}$ & $\begin{array}{r}-.763 \\
.890\end{array}$ \\
\hline \multirow[t]{3}{*}{$(0,0,1)$} & $0 \%$ & $\stackrel{M}{S D}$ & $\begin{array}{r}-.057 \\
.132\end{array}$ & $\begin{array}{r}-.006 \\
.146\end{array}$ & $\begin{array}{l}.041 \\
.113\end{array}$ & $\begin{array}{l}.007 \\
.143\end{array}$ \\
\hline & 208 & $\stackrel{M}{S D}$ & $\begin{array}{l}3.133 \\
1.387\end{array}$ & $\begin{array}{r}-.002 \\
.116\end{array}$ & $\begin{array}{l}.066 \\
.194\end{array}$ & $\begin{array}{r}-.033 \\
.223\end{array}$ \\
\hline & $40 \%$ & $\begin{array}{r}M \\
\text { SD }\end{array}$ & $\begin{array}{l}5.210 \\
2.541\end{array}$ & $\begin{array}{r}-.033 \\
.150\end{array}$ & $\begin{array}{l}.012 \\
.297\end{array}$ & $\begin{array}{l}.044 \\
.249\end{array}$ \\
\hline
\end{tabular}


Table 2

Means and Standard Deviations of Estimated Level.

Criterion $=0$.

Part II. Negative Dependency.

\begin{tabular}{|c|c|c|c|c|c|c|}
\hline $\begin{array}{l}\text { Model of } \\
\text { Series }\end{array}$ & $\begin{array}{l}\text { Perce } \\
\text { Missi }\end{array}$ & & $\underset{\text { Algorithm }}{\mathrm{EM}}$ & $\begin{array}{c}M I \\
(1,0,0)\end{array}$ & $\begin{array}{c}M L \\
(5,0,0)\end{array}$ & $\begin{array}{c}\text { ML } \\
\text { (correct) }\end{array}$ \\
\hline \multirow[t]{3}{*}{$(1,0,0)$} & 08 & $\begin{array}{r}M \\
S D\end{array}$ & $\begin{array}{l}.101 \\
.196\end{array}$ & $\begin{array}{l}.093 \\
.173\end{array}$ & $\begin{array}{r}.135 \\
.240\end{array}$ & $\begin{array}{r}.198 \\
.172\end{array}$ \\
\hline & 208 & $\begin{array}{l}M \\
\text { SD }\end{array}$ & $\begin{array}{l}2.844 \\
1.995\end{array}$ & $\begin{array}{l}.125 \\
.204\end{array}$ & $\begin{array}{l}.225 \\
.252\end{array}$ & $\begin{array}{l}.173 \\
.214\end{array}$ \\
\hline & 408 & $\stackrel{M}{S D}$ & $\begin{array}{l}5.104 \\
1.672\end{array}$ & $\begin{array}{l}.130 \\
.306\end{array}$ &. .171 & $\begin{array}{l}.305 \\
.182\end{array}$ \\
\hline \multirow[t]{3}{*}{$(2,0,0)$} & 08 & $\begin{array}{r}M \\
\text { SD }\end{array}$ & $\begin{array}{l}.090 \\
.150\end{array}$ & $\begin{array}{l}.147 \\
.159\end{array}$ & $\begin{array}{l}.127 \\
.205\end{array}$ & $\begin{array}{l}.220 \\
.160\end{array}$ \\
\hline & 208 & $\underset{S D}{M}$ & $\begin{array}{l}2.987 \\
1.256\end{array}$ & $\begin{array}{l}.115 \\
.215\end{array}$ & $\begin{array}{l}.065 \\
.336\end{array}$ & $\begin{array}{l}.209 \\
.130\end{array}$ \\
\hline & 408 & $\begin{array}{r}\mathrm{M} \\
\mathrm{SD}\end{array}$ & $\begin{array}{l}4.735 \\
2.632\end{array}$ & $\begin{array}{r}.275 \\
.287\end{array}$ & $\begin{array}{r}.302 \\
.382\end{array}$ & $\begin{array}{l}.271 \\
.363\end{array}$ \\
\hline \multirow[t]{3}{*}{$(3,0,0)$} & Oog & $\begin{array}{r}M \\
S D\end{array}$ & $\begin{array}{l}.122 \\
.193\end{array}$ & $\begin{array}{l}.004 \\
.203\end{array}$ & $\begin{array}{l}.093 \\
.224\end{array}$ & $\begin{array}{l}.072 \\
.136\end{array}$ \\
\hline & 208 & $\begin{array}{r}M \\
S D\end{array}$ & $\begin{array}{l}2.987 \\
1.846\end{array}$ & $\begin{array}{r}-.008 \\
.187\end{array}$ & $\begin{array}{r}.139 \\
.275\end{array}$ & $\begin{array}{l}.084 \\
.232\end{array}$ \\
\hline & 408 & $\stackrel{M}{S D}$ & $\begin{array}{l}4.362 \\
1.914\end{array}$ & $\begin{array}{r}-.048 \\
.351\end{array}$ & $\begin{array}{l}.154 \\
.388\end{array}$ & $\begin{array}{l}.125 \\
.321\end{array}$ \\
\hline \multirow[t]{3}{*}{$(0,0,1)$} & 08 & $\underset{S D}{M}$ & $\begin{array}{r}-.110 \\
.440\end{array}$ & $\begin{array}{l}.089 \\
.504\end{array}$ & $\begin{array}{r}-.047 \\
.338\end{array}$ & $\begin{array}{r}-.202 \\
.410\end{array}$ \\
\hline & 208 & $\stackrel{M}{S D}$ & $\begin{array}{l}2.547 \\
1.926\end{array}$ & $\begin{array}{l}.075 \\
.555\end{array}$ & $\begin{array}{r}-.053 \\
.445\end{array}$ & $\begin{array}{r}-.107 \\
.359\end{array}$ \\
\hline & 408 & $\begin{array}{r}\mathrm{M} \\
\mathrm{SD}\end{array}$ & $\begin{array}{l}6.347 \\
1.389\end{array}$ & $\begin{array}{l}.046 \\
.510\end{array}$ & $\begin{array}{l}.133 \\
.421\end{array}$ & $\begin{array}{r}-.150 \\
.216\end{array}$ \\
\hline
\end{tabular}


Simple effects tests were used to examine the nature of the interaction between Percent Missing and Technique. These tests determined that the Technique effect was nonsignificant when no data were missing, but was significant at the .001 level when either $20 \%$ or 40 s of the data were missing. Values for $\underline{F}(3,432$ ) were 650.94 and 1924.81 respectively. Tukey tests were done as a follow up to the significant simple effects tests; the critical value of mean difference was equal to 0.418 .

Major findings. Tukey tests indicated that, at both $20 \%$ and 40 missing data, use of the EM algorithm resulted in significant overestimates of baseline level of the series. The magnitude of overestimation at 408 missing data was nearly twice that when only $20 \%$ of the data were missing. All of the ML estimates were accurate and did not differ from each other regardless of the different model specifications used $(e .9 .,(1,0,0),(5,0,0)$ or the correct model). These results are presented in Figure 2.

Minor findings. The main effect for Direction of Dependency indicated that, collapsed across all other conditions, series with negative autocorrelation resulted in estimates of level $(\underline{M}=0.75$, SD $=0.57)$ that were significantly higher, and more divergent from the criterion value of zero, than series with positive autocorrelation (M $=0.36, \underline{\mathrm{SD}}=1.29)$.

Slope: Overview.

A $4 \times 4 \times 3 \times 2$ (Model $\times$ Technique $\times$ Percent Missing $\mathrm{x}$ Direction of Dependency) ANOVA was used to compare estimates of slope. Model, Direction of Dependency, and Technique were between- 
Figure 2. Technique by Percent Missing Interaction for Level

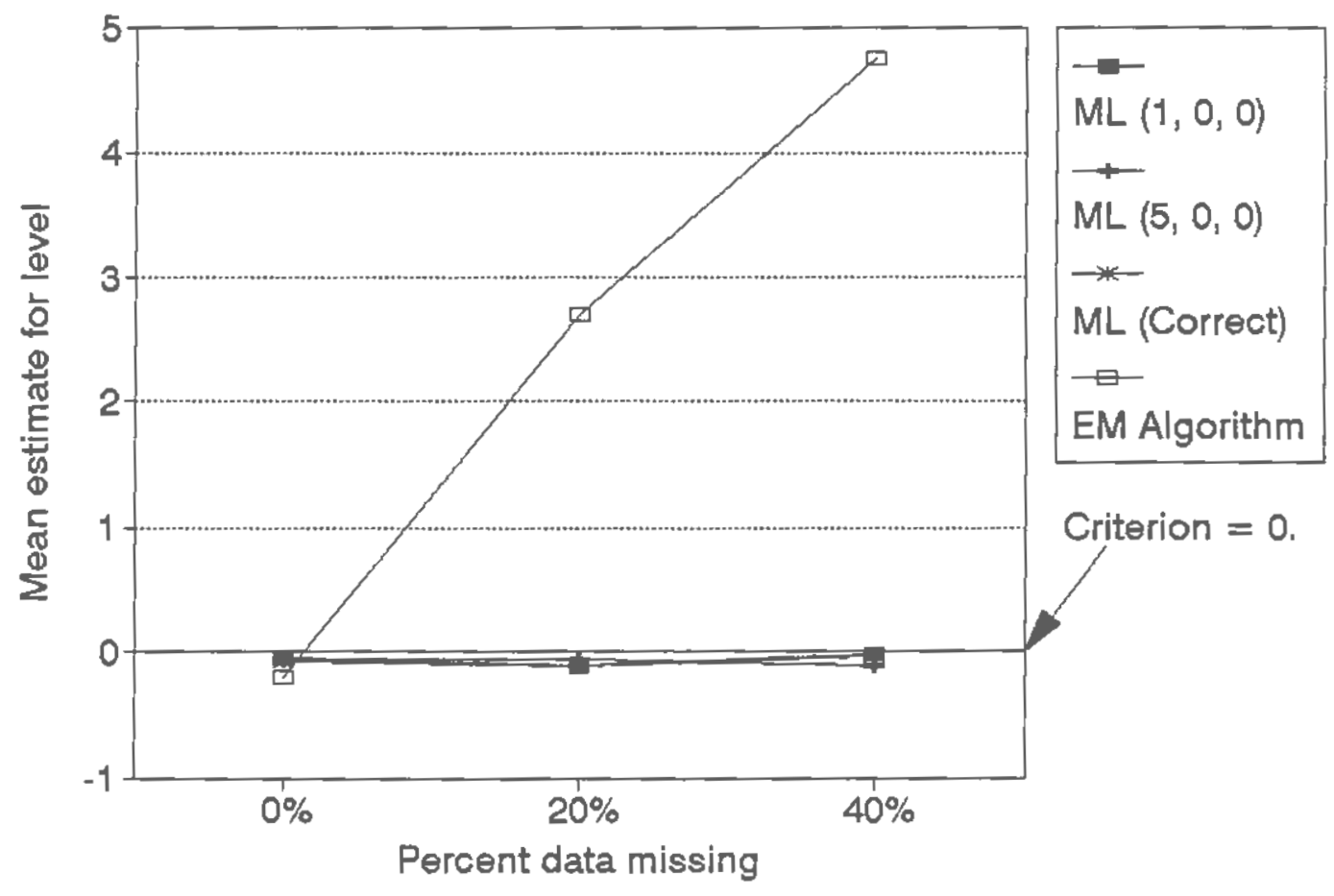


subjects factors; Percent Missing was a within-subjects factor. The means and standard deviations for slope are presented in Tables 3 and 4.

Significant overall effects. All four main effects in the analysis were significant at the $\mathrm{p}<.001$ level: $\operatorname{Model}\{\underline{F}(3,72)=$ 22.55); Direction of Dependency $(\underline{F}(1,72)=35.67)$. Percent Missing $(\underline{F}(2,144)=60.42)$, and Technique $(\underline{F}(3,216)=68.86)$. In addition, there were two significant 2-way interaction effects: Model by Direction of Dependency $(\underline{F}(3,72)=22.12, \mathrm{p}, .001)$; and Percent Missing by Technique $(\underline{F}(6,432)=66.58, \underline{P}<.001)$. No other effects in the analysis were significant.

Simple effects tests were first done to examine the interaction between Model and Direction of Dependency. These tests determined that the effect for Model was only significant when autocorrelation was positive $\{\underline{F}(3,72)=135.59, \underline{p}<.001)$. However, subsequent Tukey tests revealed no mean differences greater than the critical value (.068). A trend existed for $(2,0,0)$ series to result in underestimates of slope, but this effect did not reach the level of statistical significance.

Simple effects tests were next done to follow up the interaction between Percent Missing and Technique. These tests determined that the effect for Technique was nonsignificant when data were complete, but was significant when $20 \%$ of the data were missing $(\underline{F}(3,432)=320.0, \mathrm{P}<.001)$ and when $40 \%$ of the data were missing $(\underline{F}(3,432)=752.0, \underline{p}<.001)$. Tukey tests were done as a follow up 
Table 3

Meang and Standard Deviations of Estimated Tangent of Slope.

Criterion $=.27$.

Part I. Positive Dependency.

\begin{tabular}{|c|c|c|c|c|c|c|}
\hline $\begin{array}{l}\text { Model of } \\
\text { Series }\end{array}$ & $\begin{array}{l}\text { Percent } \\
\text { Miesing }\end{array}$ & & $\stackrel{\text { EM }}{\text { Algorithm }}$ & $\stackrel{M L}{(1,0,0)}$ & $\begin{array}{c}M U \\
(5,0,0)\end{array}$ & $\underset{\text { (correct) }}{\mathrm{ML}}$ \\
\hline \multirow[t]{3}{*}{$(1,0,0)$} & 08 & $\stackrel{M}{S D}$ & $\begin{array}{l}.264 \\
.030\end{array}$ & $\begin{array}{l}.260 \\
.016\end{array}$ & $\begin{array}{l}.262 \\
.031\end{array}$ & $\begin{array}{l}.270 \\
.021\end{array}$ \\
\hline & 208 & $\stackrel{M}{S D}$ & $\begin{array}{l}.197 \\
.064\end{array}$ & $\begin{array}{l}.260 \\
.018\end{array}$ & $\begin{array}{l}.271 \\
.023\end{array}$ & $\begin{array}{l}.275 \\
.023\end{array}$ \\
\hline & 408 & $\stackrel{M}{\text { SD }}$ & $\begin{array}{l}.152 \\
.037\end{array}$ & $\begin{array}{l}.261 \\
.016\end{array}$ & $\begin{array}{l}.270 \\
.024\end{array}$ & $\begin{array}{l}.270 \\
.019\end{array}$ \\
\hline \multirow[t]{3}{*}{$(2,0,0)$} & 08 & $\stackrel{M}{S D}$ & $\begin{array}{l}.203 \\
.043\end{array}$ & $\begin{array}{l}.183 \\
.050\end{array}$ & $\begin{array}{l}.217 \\
.049\end{array}$ & $\begin{array}{l}.203 \\
.051\end{array}$ \\
\hline & 208 & $\stackrel{M}{\text { SD }}$ & $\begin{array}{l}.158 \\
.073\end{array}$ & $\begin{array}{l}.188 \\
.053\end{array}$ & $\begin{array}{l}.211 \\
.055\end{array}$ & $\begin{array}{l}.208 \\
.053\end{array}$ \\
\hline & 408 & $\stackrel{M}{\mathrm{SD}}$ & $\begin{array}{l}.130 \\
.066\end{array}$ & $\begin{array}{l}.183 \\
.057\end{array}$ & $\begin{array}{l}.230 \\
.050\end{array}$ & $\begin{array}{l}.198 \\
.050\end{array}$ \\
\hline \multirow[t]{3}{*}{$(3,0,0)$} & 08 & $\begin{array}{r}M \\
S D\end{array}$ & $\begin{array}{l}.260 \\
.040\end{array}$ & $\begin{array}{l}.268 \\
.016\end{array}$ & $\begin{array}{l}.252 \\
.047\end{array}$ & $\begin{array}{l}.259 \\
.035\end{array}$ \\
\hline & 208 & $\begin{array}{r}M \\
\text { SD }\end{array}$ & $\begin{array}{l}.190 \\
.070\end{array}$ & $\begin{array}{l}.271 \\
.032\end{array}$ & $\begin{array}{l}.255 \\
.038\end{array}$ & $\begin{array}{l}.256 \\
.038\end{array}$ \\
\hline & 408 & $\begin{array}{l}M \\
S D\end{array}$ & $\begin{array}{l}.180 \\
.052\end{array}$ & $\begin{array}{l}.264 \\
.022\end{array}$ & $\begin{array}{l}.269 \\
.039\end{array}$ & $\begin{array}{l}.259 \\
.039\end{array}$ \\
\hline \multirow[t]{3}{*}{$(0,0,1)$} & 0용 & $\begin{array}{r}\mathrm{M} \\
\mathrm{SD}\end{array}$ & $\begin{array}{l}.271 \\
.006\end{array}$ & $\begin{array}{l}.269 \\
.005\end{array}$ & $\begin{array}{l}.267 \\
.003\end{array}$ & $\begin{array}{l}.267 \\
.006\end{array}$ \\
\hline & 208 & $\begin{array}{r}M \\
\text { SD }\end{array}$ & $\begin{array}{l}.200 \\
.039\end{array}$ & $\begin{array}{l}.269 \\
.003\end{array}$ & $\begin{array}{l}.266 \\
.007\end{array}$ & $\begin{array}{l}.268 \\
.008\end{array}$ \\
\hline & 408 & $\begin{array}{r}M \\
S D\end{array}$ & $\begin{array}{l}.179 \\
.093\end{array}$ & $\begin{array}{l}.272 \\
.007\end{array}$ & $\begin{array}{l}.269 \\
.014\end{array}$ & $\begin{array}{l}.266 \\
.009\end{array}$ \\
\hline
\end{tabular}


Table 4

Means and Standard Deviations of Tanqent of Slope.

Criterion $=.27$.

Part II. Negative Dependency.

\begin{tabular}{|c|c|c|c|c|c|c|}
\hline $\begin{array}{l}\text { Model of } \\
\text { Series }\end{array}$ & $\begin{array}{l}\text { Percent } \\
\text { Missing }\end{array}$ & & $\begin{array}{c}E M \\
\text { Algorithm }\end{array}$ & $\begin{array}{c}M L \\
(1,0,0)\end{array}$ & $\stackrel{M I}{(5,0,0)}$ & $\begin{array}{c}\text { MI } \\
\text { (correct) }\end{array}$ \\
\hline \multirow[t]{3}{*}{$(1,0,0)$} & 08 & $\begin{array}{l}M \\
\text { SD }\end{array}$ & $\begin{array}{l}.267 \\
.007\end{array}$ & $\begin{array}{l}.269 \\
.006\end{array}$ & $\begin{array}{l}.265 \\
.010\end{array}$ & $\begin{array}{l}.263 \\
.009\end{array}$ \\
\hline & 208 & $\stackrel{M}{S D}$ & $\begin{array}{l}.216 \\
.055\end{array}$ & $\begin{array}{l}.269 \\
.009\end{array}$ & $\begin{array}{l}.263 \\
.009\end{array}$ & $\begin{array}{l}.264 \\
.008\end{array}$ \\
\hline & $40 \frac{0}{8}$ & $\begin{array}{r}M \\
\text { SD }\end{array}$ & $\begin{array}{l}.194 \\
.057\end{array}$ & $\begin{array}{l}.266 \\
.016\end{array}$ & $\begin{array}{l}.265 \\
.015\end{array}$ & $\begin{array}{l}.261 \\
.013\end{array}$ \\
\hline \multirow[t]{3}{*}{$(2,0,0)$} & 08 & $\begin{array}{l}M \\
S D\end{array}$ & $\begin{array}{l}.271 \\
.005\end{array}$ & $\begin{array}{l}.268 \\
.006\end{array}$ & $\begin{array}{l}.269 \\
.007\end{array}$ & $\begin{array}{l}.266 \\
.005\end{array}$ \\
\hline & 208 & $\begin{array}{r}M \\
\text { SD }\end{array}$ & $\begin{array}{l}.210 \\
.038\end{array}$ & $\begin{array}{l}.269 \\
.008\end{array}$ & $\begin{array}{l}.271 \\
.012\end{array}$ & $\begin{array}{l}.266 \\
.004\end{array}$ \\
\hline & 408 & $\begin{array}{r}M \\
S D\end{array}$ & $\begin{array}{l}.181 \\
.069\end{array}$ & $\begin{array}{l}.260 \\
.009\end{array}$ & $\begin{array}{l}.263 \\
.011\end{array}$ & $\begin{array}{l}.266 \\
.013\end{array}$ \\
\hline \multirow[t]{3}{*}{$(3,0,0)$} & 0 음 & $\begin{array}{r}M \\
S D\end{array}$ & $\begin{array}{l}.268 \\
.007\end{array}$ & $\begin{array}{l}.272 \\
.006\end{array}$ & $\begin{array}{l}.268 \\
.007\end{array}$ & $\begin{array}{l}.269 \\
.005\end{array}$ \\
\hline & 20 웅 & $\begin{array}{r}M \\
\text { SD }\end{array}$ & $\begin{array}{l}.221 \\
.064\end{array}$ & $\begin{array}{l}.273 \\
.006\end{array}$ & $\begin{array}{l}.267 \\
.009\end{array}$ & $\begin{array}{l}.270 \\
.007\end{array}$ \\
\hline & $40 \frac{8}{8}$ & $\underset{S D}{M}$ & $\begin{array}{l}.200 \\
.056\end{array}$ & $\begin{array}{l}.272 \\
.010\end{array}$ & $\begin{array}{l}.266 \\
.013\end{array}$ & $\begin{array}{l}.267 \\
.011\end{array}$ \\
\hline \multirow[t]{3}{*}{$(0,0,1)$} & 0 용 & $\begin{array}{r}M \\
S D\end{array}$ & $\begin{array}{l}.270 \\
.017\end{array}$ & $\begin{array}{l}.264 \\
.018\end{array}$ & $\begin{array}{l}.265 \\
.010\end{array}$ & $\begin{array}{l}.273 \\
.015\end{array}$ \\
\hline & 208 & $\stackrel{M}{\mathrm{SD}}$ & $\begin{array}{l}.222 \\
.061\end{array}$ & $\begin{array}{l}.265 \\
.018\end{array}$ & $\begin{array}{l}.265 \\
.015\end{array}$ & $\begin{array}{l}.269 \\
.013\end{array}$ \\
\hline & $40 \%$ & $\underset{S D}{M}$ & $\begin{array}{l}.144 \\
.044\end{array}$ & $\begin{array}{l}.267 \\
.018\end{array}$ & $\begin{array}{l}.260 \\
.010\end{array}$ & $\begin{array}{l}.273 \\
.013\end{array}$ \\
\hline
\end{tabular}


to the simple effects tests. The critical value of mean difference was equal to 0.012 .

Major findings. Use of the EM algorithm yielded significant underestimates of slope when either 20 or 40 of the data were missing (see Figure 3). All other techniques for data estimation resulted in accurate slope estimates across conditions.

\section{Error Variance: overview.}

A $4 \times 4 \times 3 \times 2$ (Model $\times$ Technique $\times$ Percent Missing $\mathrm{x}$ Direction of Dependency) ANOVA was used to compare estimates of error variance. Model, Direction of Dependency, and Technique were between-subjects factors; Percent Missing was a within-subjects factor. The means and standard deviations for variance are presented in Tables 5 and 6.

Significant overall effects. Two main effects in the analysis were significant, both at the $\mathrm{p}<.001$ level: Percent Missing ( $\mathrm{E}$ (2, $144)=1285.65)$, and Technique $(\underline{E}(3,216)=2978.83)$. Their interaction, Percent Missing by Technique, was also significant ( $(6,432)=1267.54, p<.001)$. No other effects in the aralysis were significant.

Simple effects tests were done to examine the interaction between Percent Missing and Technique. These tests determined that the effect for Techrique was significant at the .001 level when either $20 \%$ or $40 \%$ of the data were missing. Values for $\underline{F}\langle 3,432\rangle=$ 4968.29 and $15,085.50$ respectively.

Major findings. Tukey tests further demonstrated that use of the EM algorithm for estimating missing data resulted in grossiy 
Figure 3. Technique by Percent Missing Interaction for Slope

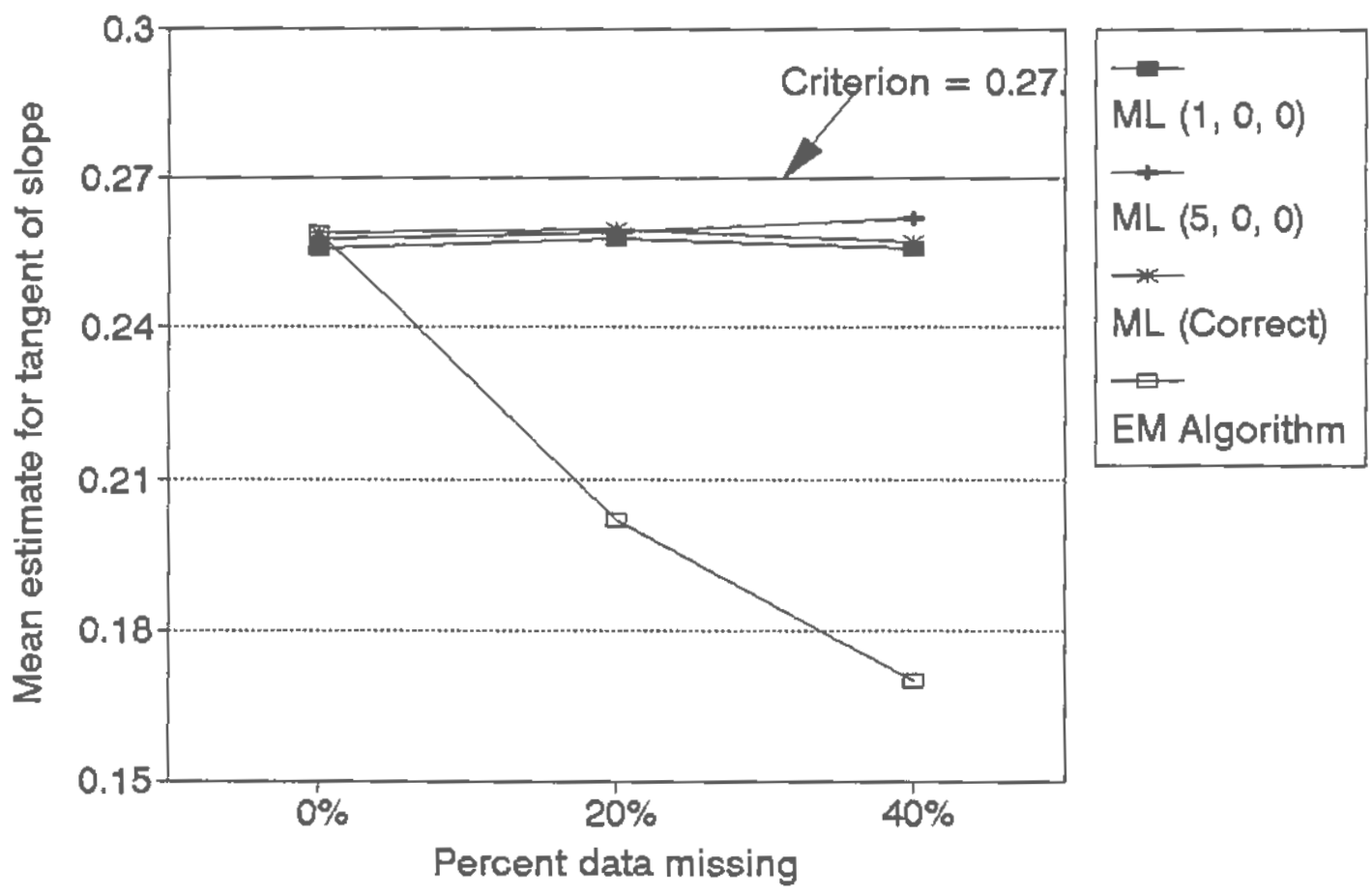


Table 5

Means and Standard Deviations of Estimeted Error Variance.

Criterion $=1.0$.

Part I. Positive Dependency.

\begin{tabular}{|c|c|c|c|c|c|c|}
\hline $\begin{array}{l}\text { Model of } \\
\text { Series }\end{array}$ & $\begin{array}{l}\text { Percent } \\
\text { Missing }\end{array}$ & & $\begin{array}{c}\text { EM } \\
\text { Algorithm }\end{array}$ & $\begin{array}{c}M L \\
(1,0,0)\end{array}$ & $\begin{array}{c}\mathrm{ML} \\
(5,0,0)\end{array}$ & $\begin{array}{c}M L_{\text {s }} \\
\text { (correct) }\end{array}$ \\
\hline \multirow[t]{3}{*}{$(1,0,0)$} & 0 왕 & $\stackrel{M}{S D}$ & $\begin{array}{r}.972 \\
.149\end{array}$ & $\begin{array}{l}.914 \\
.114\end{array}$ & $\begin{array}{l}.853 \\
.090\end{array}$ & $\begin{array}{l}.951 \\
.100\end{array}$ \\
\hline & $20 \%$ & $\stackrel{M}{S D}$ & $\begin{array}{r}27.217 \\
5.115\end{array}$ & $\begin{array}{l}.982 \\
.146\end{array}$ & $\begin{array}{r}.911 \\
.119\end{array}$ & $\begin{array}{l}.988 \\
.144\end{array}$ \\
\hline & $40 \frac{8}{2}$ & $\stackrel{M}{S D}$ & $\begin{array}{r}44.493 \\
8.174\end{array}$ & $\begin{array}{r}1.009 \\
.156\end{array}$ & $\begin{array}{l}.952 \\
.233\end{array}$ & $\begin{array}{r}1.067 \\
.133\end{array}$ \\
\hline \multirow[t]{3}{*}{$(2,0,0)$} & 08 & $\stackrel{M}{S D}$ & $\begin{array}{r}.913 \\
.116\end{array}$ & $\begin{array}{r}1.074 \\
.189\end{array}$ & $\begin{array}{l}.904 \\
.129\end{array}$ & $\begin{array}{l}.875 \\
.116\end{array}$ \\
\hline & 208 & $\stackrel{M}{S D}$ & $\begin{array}{r}24.584 \\
8.896\end{array}$ & $\begin{array}{r}1.138 \\
.226\end{array}$ & $\begin{array}{r}.976 \\
.182\end{array}$ & $\begin{array}{l}.936 \\
.140\end{array}$ \\
\hline & 408 & $\stackrel{M}{S D}$ & $\begin{array}{l}42.559 \\
11.763\end{array}$ & $\begin{array}{r}1.174 \\
.230\end{array}$ & $\begin{array}{r}1.054 \\
.231\end{array}$ & $\begin{array}{r}1.011 \\
.144\end{array}$ \\
\hline \multirow[t]{3}{*}{$(3,0,0)$} & $0 ㅇ ㅛ ㅇ$ & $\stackrel{M}{S D}$ & $\begin{array}{l}.991 \\
.047\end{array}$ & $\begin{array}{r}1.081 \\
.172\end{array}$ & $\begin{array}{r}.902 \\
.108\end{array}$ & $\begin{array}{l}.984 \\
.117\end{array}$ \\
\hline & 208 & $\stackrel{M}{\mathrm{SD}}$ & $\begin{array}{r}28.873 \\
6.509\end{array}$ & $\begin{array}{r}1.166 \\
.207\end{array}$ & $\begin{array}{r}.946 \\
.126\end{array}$ & $\begin{array}{r}1.050 \\
.146\end{array}$ \\
\hline & $40 \%$ & $\stackrel{M}{\mathrm{MD}}$ & $\begin{array}{r}45.638 \\
6.266\end{array}$ & $\begin{array}{r}1.173 \\
.204\end{array}$ & $\begin{array}{l}.954 \\
.180\end{array}$ & $\begin{array}{r}1.057 \\
.124\end{array}$ \\
\hline \multirow[t]{3}{*}{$(0,0,1)$} & 0 웅 & $\stackrel{M}{\mathrm{SD}}$ & $\begin{array}{l}.949 \\
.106\end{array}$ & $\begin{array}{r}1.016 \\
.151\end{array}$ & $\begin{array}{r}.959 \\
.137\end{array}$ & $\begin{array}{l}.905 \\
.077\end{array}$ \\
\hline & 208 & $\begin{array}{r}M \\
\text { SD }\end{array}$ & $\begin{array}{r}24.815 \\
4.825\end{array}$ & $\begin{array}{r}1.055 \\
.169\end{array}$ & $\begin{array}{r}1.014 \\
.180\end{array}$ & $\begin{array}{r}.981 \\
.150\end{array}$ \\
\hline & 408 & $\begin{array}{l}M \\
\text { SD }\end{array}$ & $\begin{array}{r}46.771 \\
7.722\end{array}$ & $\begin{array}{r}1.175 \\
.278\end{array}$ & $\begin{array}{r}1.096 \\
.226\end{array}$ & $\begin{array}{r}1.090 \\
.130\end{array}$ \\
\hline
\end{tabular}


Table 6

Means and Standard Deviations of Estimated Error Variance.

Criterion = 1.0.

Part II. Negative Dependency.

\begin{tabular}{|c|c|c|c|c|c|c|}
\hline $\begin{array}{l}\text { ModeI of } \\
\text { Series }\end{array}$ & $\begin{array}{l}\text { Percent } \\
\text { Missing }\end{array}$ & & $\underset{\text { Algorithm }}{\text { Algor }}$ & $\begin{array}{c}\mathrm{ML} \\
(1,0,0)\end{array}$ & $\begin{array}{c}M I \\
(5,0,0)\end{array}$ & $\begin{array}{c}\text { MI } \\
\text { (correct) }\end{array}$ \\
\hline \multirow[t]{3}{*}{$(1,0,0)$} & 08 & $\begin{array}{r}M \\
S D\end{array}$ & $\begin{array}{l}.963 \\
.124\end{array}$ & $\begin{array}{l}.967 \\
.124\end{array}$ & $\begin{array}{l}.886 \\
.093\end{array}$ & $\begin{array}{l}.970 \\
.152\end{array}$ \\
\hline & 208 & $\begin{array}{r}M \\
S D\end{array}$ & $\begin{array}{r}26.534 \\
2.713\end{array}$ & $\begin{array}{l}.997 \\
.076\end{array}$ & $\begin{array}{r}.925 \\
.118\end{array}$ & $\begin{array}{r}1.085 \\
.205\end{array}$ \\
\hline & $40 \%$ & $\begin{array}{r}M \\
\text { SD }\end{array}$ & $\begin{array}{r}45.459 \\
7.127\end{array}$ & $\begin{array}{r}1.220 \\
.499\end{array}$ & $\begin{array}{r}1.022 \\
.172\end{array}$ & $\begin{array}{r}1.029 \\
.245\end{array}$ \\
\hline \multirow[t]{3}{*}{$(2,0,0)$} & 08 & $\underset{S D}{M}$ & $\begin{array}{l}.869 \\
.075\end{array}$ & $\begin{array}{r}1.044 \\
.137\end{array}$ & $\begin{array}{l}.951 \\
.103\end{array}$ & $\begin{array}{l}.978 \\
.228\end{array}$ \\
\hline & 208 & $\begin{array}{r}M \\
S D\end{array}$ & $\begin{array}{r}21.700 \\
6.028\end{array}$ & $\begin{array}{r}1.140 \\
.157\end{array}$ & $\begin{array}{r}1.012 \\
.176\end{array}$ & $\begin{array}{r}1.076 \\
.299\end{array}$ \\
\hline & 408 & $\stackrel{M}{S D}$ & $\begin{array}{r}43.278 \\
5.913\end{array}$ & $\begin{array}{r}1.164 \\
.224\end{array}$ & $\begin{array}{r}1.020 \\
.133\end{array}$ & $\begin{array}{r}1.152 \\
.296\end{array}$ \\
\hline \multirow[t]{3}{*}{$(3,0,0)$} & 08 & $\begin{array}{r}M \\
\text { SD }\end{array}$ & $\begin{array}{l}.987 \\
.154\end{array}$ & $\begin{array}{r}1.188 \\
.221\end{array}$ & $\begin{array}{l}.893 \\
.164\end{array}$ & $\begin{array}{l}.997 \\
.183\end{array}$ \\
\hline & 208 & $\begin{array}{r}M \\
\text { SD }\end{array}$ & $\begin{array}{r}27.548 \\
4.762\end{array}$ & $\begin{array}{r}1.275 \\
.252\end{array}$ & $\begin{array}{l}.987 \\
.178\end{array}$ & $\begin{array}{r}1.091 \\
.218\end{array}$ \\
\hline & 408 & $\begin{array}{r}M \\
\text { SD }\end{array}$ & $\begin{array}{r}39.602 \\
9.530\end{array}$ & $\begin{array}{r}1.283 \\
.281\end{array}$ & $\begin{array}{r}1.019 \\
.299\end{array}$ & $\begin{array}{r}1.151 \\
.235\end{array}$ \\
\hline \multirow[t]{3}{*}{$(0,0,1)$} & 08 & $\underset{S D}{M}$ & $\begin{array}{l}.962 \\
.141\end{array}$ & $\begin{array}{l}.933 \\
.178\end{array}$ & $\begin{array}{l}.888 \\
.109\end{array}$ & $\begin{array}{r}.950 \\
.132\end{array}$ \\
\hline & $20 \%$ & $\begin{array}{c}M \\
\text { SD }\end{array}$ & $\begin{array}{r}25.393 \\
6.478\end{array}$ & $\begin{array}{l}.994 \\
.204\end{array}$ & $\begin{array}{l}.931 \\
.104\end{array}$ & $\begin{array}{r}1.044 \\
.180\end{array}$ \\
\hline & 408 & $\stackrel{M}{M D}$ & $\begin{array}{r}46.575 \\
6.773\end{array}$ & $\begin{array}{l}.959 \\
.238\end{array}$ & $\begin{array}{l}.922 \\
.193\end{array}$ & $\begin{array}{r}1.072 \\
.242\end{array}$ \\
\hline
\end{tabular}


overestimated error variance; 25 times greater than criterion when 20 of the data were missing, and 44 times greater than criterion when $40 \%$ of data were missing (see Figure 4 ). All other missing data techniques resulted in accurate estimates of variance, and did not differ from each other significantly regardless of the percentage of data missing. Although the criterion value for significant mean differences was 1.342 , techniques other than EM did not differ in their estimates of variance by more than 0.14 , even when 40 of of the data were missing.

Change in Level: Overview.

A $4 \times 4 \times 3 \times 2$ (Model $\times$ Technique $\times$ Percent Missing $\mathrm{x}$ Direction of Dependency) ANOVA was used to compare estimates of change in level. Model, Direction of Dependency, and Technique were between-subjects factors; Percent Missing was a within-subjects factor. The means and standard deviations for change in level are presented in Tables 7 and 8 .

Significant overall effects. There was one significant main effect in the analysis, which was Technique $(\underline{F}(3,216)=11.44, p<$ .01). Technique also significantly interacted with Percent Missing $(\underline{F}(6,432)=5.64, \underline{p}<.001)$. No other effects were significant in the ANOVA.

Simple effects tests were used to follow up the interaction between Percent Missing and Technique. These tests determined that the Technique effect was significant when 20 \% of the data were missing $(\underline{F}(3,432)=6.90, \underline{p}<.001)$ and when $40 \%$ of the data were missing $(\underline{F}(3,432)=62.81, \underline{p}<.001)$. Tukey tests were done with a 
Figure 4. Technique by Percent Missing Interaction for Variance

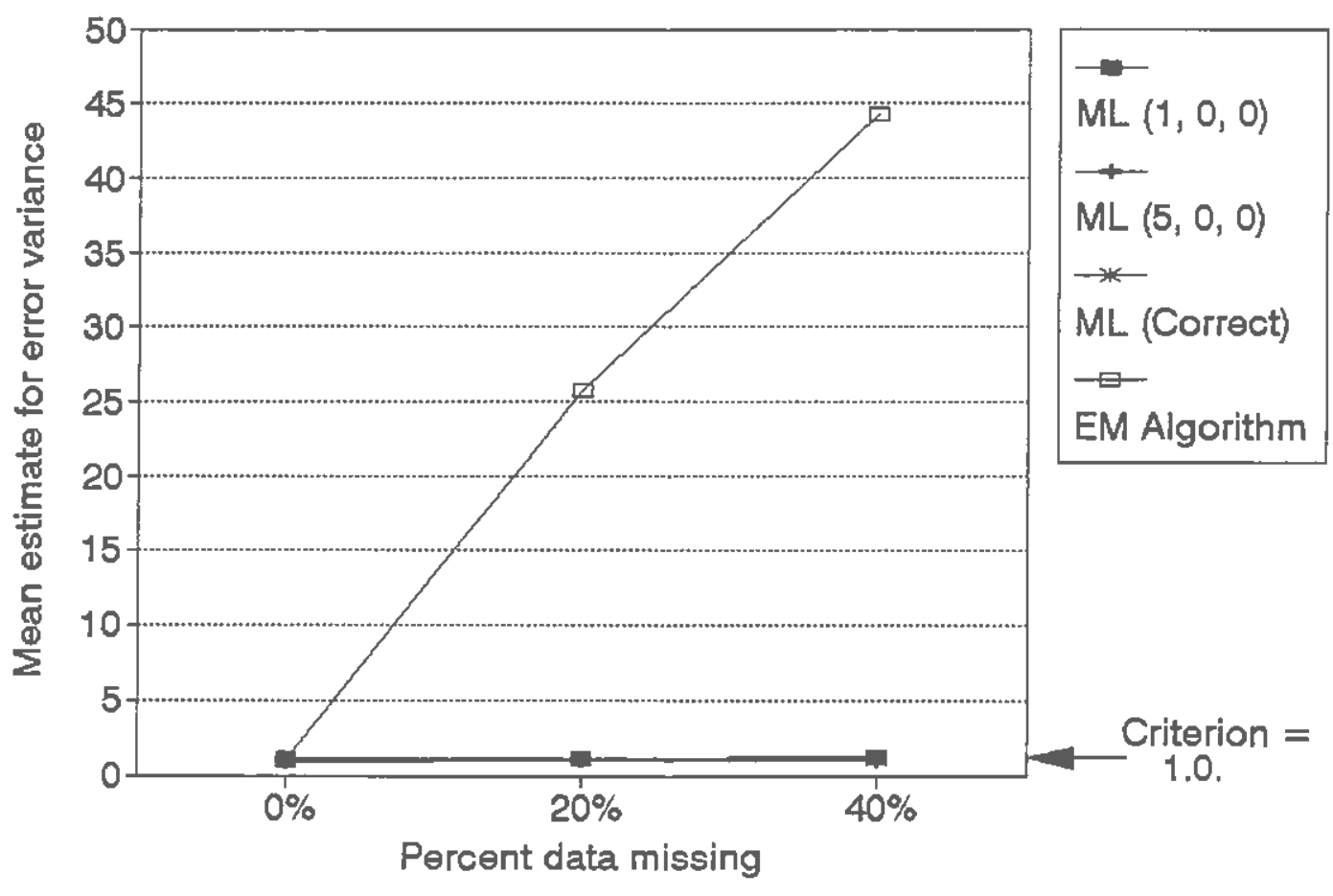


Table 7

Means and Standard Deviations for Estimated Change in Level.

Criterion $=1.5$.

Part I. Positive Dependency.

\begin{tabular}{|c|c|c|c|c|c|c|}
\hline $\begin{array}{l}\text { Model of } \\
\text { Series }\end{array}$ & $\begin{array}{l}\text { Percent } \\
\text { Missing }\end{array}$ & & $\begin{array}{c}\text { EM } \\
\text { Algorithm }\end{array}$ & $\begin{array}{c}M I \\
(1,0,0)\end{array}$ & $\stackrel{M U}{(5,0,0)}$ & $\begin{array}{c}M I_{1} \\
\text { (correct) }\end{array}$ \\
\hline \multirow[t]{3}{*}{$(1,0,0)$} & $0 \%$ & $\stackrel{M}{S D}$ & $\begin{array}{r}1.391 \\
.922\end{array}$ & $\begin{array}{r}1.959 \\
.937\end{array}$ & $\begin{array}{l}.858 \\
.980\end{array}$ & $\begin{array}{r}1.071 \\
.437\end{array}$ \\
\hline & 208 & $\stackrel{M}{S D}$ & $\begin{array}{l}1.537 \\
2.132\end{array}$ & $\begin{array}{l}1.894 \\
1.083\end{array}$ & $\begin{array}{r}1.032 \\
.819\end{array}$ & $\begin{array}{l}.909 \\
.380\end{array}$ \\
\hline & 408 & $\stackrel{M}{\text { SD }}$ & $\begin{array}{l}1.869 \\
2.743\end{array}$ & $\begin{array}{l}1.822 \\
1.100\end{array}$ & $\begin{array}{r}1.085 \\
.745\end{array}$ & $\begin{array}{r}1.071 \\
.799\end{array}$ \\
\hline \multirow[t]{3}{*}{$(2,0,0)$} & 08 & $\stackrel{M}{S D}$ & $\begin{array}{r}1.832 \\
.644\end{array}$ & $\begin{array}{l}2.105 \\
1.218\end{array}$ & $\begin{array}{r}1.916 \\
.978\end{array}$ & $\begin{array}{l}1.568 \\
1.241\end{array}$ \\
\hline & 208 & $\stackrel{M}{S D}$ & $\begin{array}{l}2.051 \\
1.463\end{array}$ & $\begin{array}{l}2.079 \\
1.394\end{array}$ & $\begin{array}{l}2.181 \\
1.273\end{array}$ & $\begin{array}{l}1.340 \\
1.510\end{array}$ \\
\hline & 408 & $\stackrel{M}{\text { SD }}$ & $\begin{array}{l}1.695 \\
3.297\end{array}$ & $\begin{array}{l}1.762 \\
1.138\end{array}$ & $\begin{array}{r}2.184 \\
.957\end{array}$ & $\begin{array}{l}2.062 \\
2.015\end{array}$ \\
\hline \multirow[t]{3}{*}{$(3,0,0)$} & 08 & $\begin{array}{r}M \\
\text { SD }\end{array}$ & $\begin{array}{r}1.843 \\
.933\end{array}$ & $\begin{array}{l}1.782 \\
1.485\end{array}$ & $\begin{array}{l}1.599 \\
1.189\end{array}$ & $\begin{array}{r}2.042 \\
.908\end{array}$ \\
\hline & 208 & $\stackrel{M}{S D}$ & $\begin{array}{l}1.078 \\
1.521\end{array}$ & $\begin{array}{l}1.930 \\
1.764\end{array}$ & $\begin{array}{l}1.407 \\
1.183\end{array}$ & $\begin{array}{r}2.144 \\
.858\end{array}$ \\
\hline & 408 & $\begin{array}{r}\mathrm{M} \\
\text { SD }\end{array}$ & $\begin{array}{r}.353 \\
2.531\end{array}$ & $\begin{array}{l}1.675 \\
1.185\end{array}$ & $\begin{array}{l}1.565 \\
1.539\end{array}$ & $\begin{array}{l}2.075 \\
1.665\end{array}$ \\
\hline \multirow[t]{3}{*}{$(0,0,1)$} & 08 & $\begin{array}{l}M \\
\text { SD }\end{array}$ & $\begin{array}{r}1.410 \\
.184\end{array}$ & $\begin{array}{r}1.387 \\
.226\end{array}$ & $\begin{array}{r}1.497 \\
.158\end{array}$ & $\begin{array}{r}1.488 \\
.165\end{array}$ \\
\hline & 208 & $\begin{array}{l}M \\
\text { SD }\end{array}$ & $\begin{array}{l}1.421 \\
1.542\end{array}$ & $\begin{array}{r}1.357 \\
.184\end{array}$ & $\begin{array}{r}1.602 \\
.182\end{array}$ & $\begin{array}{r}1.533 \\
.308\end{array}$ \\
\hline & 408 & $\begin{array}{l}M \\
\text { SD }\end{array}$ & $\begin{array}{r}.067 \\
3.223\end{array}$ & $\begin{array}{r}1.306 \\
.370\end{array}$ & $\begin{array}{r}1.394 \\
.524\end{array}$ & $\begin{array}{r}1.490 \\
.415\end{array}$ \\
\hline
\end{tabular}


Table 8

Means and Standard Deviations for Estimated Change in Level.

Criterion $=1.5$.

Part II. Negative Dependency.

\begin{tabular}{|c|c|c|c|c|c|c|}
\hline $\begin{array}{l}\text { Model of } \\
\text { Series }\end{array}$ & $\begin{array}{l}\text { Percent } \\
\text { Missing }\end{array}$ & & $\begin{array}{c}E M \\
\text { Algorithm }\end{array}$ & $\begin{array}{c}M I \\
(1,0,0)\end{array}$ & $\frac{M L}{(5,0,0)}$ & $\begin{array}{c}\mathrm{ML} \\
\text { (correct) }\end{array}$ \\
\hline \multirow[t]{3}{*}{$(1,0,0)$} & 08 & $\stackrel{M}{\mathrm{SD}}$ & $\begin{array}{r}1.573 \\
.338\end{array}$ & $\begin{array}{r}1.494 \\
.381\end{array}$ & $\begin{array}{r}1.660 \\
.472\end{array}$ & $\begin{array}{r}1.612 \\
.290\end{array}$ \\
\hline & 208 & $\begin{array}{r}M \\
S D\end{array}$ & $\begin{array}{r}.077 \\
1.906\end{array}$ & $\begin{array}{r}1.501 \\
.504\end{array}$ & $\begin{array}{r}1.662 \\
.426\end{array}$ & $\begin{array}{r}1.556 \\
.301\end{array}$ \\
\hline & 408 & $\begin{array}{l}M \\
S D\end{array}$ & $\begin{array}{l}-.648 \\
2.602\end{array}$ & $\begin{array}{r}1.511 \\
.729\end{array}$ & $\begin{array}{r}1.609 \\
.429\end{array}$ & $\begin{array}{r}1.595 \\
.534\end{array}$ \\
\hline \multirow[t]{3}{*}{$(2,0,0)$} & 08 & $\underset{S D}{M}$ & $\begin{array}{r}1.449 \\
.103\end{array}$ & $\begin{array}{r}1.561 \\
.255\end{array}$ & $\begin{array}{r}1.460 \\
.153\end{array}$ & $\begin{array}{r}1.539 \\
.215\end{array}$ \\
\hline & 208 & $\begin{array}{r}M \\
S D\end{array}$ & $\begin{array}{l}1.811 \\
1.712\end{array}$ & $\begin{array}{r}1.443 \\
.284\end{array}$ & $\begin{array}{r}1.448 \\
.361\end{array}$ & $\begin{array}{r}1.547 \\
.220\end{array}$ \\
\hline & 408 & $\stackrel{M}{\mathrm{SD}}$ & $\begin{array}{r}.853 \\
2.296\end{array}$ & $\begin{array}{r}1.932 \\
.498\end{array}$ & $\begin{array}{r}1.643 \\
.447\end{array}$ & $\begin{array}{r}1.574 \\
.378\end{array}$ \\
\hline \multirow[t]{3}{*}{$(3,0,0)$} & 08 & $\begin{array}{r}\mathrm{M} \\
\mathrm{SD}\end{array}$ & $\begin{array}{r}1.428 \\
.316\end{array}$ & $\begin{array}{r}1.434 \\
.214\end{array}$ & $\begin{array}{r}1.609 \\
.205\end{array}$ & $\begin{array}{r}1.507 \\
.250\end{array}$ \\
\hline & $20 \%$ & $\begin{array}{r}M \\
S D\end{array}$ & $\begin{array}{l}1.313 \\
2.280\end{array}$ & $\begin{array}{r}1.396 \\
.210\end{array}$ & $\begin{array}{r}1.649 \\
.276\end{array}$ & $\begin{array}{r}1.488 \\
.311\end{array}$ \\
\hline & 408 & $\begin{array}{r}M \\
\text { SD }\end{array}$ & $\begin{array}{r}-.209 \\
2.085\end{array}$ & $\begin{array}{r}1.459 \\
.406\end{array}$ & $\begin{array}{r}1.648 \\
.446\end{array}$ & $\begin{array}{r}1.601 \\
.613\end{array}$ \\
\hline \multirow[t]{3}{*}{$(0,0,1)$} & 08 & $\begin{array}{r}\mathrm{M} \\
\mathrm{SD}\end{array}$ & $\begin{array}{r}1.526 \\
.677\end{array}$ & $\begin{array}{r}1.373 \\
.847\end{array}$ & $\begin{array}{r}1.357 \\
.608\end{array}$ & $\begin{array}{r}1.429 \\
.612\end{array}$ \\
\hline & 208 & $\begin{array}{r}M \\
S D\end{array}$ & $\begin{array}{r}.680 \\
1.944\end{array}$ & $\begin{array}{r}1.400 \\
.827\end{array}$ & $\begin{array}{r}1.356 \\
.786\end{array}$ & $\begin{array}{r}1.507 \\
.590\end{array}$ \\
\hline & 408 & $\begin{array}{l}M \\
\text { SD }\end{array}$ & $\begin{array}{r}.842 \\
2.316\end{array}$ & $\begin{array}{r}1.147 \\
.910\end{array}$ & $\begin{array}{r}1.551 \\
.812\end{array}$ & $\begin{array}{r}1.375 \\
.714\end{array}$ \\
\hline
\end{tabular}


critical value of mean difference equal to 0.475 . Although the simple effects test was significant at $20 \%$ missing data, none of the mean differences compared for the various data estimation techniques were significantly different from each other at this level of missing data .

Major findings. When $40 \%$ of the data were missing, Tukey tests indicated that use of the EM algorithm resulted in significant underestimates of change in level compared with the different maximum likelihood estinates, which were accurate and did not differ from each other (see Figure 5).

Change in slope: overview.

A $4 \times 4 \times 3 \times 2$ (Model $\times$ Technique $x$ Percent Missing $x$ Direction of Dependency) ANOVA was used to compare estimates of change in slope. Model, Direction of Dependency, and Technique were between-subjects factors; Percent Missing was a within-subjects factor. The means and standard deviations for change in slope are presented in Tables 9 and 10.

Significant overall effects. There were two main effects and two 2 -way interaction effects that were significant in the analysis. Model, Direction of Dependency, and their interaction were significant $(\underline{F}(3,72)=5.59, \underline{p}<.01),(\underline{F}(1,72)=10.49, \underline{p}<$ $.01)$, and $(\underline{F}(3,72)=7.20, \mathrm{p}<.001)$, respectively. In addition, there was a significant 2-way interaction between Percent Missing and Technique $(\underline{F}(6,432)=2.91, \underline{P}<.01)$. No other effects in the analysis were significant. 
Figure 5. Technique by Percent Missing Interaction for Change in Level

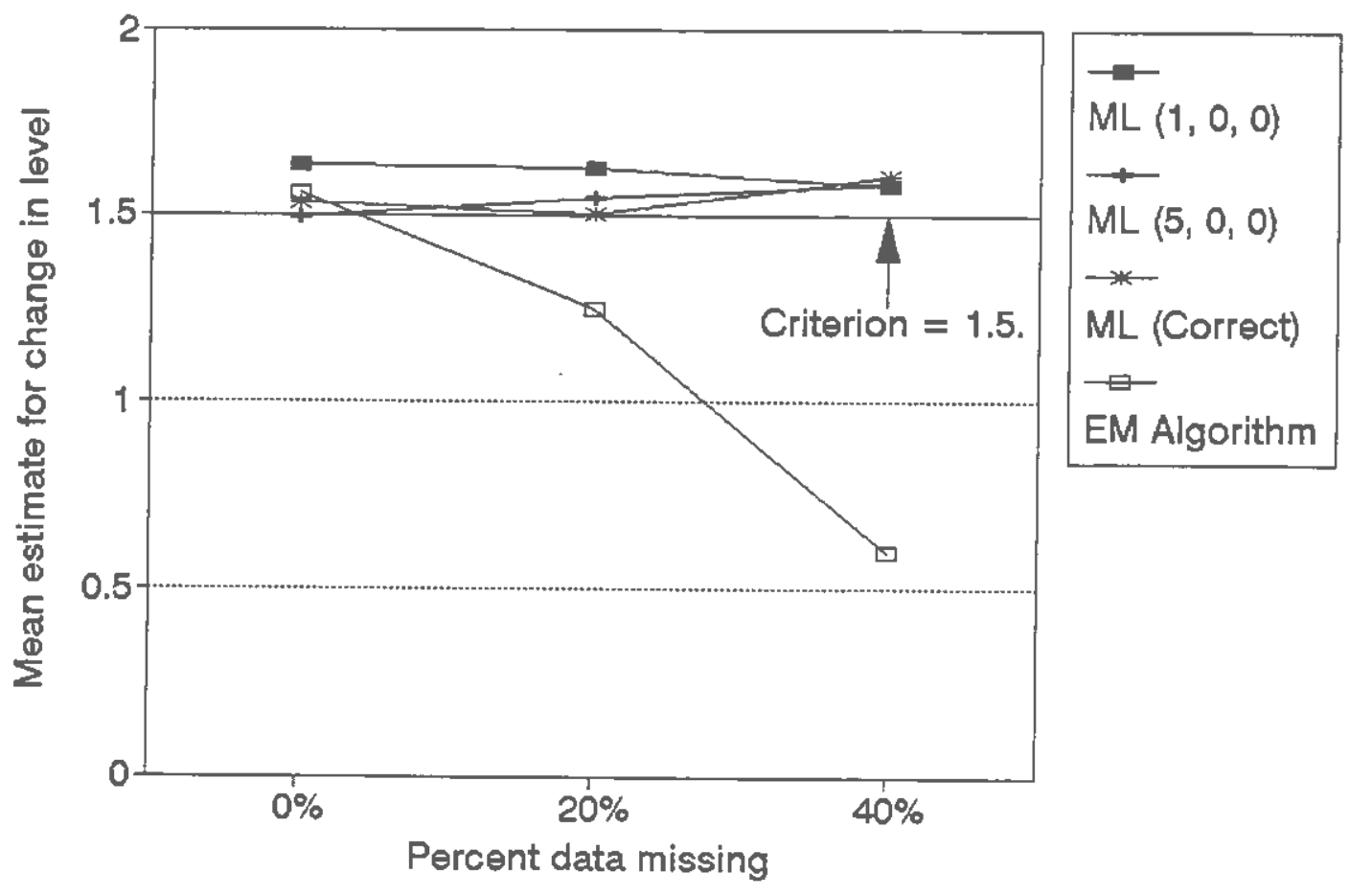


Table 9

Means and Standard Deviations for Estimated Change in Slope.

Criterion $=0$.

Part I. Positive Dependency.

\begin{tabular}{|c|c|c|c|c|c|c|}
\hline $\begin{array}{l}\text { Model of } \\
\text { Series }\end{array}$ & $\begin{array}{l}\text { Perce } \\
\text { Missi }\end{array}$ & & $\frac{\text { EM }}{\text { Algorithrn }}$ & $\begin{array}{c}\mathrm{ML} \\
(1,0,0)\end{array}$ & $\begin{array}{c}\text { ML } \\
(5,0,0)\end{array}$ & $\begin{array}{c}M L \\
(\operatorname{correct})\end{array}$ \\
\hline \multirow[t]{3}{*}{$(1,0,0)$} & 0 웅 & $\stackrel{M}{S D}$ & $\begin{array}{l}.013 \\
.042\end{array}$ & $\begin{array}{l}.009 \\
.030\end{array}$ & $\begin{array}{l}.006 \\
.034\end{array}$ & $\begin{array}{l}.007 \\
.038\end{array}$ \\
\hline & 208 & $\begin{array}{r}M \\
\text { SD }\end{array}$ & $\begin{array}{l}.017 \\
.095\end{array}$ & $\begin{array}{l}.011 \\
.030\end{array}$ & $\begin{array}{l}.003 \\
.028\end{array}$ & $\begin{array}{l}.004 \\
.042\end{array}$ \\
\hline & 408 & $\mathbf{M}$ & $\begin{array}{r}-.007 \\
.065\end{array}$ & $\begin{array}{l}.012 \\
.035\end{array}$ & $\begin{array}{l}.004 \\
.034\end{array}$ & $\begin{array}{l}.003 \\
.037\end{array}$ \\
\hline \multirow[t]{3}{*}{$(2,0,0)$} & $0 \%$ & $\mathbf{S D}$ & $\begin{array}{l}.068 \\
.086\end{array}$ & $\begin{array}{l}.106 \\
.066\end{array}$ & $\begin{array}{l}.008 \\
.097\end{array}$ & $\begin{array}{l}.047 \\
.092\end{array}$ \\
\hline & 208 & $\begin{array}{r}M \\
S D\end{array}$ & $\begin{array}{l}.043 \\
.114\end{array}$ & $\begin{array}{r}.103 \\
.073\end{array}$ & $\begin{array}{l}.016 \\
.105\end{array}$ & $\begin{array}{l}.045 \\
.095\end{array}$ \\
\hline & 408 & $\stackrel{M}{S D}$ & $\begin{array}{r}.017 \\
.117\end{array}$ & $\begin{array}{r}.113 \\
.082\end{array}$ & $\begin{array}{r}-.023 \\
.103\end{array}$ & $\begin{array}{r}.043 \\
.101\end{array}$ \\
\hline \multirow[t]{3}{*}{$(3,0,0)$} & 08 & $\begin{array}{r}M \\
S D\end{array}$ & $\begin{array}{l}.009 \\
.082\end{array}$ & $\begin{array}{r}-.008 \\
.051\end{array}$ & $\begin{array}{r}.012 \\
.067\end{array}$ & $\begin{array}{r}-.008 \\
.053\end{array}$ \\
\hline & 208 & $\begin{array}{r}M \\
S D\end{array}$ & $\begin{array}{l}.027 \\
.113\end{array}$ & $\begin{array}{r}-.014 \\
.062\end{array}$ & $\begin{array}{l}.013 \\
.060\end{array}$ & $\begin{array}{r}-.007 \\
.056\end{array}$ \\
\hline & 408 & $\begin{array}{r}M \\
S D\end{array}$ & $\begin{array}{r}-.021 \\
.072\end{array}$ & $\begin{array}{r}-.011 \\
.045\end{array}$ & $\begin{array}{l}.003 \\
.059\end{array}$ & $\begin{array}{r}-.009 \\
.049\end{array}$ \\
\hline \multirow[t]{3}{*}{$(0,0,1)$} & 08 & $\begin{array}{r}M \\
S D\end{array}$ & $\begin{array}{r}-.002 \\
.007\end{array}$ & $\begin{array}{l}.000 \\
.005\end{array}$ & $\begin{array}{l}.002 \\
.005\end{array}$ & $\begin{array}{r}.003 \\
.008\end{array}$ \\
\hline & 208 & $\begin{array}{r}M \\
S D\end{array}$ & $\begin{array}{l}.014 \\
.055\end{array}$ & $\begin{array}{l}.002 \\
.005\end{array}$ & $\begin{array}{l}.002 \\
.010\end{array}$ & $\begin{array}{r}-.001 \\
.008\end{array}$ \\
\hline & 408 & $\begin{array}{r}M \\
S D\end{array}$ & $\begin{array}{r}-.022 \\
.127\end{array}$ & $\begin{array}{r}-.003 \\
.015\end{array}$ & $\begin{array}{l}.003 \\
.014\end{array}$ & $\begin{array}{r}.002 \\
.015\end{array}$ \\
\hline
\end{tabular}


Table 10

Means and Standard Deviations for Estimated Change in Slope.

Criterion $=0$.

Part II. Negative Dependency.

\begin{tabular}{|c|c|c|c|c|c|c|}
\hline $\begin{array}{l}\text { Model of } \\
\text { Series }\end{array}$ & $\begin{array}{l}\text { Percent } \\
\text { Missing }\end{array}$ & & $\begin{array}{c}\text { EM } \\
\text { Algorithm }\end{array}$ & $\begin{array}{c}M L \\
(1,0,0)\end{array}$ & $\begin{array}{c}M L \\
(5,0,0)\end{array}$ & $\begin{array}{c}\text { ML } \\
\text { (correct) }\end{array}$ \\
\hline \multirow[t]{3}{*}{$(1,0,0)$} & 08 & $\begin{array}{r}M \\
S D\end{array}$ & $\begin{array}{r}-.002 \\
.008\end{array}$ & $\begin{array}{r}-.001 \\
.008\end{array}$ & $\begin{array}{l}.000 \\
.012\end{array}$ & $\begin{array}{l}.005 \\
.012\end{array}$ \\
\hline & 208 & $\stackrel{M}{S D}$ & $\begin{array}{l}.017 \\
.095\end{array}$ & $\begin{array}{r}-.030 \\
.087\end{array}$ & $\begin{array}{l}.000 \\
.012\end{array}$ & $\begin{array}{l}.007 \\
.009\end{array}$ \\
\hline & 40 웅 & $\begin{array}{r}M \\
S D\end{array}$ & $\begin{array}{r}-.022 \\
.093\end{array}$ & $\begin{array}{l}.004 \\
.017\end{array}$ & $\begin{array}{l}.001 \\
.020\end{array}$ & $\begin{array}{l}.007 \\
.012\end{array}$ \\
\hline \multirow[t]{3}{*}{$(2,0,0)$} & 08 & $\begin{array}{l}M \\
\text { SD }\end{array}$ & $\begin{array}{r}-.004 \\
.007\end{array}$ & $\begin{array}{r}-.001 \\
.010\end{array}$ & $\begin{array}{r}-.003 \\
.012\end{array}$ & $\begin{array}{l}.002 \\
.009\end{array}$ \\
\hline & 208 & $\begin{array}{r}M \\
\text { SD }\end{array}$ & $\begin{array}{r}-.006 \\
.055\end{array}$ & $\begin{array}{r}-.001 \\
.011\end{array}$ & $\begin{array}{r}-.005 \\
.016\end{array}$ & $\begin{array}{l}.001 \\
.013\end{array}$ \\
\hline & 408 & $\begin{array}{l}M \\
S D\end{array}$ & $\begin{array}{r}-.039 \\
.099\end{array}$ & $\begin{array}{l}.001 \\
.013\end{array}$ & $\begin{array}{l}.001 \\
.012\end{array}$ & $\begin{array}{l}.002 \\
.020\end{array}$ \\
\hline \multirow[t]{3}{*}{$(3,0,0)$} & 08 & $\underset{S D}{M}$ & $\begin{array}{l}.002 \\
.007\end{array}$ & $\begin{array}{r}-.002 \\
.007\end{array}$ & $\begin{array}{r}-.003 \\
.007\end{array}$ & $\begin{array}{r}-.002 \\
.007\end{array}$ \\
\hline & 208 & $\begin{array}{r}M \\
\text { SD }\end{array}$ & $\begin{array}{r}-.038 \\
.064\end{array}$ & $\begin{array}{r}-.002 \\
.010\end{array}$ & $\begin{array}{r}-.003 \\
.011\end{array}$ & $\begin{array}{r}-.003 \\
.007\end{array}$ \\
\hline & 408 & $\stackrel{M}{S D}$ & $\begin{array}{r}-.023 \\
.050\end{array}$ & $\begin{array}{r}-.002 \\
.016\end{array}$ & $\begin{array}{r}-.001 \\
.012\end{array}$ & $\begin{array}{r}-.001 \\
.014\end{array}$ \\
\hline \multirow[t]{3}{*}{$(0,0,1)$} & 08 & $\begin{array}{l}M \\
S D\end{array}$ & $\begin{array}{l}.000 \\
.023\end{array}$ & $\begin{array}{l}.012 \\
.017\end{array}$ & $\begin{array}{l}.012 \\
.017\end{array}$ & $\begin{array}{r}-.004 \\
.018\end{array}$ \\
\hline & 208 & $\begin{array}{l}M \\
S D\end{array}$ & $\begin{array}{r}-.012 \\
.079\end{array}$ & $\begin{array}{l}.010 \\
.020\end{array}$ & $\begin{array}{l}.013 \\
.016\end{array}$ & $\begin{array}{r}-.002 \\
.019\end{array}$ \\
\hline & 408 & $\begin{array}{r}M \\
\text { SD }\end{array}$ & $\begin{array}{l}.007 \\
.062\end{array}$ & $\begin{array}{l}.011 \\
.018\end{array}$ & $\begin{array}{l}.013 \\
.021\end{array}$ & $\begin{array}{r}-.005 \\
.017\end{array}$ \\
\hline
\end{tabular}


Simple effects tests were first done to examine the interaction between Model and Direction of Dependency. These tests determined that the effect for Model was only significant when autocorrelation was positive $(\underline{F}(3,72)=35.71, \underline{p}<.001)$. However, Tukey tests did not show any mean differences greater than the critical value for significance (i.e., 0.104).

simple effects tests were next done to follow up the interaction between Percent Missing and Technique. These tests determined that the effect for Technique was only significant when 40 of the data were missing $(\mathrm{F}(3,432)=30.77, \mathrm{p}<.001)$. Subsequent Tukey tests were again all nonsignificant the critical value for mean differences was 0.050$)$.

Major findings. None of the factors tested in this design led to significantly inaccurate estimates of the change in slope parameter.

Phi (Autoregressive Models): Overview.

Because Direction of Dependency was also an independent variable in this design, estimates of $\phi_{1}$ were analyzed in two separate ANOVA's, one selecting series with positive autocorrelation, the other for negatively autocorrelated series. Series with a first order moving averages model $(0,0,1)$ underlying the data were also analyzed separately (see below), since two of the data estimation techniques did not yield $\phi$ estimates for $(0,0,1)$ models. Analysis of $\phi$ was performed using two separate $3 \times 4 \times 3$ (underlying ARIMA Model, including only autoregressive models, $x$ missing data estimation Technique $x$ Percent Missing) analyses of 
variance. Model and Technique were between-subjects factors and Percent Missing was a within-subjects factor. The means and standard deviations for $\phi$ are presented in Tables 11 and 12 .

A. Positive Autocorrelation.

Significant overall effects. Main effects for Percent Missing and Technique were significant, and their interaction was also significant, all at the .001 level $(\underline{F}(2,54)=62.40, \underline{F}(3,81)=$ 77.21 , and $\underline{F}(6,162)=105.22$, respectively. In addition, the 3 -way interaction between Percent Missing, Technique, and Model was also a significant effect $(\underline{F}(12,162)=2.38, p<.01)$. No other effects in the analysis were significant.

Simple effects tests were first done to follow up the 3-way interaction effect; these tests examined the interaction between Technique and Model at each level of Percent Missing, and determined that the effect was significant at every level of missing data (at $0 \%$ missing, $\underline{F}(6,162)=22.09 ;$ at 20 o missing, $\underline{F}(6,162)=20.93 ;$ and at 40 o missing, $E(6,162)=37.21$, all $\left.\mathrm{p}^{\prime} \mathrm{s}<.001\right)$. Simple simple effects tests were then used to follow up these significant interaction effects. These tests found the effect for Technique to be significant at every combination of Model and Percent Missing, with the single exception of the first order autoregressive model $(1,0,0)$ when no data were missing. Detailed results (i.e., F-values and $p$-values) of these simple simple effects tests are summarized in Appendix L.

Major findings. Subsequent Tukey tests were used as a follow up to the significant simple simple effects tests; the critical value 
Table 11

Means and Standard Deviations for Estimated Phi.

Criterion $=0.60$.

\begin{tabular}{|c|c|c|c|c|c|c|}
\hline $\begin{array}{l}\text { Model of } \\
\text { Series }\end{array}$ & $\begin{array}{l}\text { Percent } \\
\text { Missing }\end{array}$ & & $\begin{array}{c}\mathbf{E M} \\
\text { Algorithm }\end{array}$ & $\begin{array}{c}M I \\
(1,0,0)\end{array}$ & $\begin{array}{c}M L \\
(5,0,0)\end{array}$ & $\underset{\text { (correct) }}{M L}$ \\
\hline \multirow[t]{3}{*}{$(1,0,0)$} & 08 & $\underset{S D}{M}$ & $\begin{array}{l}.497 \\
.101\end{array}$ & $\begin{array}{l}.513 \\
.102\end{array}$ & $\begin{array}{l}.578 \\
.119\end{array}$ & $\begin{array}{l}.581 \\
.126\end{array}$ \\
\hline & 208 & $\stackrel{M}{S D}$ & $\begin{array}{l}.008 \\
.078\end{array}$ & $\begin{array}{l}.511 \\
.108\end{array}$ & $\begin{array}{l}.585 \\
.187\end{array}$ & $\begin{array}{l}.586 \\
.160\end{array}$ \\
\hline & 408 & $\begin{array}{r}M \\
S D\end{array}$ & $\begin{array}{r}-.025 \\
.107\end{array}$ & $\begin{array}{l}.479 \\
.165\end{array}$ & $\begin{array}{l}.551 \\
.147\end{array}$ & $\begin{array}{l}.501 \\
.179\end{array}$ \\
\hline \multirow[t]{3}{*}{$(2,0,0)$} & D용 & $\begin{array}{r}\mathrm{M} \\
\mathrm{SD}\end{array}$ & $\begin{array}{l}.577 \\
.105\end{array}$ & $\begin{array}{l}.659 \\
.147\end{array}$ & $\begin{array}{r}.529 \\
.135\end{array}$ & $\begin{array}{l}.525 \\
.114\end{array}$ \\
\hline & 208 & $\begin{array}{r}M \\
S D\end{array}$ & $\begin{array}{l}.017 \\
.116\end{array}$ & $\begin{array}{l}.682 \\
.129\end{array}$ & $\begin{array}{l}.528 \\
.153\end{array}$ & $\begin{array}{l}.585 \\
.101\end{array}$ \\
\hline & $40 \%$ & $\begin{array}{r}\mathrm{M} \\
\mathrm{SD}\end{array}$ & $\begin{array}{r}-.082 \\
.074\end{array}$ & $\begin{array}{l}.710 \\
.188\end{array}$ & $\begin{array}{r}.714 \\
.272\end{array}$ & $\begin{array}{l}.648 \\
.204\end{array}$ \\
\hline \multirow[t]{3}{*}{$(3,0,0)$} & 08 & SD & $\begin{array}{l}.571 \\
.090\end{array}$ & $\begin{array}{l}.641 \\
.139\end{array}$ & $\begin{array}{l}.506 \\
.100\end{array}$ & $\begin{array}{r}.533 \\
.119\end{array}$ \\
\hline & 208 & $\begin{array}{r}\mathrm{M} \\
\mathrm{SD}\end{array}$ & $\begin{array}{l}.036 \\
.132\end{array}$ & $\begin{array}{l}.653 \\
.161\end{array}$ & $\begin{array}{l}.523 \\
.150\end{array}$ & $\begin{array}{l}.568 \\
.155\end{array}$ \\
\hline & 408 & $\underset{S D}{M}$ & $\begin{array}{r}-.022 \\
.127\end{array}$ & $\begin{array}{l}.694 \\
.114\end{array}$ & $\begin{array}{l}.574 \\
.153\end{array}$ & $\begin{array}{l}.624 \\
.266\end{array}$ \\
\hline
\end{tabular}


Table 12

Means and Standard Deviations for Estimated Phi.

Criterion $=-0.60$.

\begin{tabular}{|c|c|c|c|c|c|c|}
\hline $\begin{array}{l}\text { Model of } \\
\text { Series }\end{array}$ & $\begin{array}{l}\text { Percent } \\
\text { Missing }\end{array}$ & & $\begin{array}{c}\text { EM } \\
\text { Algorithm }\end{array}$ & $(1,0,0)$ & $\frac{M I_{2}}{(5,0,0)}$ & $\begin{array}{c}M I \\
\text { (correct) }\end{array}$ \\
\hline \multirow[t]{3}{*}{$(1,0,0)$} & $0 \%$ & $\begin{array}{r}M \\
S D\end{array}$ & $\begin{array}{r}-.580 \\
.063\end{array}$ & $\begin{array}{r}-.619 \\
.081\end{array}$ & $\begin{array}{r}-.564 \\
.129\end{array}$ & $\begin{array}{r}-.656 \\
.038\end{array}$ \\
\hline & 208 & $\underset{S D}{M}$ & $\begin{array}{l}.009 \\
.158\end{array}$ & $\begin{array}{r}-.495 \\
.381\end{array}$ & $\begin{array}{r}-.593 \\
.142\end{array}$ & $\begin{array}{r}-.649 \\
.052\end{array}$ \\
\hline & 408 & $\begin{array}{r}M \\
S D\end{array}$ & $\begin{array}{r}-.044 \\
.093\end{array}$ & $\begin{array}{r}-.597 \\
.162\end{array}$ & $\begin{array}{r}-.446 \\
.229\end{array}$ & $\begin{array}{r}-.662 \\
.129\end{array}$ \\
\hline \multirow[t]{3}{*}{$(2,0,0)$} & 00 & $\stackrel{M}{S D}$ & $\begin{array}{r}-.556 \\
.103\end{array}$ & $\begin{array}{r}-.452 \\
.064\end{array}$ & $\begin{array}{r}-.640 \\
.054\end{array}$ & $\begin{array}{r}-.626 \\
.073\end{array}$ \\
\hline & 20 염 & $\begin{array}{r}M \\
\text { SD }\end{array}$ & $\begin{array}{r}-.059 \\
.087\end{array}$ & $\begin{array}{r}-.407 \\
.092\end{array}$ & $\begin{array}{r}-.635 \\
.137\end{array}$ & $\begin{array}{r}-.592 \\
.079\end{array}$ \\
\hline & 408 & $\underset{S D}{M}$ & $\begin{array}{r}-.021 \\
.139\end{array}$ & $\begin{array}{r}-.341 \\
.094\end{array}$ & $\begin{array}{r}-.561 \\
.207\end{array}$ & $\begin{array}{r}-.550 \\
.128\end{array}$ \\
\hline \multirow[t]{3}{*}{$(3,0,0)$} & 08 & $\begin{array}{l}M \\
\text { SD }\end{array}$ & $\begin{array}{r}-.658 \\
.058\end{array}$ & $\begin{array}{r}-.469 \\
.037\end{array}$ & $\begin{array}{r}-.674 \\
.136\end{array}$ & $\begin{array}{r}-.653 \\
.067\end{array}$ \\
\hline & 208 & $\begin{array}{l}M \\
\text { SD }\end{array}$ & $\begin{array}{r}-.087 \\
.121\end{array}$ & $\begin{array}{r}-.412 \\
.057\end{array}$ & $\begin{array}{r}-.676 \\
.170\end{array}$ & $\begin{array}{r}-.607 \\
.081\end{array}$ \\
\hline & $40 \frac{8}{8}$ & $\underset{S D}{M}$ & $\begin{array}{r}-.071 \\
.065\end{array}$ & $\begin{array}{r}-.387 \\
.029\end{array}$ & $\begin{array}{r}-.675 \\
.231\end{array}$ & $\begin{array}{r}-.626 \\
.174\end{array}$ \\
\hline
\end{tabular}


for mean differences was 0.207 . The pattern of results was consistent across the three different underlying models: when no data were missing from the series, there were no significant group differences based on technique (indicating that model specification per se did not result in different estimates of $\phi)$. When $20 \%$ or 408 of the data were missing, the EM algorithm resulted in significantly lower estimates of $\phi$ than all other data estimation approaches, which did not differ from each other. As can be seen in Figure 6, $\phi$ estimates were approximately zero when the EM algorithm was used to estimate missing data.

B. Negative Autocorrelation.

Significant overall effects. Main effects for Percent Missing and Technique were significant, and their interaction was significant, all at the $\underline{p}<.001$ level $(\underline{F}(2,54)=106.55, \underline{F}(3,81)$ $=93.17$, and $\underline{E}(6,162)=54.77$, respectively). In addition, the 2way interaction between Technique and Model was significant ( $81)=4.21, \mathrm{p}<.01)$. No other effects in the analysis were significant.

Simple effects tests were first done to follow up the 2-way interaction between Technique and Model. These tests determined that the effect for Technique was significant for each underlying model (for the $(1,0,0)$ model, $\underline{F}(3,81)=109.01$; for the $(2,0,0)$ model, $\underline{F}(3,81)=97.52$; and for the $(3,0,0) \operatorname{model}, \underline{F}(3,81)=$ 97.83, all $\left.\mathrm{p}^{\prime} \mathrm{s}<.001\right)$.

Subsequent Tukey tests were performed as a follow up to these significant effects; the critical value for significant mean 
Figure 6. Technique by Percent Missing by Model Interaction for Phi

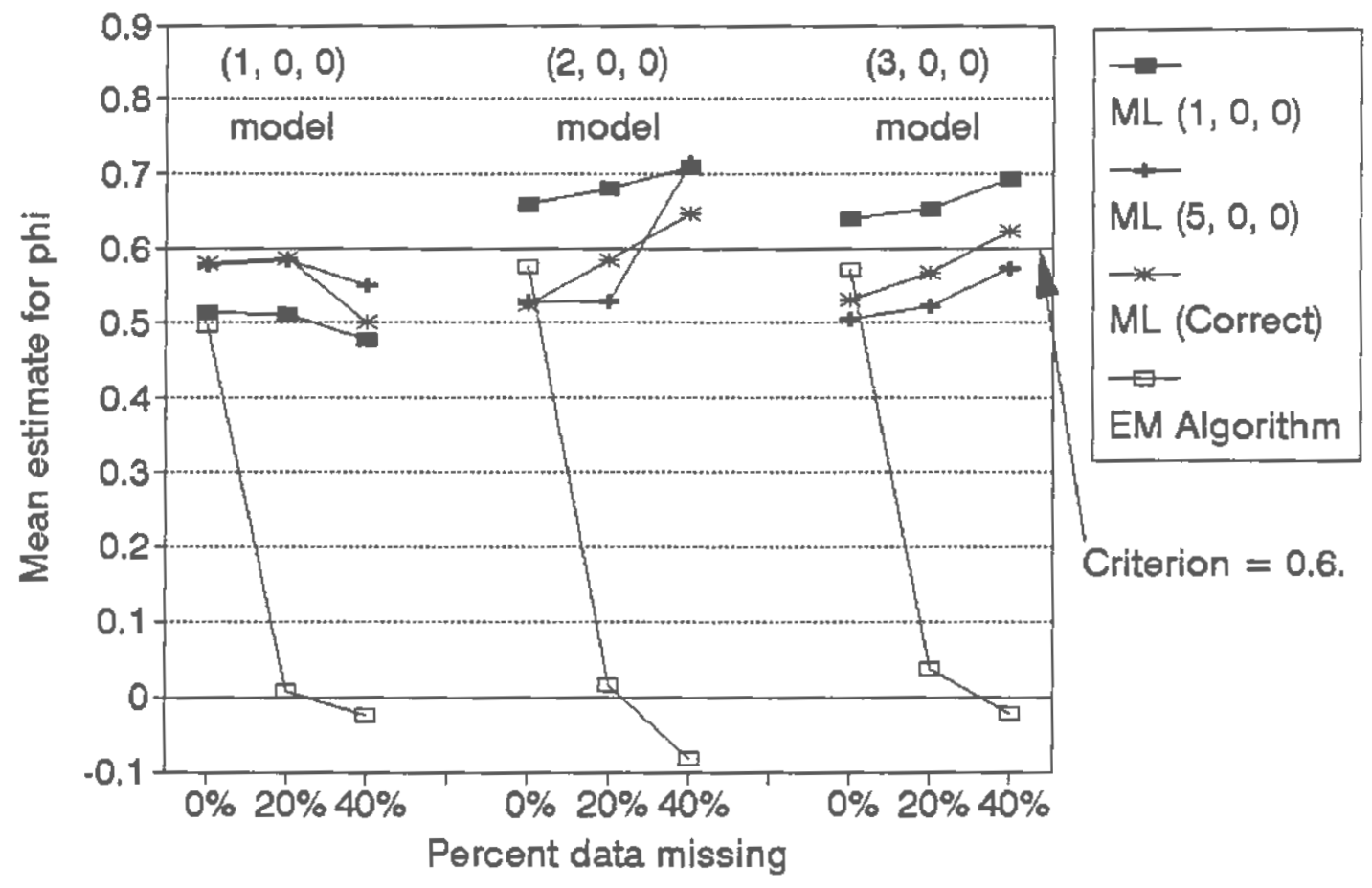


differences was 0.250 . Results of these tests are depicted in Figure 7. For the (1, 0, 0) model, the EM algorithm resulted in significantly lower estimates of autocorrelation than the three ML methods which did not differ from each other. When the underlying model was a $(2,0,0)$ model, $E M$ estimates were significantly lower than ML with (5, 0, 0) specification or correct model specification (i.e., 2, 0, O specification), but did not differ from ML estimates when a $(1,0,0)$ model was specified). ML $(1,0,0)$ estimates of $\phi$ did not differ significantly from any other group mean estimates. When the underlying model of the series was a $(3,0,0)$ model, the pattern of results was the same as for the $(2,0,0)$ model, except that the ML $(1,0,0)$ phi estimates were significantly lower than those of the ML $(5,0,0)$ method of data estimation. Simple effects tests were next done to follow up the 2-way interaction between Technique and Percent Missing. These tests determined that the effect for Technique was significant at each level of Percent Missing (at oo missing $\underline{F}(3,162)=24.79$; at $20 \%$ missing, $\underline{F}(3,162)=556.20$; and at $40 \%$ missing, $\underline{F}(3,162)=$ 490.08, all $\left.\mathrm{p}^{\prime} \mathrm{s}<.001\right)$

Subsequent Tukey tests were done to follow up these significant effects; the critical value for significant mean differences was 0.088 . The nature of this interaction can be discerned from Figure 8. When none of the data were missing, the ML approach with ( 1,0 , 0) specification resulted in significantly lower $\phi$ estimates than the other two MI approaches and the EM algorithm approach. The latter three techniques' $\phi$ estimates did not differ from each other. The 
Figure 7. Technique by Model Interaction for Negative Phi

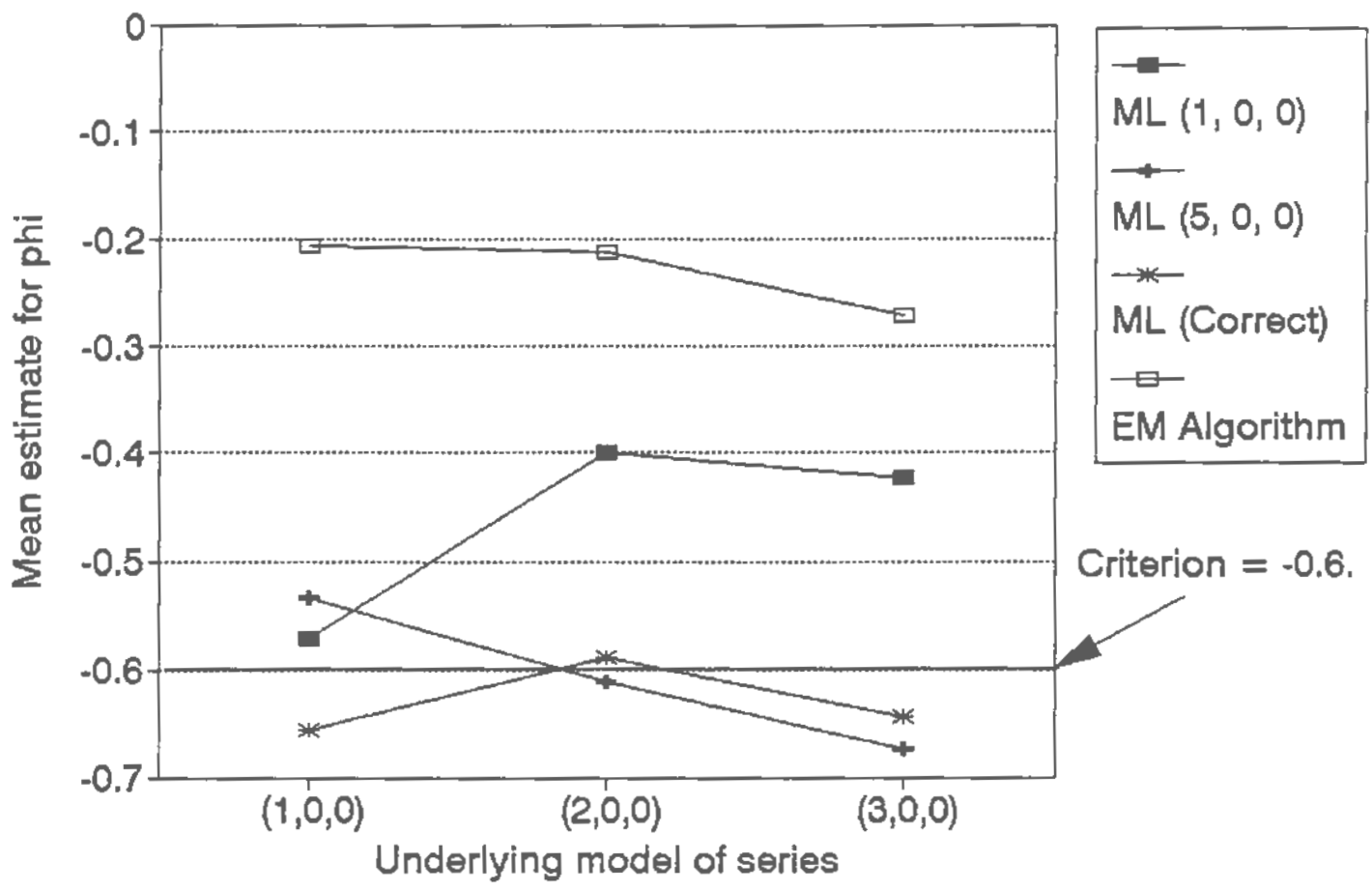


Figure 8. Technique by Percent Missing Interaction for Negative Phi

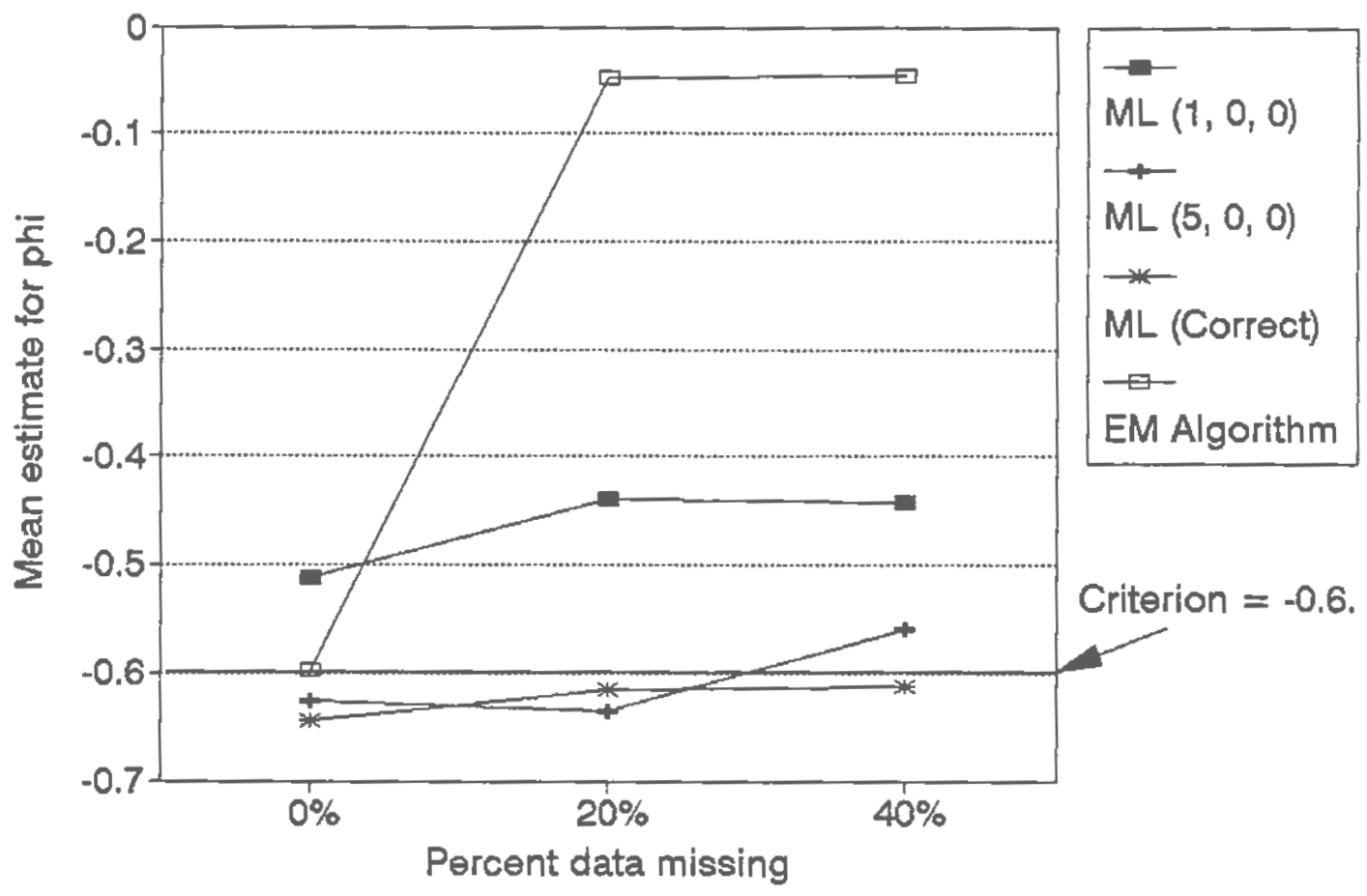


pattern of results when either 208 or 408 of the data were missing was consistent: EM algorithm resulted in significantly lower $\phi$ estimates than every other technique, and ML $(1,0,0)$ estimates were significantly lower than the $\mathrm{ML}(5,0,0)$ and the $\mathrm{ML}$ (correct) techniques. The two latter ML techniques resulted in $\phi$ estimates close to criterion and not different from each other.

Phi (Moving Averages Mode1): Overview.

Estimates of $\phi$ were analyzed in two separate ANovA's, one for each direction of dependency. These analyses were limited to series with a first order moving averages $(0,0,1)$ model underlying the data, and missing data were estimated using the ML approach with either $a(1,0,0)$ or $a(5,0,0)$ model specified. These were the only techniques that yielded a $\phi$ estimate for the moving averages model.

Analysis of $\phi$ was performed using $2 \times 3$ imissing data estimation Technique $\mathrm{x}$ Percent Missing) ANovA's. Technique was a between-subjects factor and Percent Missing was a within-subjects factor. The means and standard deviations for $\phi$ are presented in Table 13.

A. Positive Autocorrelation.

Significant overall effects. The main effect for Technique was the only significant effect in the analysis $(\underline{E}(1,9)=25.13, \underline{P}<$ $.01)$, indicating that the (1,0,0) specification yielded significantly lower-magnitude estimates of $\phi(\underline{M}=-.434, \underline{S D}=.128)$ than the $(5,0,0)$ specification $(\underline{M}=-.638, \underline{S D}=.149)$. The criterion value for $\phi$ was $=0.60$; all estimates were in the incorrect 
Table 13

Means and Standard Deviations of Estimated Autocorrelation in

Autoregressive Model.

Part I. Criterion $=0.60$

theta est. phi est. phi est. thota est.

\begin{tabular}{lrrrrr}
$\begin{array}{l}\text { Percent } \\
\text { Missing }\end{array}$ & & $\begin{array}{c}\text { EM } \\
\text { Algorithm }\end{array}$ & $\begin{array}{c}\text { ML } \\
(1,0,0)\end{array}$ & $\begin{array}{c}\text { ML } \\
(5,0,0)\end{array}$ & $\begin{array}{c}\text { ML } \\
\text { (correct) }\end{array}$ \\
\hline \multirow{2}{*}{08 8 } & M & .799 & -.470 & -.640 & .717 \\
& SD & .154 & .112 & .112 & .141 \\
208 & $M$ & .018 & -.425 & -.615 & .679 \\
& SD & .148 & .109 & .143 & .180 \\
408 & M & .131 & -.408 & -.658 & .605 \\
& SD & .145 & .164 & .193 & .176
\end{tabular}

\begin{tabular}{|c|c|c|c|c|c|}
\hline 0 융 & $\begin{array}{r}M \\
S D\end{array}$ & $\begin{array}{r}-.614 \\
.078\end{array}$ & $\begin{array}{l}.416 \\
.069\end{array}$ & $\begin{array}{r}.515 \\
.097\end{array}$ & $\begin{array}{r}-.598 \\
.145\end{array}$ \\
\hline 18 & $\begin{array}{r}\mathrm{M} \\
\mathrm{SD}\end{array}$ & $\begin{array}{l}.034 \\
.096\end{array}$ & $\begin{array}{l}.371 \\
.080\end{array}$ & $\begin{array}{r}.475 \\
.094\end{array}$ & $\begin{array}{r}-.526 \\
.086\end{array}$ \\
\hline 08 & $\begin{array}{r}M \\
\text { SD }\end{array}$ & $\begin{array}{r}.070 \\
.157\end{array}$ & $\begin{array}{r}.336 \\
.224\end{array}$ & $\begin{array}{r}.407 \\
.126\end{array}$ & $\begin{array}{r}-.439 \\
.137\end{array}$ \\
\hline
\end{tabular}


direction for dependency. The reason for this reversal of positive vs. negative sign is addressed below in the Discussion section of study 1.

B. Negative Autocorrelation.

Significant overall effects. None of the effects in this analysis were significant, indicating that estimates of negative $\phi$ did not differ significantly by technique used to estimate missing data or by the percent of data missing. However, as in the above analysis, the sign of the $\phi$ estimates was opposite that of the criterion value (see Table 13).

Theta (Moving Averages Model): Overview.

Estimates of $\theta$ were analyzed in two separate ANOVA's, one for each direction of dependency. All series had a first order moving averages model $(0,0,1)$ underlying the data, and missing data were estimated using the EM or ML algorithm with the correct model specified. This is the only set of conditions under which a $\theta$ estimate was proaliced.

Analysis of $\theta$ was performed using $2 \times 3$ (missing data estimation Technique $\mathrm{x}$ Percent Missing) ANovA's. Technique was a between-subjects factor and Percent Missing was a within-subjects factor. The means and standard deviations for $\theta$ are presented in Table 13.

A. Positive Autocorrelation.

Significant overall effects. All effects in this analysis were significant at the $\mathrm{P}<.001$ level: Percent Missing $(\underline{F}(2,18)=$ 49.15): Technique $(\underline{F}(1,9)=227.41)$ : and their interaction $(\underline{F}(2$, 
18) $=28.83)$. Simple effects tests were used to examine the nature of the interaction between Technique and Percent Missing. These tests determined that the effect for Technique was significant when 208 of the data were missing $(\underline{F}(1,18)=83.91, p<.001)$ and when 40 of the data were missing $(\underline{F}(1,18)=43.30, \mathrm{p}<.001)$.

Major findings. At both levels of missing data, the mean $\theta$ estimate when using the EM algorithm was significantly lower than when using ML with correct model specification. The latter approach's estimates of $\theta$ were also closer to criterion. MI with correct model specification estimated $\theta$ to be $0.679(\underline{S D}=.180$ ) at $20 \%$ missing data and $0.605(\underline{\operatorname{SD}}=.176)$ at $40 \%$ missing data, while EM algorithm's estimates were $0.018(\underline{S D}=.148)$ and $0.131(\underline{S D}=.145)$ respectively.

B. Negative Autocorrelation.

Significant overall effects. All effects in this analysis were significant at the $\mathrm{p}<.001$ level: Percent Missing $(\underline{F}(2,18)=$ 101.69); Technique $(\underline{F}(1,9)=92.60)$ : and their interaction $(F(2$, $18)=37.14)$. Simple effects tests were used to examine the nature of the interaction between Technique and Percent Missing. The tests determined that the effect for Technique was significant when $20 \%$ of the data were missing $(\underline{F}\{1,18)=112.95, \underline{p}<.001)$ and when 40 g of the data were missing $(\underline{F}(1,18)=93.53, \mathrm{p}<.001\}$.

Major findings. At both levels of missing data, the mean $\theta$ estimate when using the EM algorithm was significantly lower in absolute value than those for ML with correct model specification. The latter approach's estimates of $\theta$ were closer to criterion, 
although appear less accurate than in the positive autocorrelation condition described above, particularly when 40 of the data were missing. ML (correct) estimated $\theta$ to be $-.526(\underline{S D}=.086)$ at $20 \%$ missing data and $-.439(\underline{S D}=.137)$ at $40 \%$ missing data, while EM algorithm's estimates were $0.034(\underline{S D}=.096)$ and $0.070(\underline{S D}=.157)$ respectively.

\section{Discussion}

Findings summarized for all dependent variables in study 1 point to two major conclusions: the inaccuracy of EM, and the accuracy of ML regardless of model specification under most conditions tested. In the limited circumstances which found differences between ML estimation which could be attributed to model specification, the $(5,0,0)$ specification performed as well as the correct model specification, while the $(1,0,0)$ specification was slightly inaccurate. These findings were limited to estimates of autocorrelation. When the direction of dependency was negative, use of ML with a $(1,0,0)$ model specification resulted in slight underestimates of the phi parameter. Since the correct model cannot be known a priori in order to specify it, these results support the use of a $(5,0,0)$ specification for time series analysis with missing data. All other dependent variables were accurately estimated by ML despite the fact that four underlying models were used and intentionally misspecified when using ML. The accuracy of the Jones (1980) algorithm, even under conditions of model misspecification can be contrasted with the poor performance of EMCOV's application of the EM algorithm, which was inaccurate although all subsequent time 
series had correct model specification. EMCOV estimation of missing data resulted in particularly problematic variance estimates (gross overestimates) and autocorrelation coefficient estimates (approximately zero in most conditions). In addition, the baseline parameters of level and slope were inaccurate llevel was overestimated while slope was underestimated. EMCOV was more accurate when estimating the intervention parameters; change in level was only underestimated when $40 \%$ of the data were missing; change in slope was accurately estimated under all conditions. Still, the implications of using EMCOV include increased Type II error rate for tests of interventions, since the variance parameter is so extremely overestimated.

A sign reversal was seen in phi estimates when the underlying model was moving averages but an autoregressive model was specified. In retrospect, this outcome is logical and expected, given the different equations for phi versus theta autocorrelation coefficients, which put the coefficient on opposite sides of the equation. Although the finding makes sense, it is not well known or reported in applied studies that assume autoregressive models. Different interpretations or conclusions about processes underlying a behavior of interest might be drawn from detecting positive autocorrelation in an autoregressive model versus negative autocorrelation in a moving averages model. This result of specifying exclusively autoregressive models should be considered prior to implementing that approach. 
Because the EMcov estimation was so inaccurate under some circumstances, a concern may arise that the increased overall error variance (attributed to EMCov inaccuracy) may mask real differences between the Jones ML algorithm with different model specifications. For all dependent variables except phi, perusal of the associated Figures (1 through 8) and Tables (1 through 10) would likely allay these concerns. Although some critical values for significant mean differences were large, actual differences between the ML approaches were extremely small. However, in the case of estimating negative phi in the autoregressive models, it is plausible that ML with a $(1,0,0)$ model specification would have been found to be producing significant underestimates of phi when the underlying model was a $(2,0,0)$ or a $(3,0,0)$ if EM had not been compared in the same design. How important is this possible masking of effect? The fact that it is clearly limited to one dependent variable, and that the difference in interpretation of a phi estimate of -.60 versus -.40 is negligible, concerns over masking effects are not substantive.

overall conclusions for study 1 are: (1) model misspecification had little impact on the accuracy of the Jones (1980) ML algorithm for estimation of missing data; (2) correct model specification and $(5,0,0)$ specification were both very accurate; (3) limited differences between generic specification of $(1,0,0)$ versus $(5,0,0)$ models support the latter approach; and (4) EMCOV estimation in its current form is not appropriate for the time series data tested in this study. 
Study 2:. The effects of systematic missing data patterns on the accuracy of missing data estimation in time series.

\section{Method}

study 2 compares the accuracy of EM and ML estimation under conditions that represent another real world problem: data that are missing in a systematic pattern rather than missing completely at random. In study 2 , the same first order autoregressive data series that were simulated for study 1 were again used, but data were eliminated in three different arrangements: (1) systematically missing, with complete data in some parts of the series, and alternating observations missing in other parts of the series; systematically missing, with all missing data occurring on consecutive observations; and (3) data missing completely at random, from Study 1. Missing data were then estimated using the EM algorithm and the two ML estimation methods, as in study 1 . (Because the underlying model was a 1,0,0 model, ML with "1,0,0" specification and "correct" specification were equivalent. "5, 0,0" specification was retained in this design for comparison). Next, SAS/ETS was used for time series analysis, and parameter estimates resulting from each condition were compared.

The conditions of study 2 are described in greater detail below. Rationales for certain design choices that are redundant with the same choices made for study 1 are only detailed in study 1. Number of Observations (N) . Generated times series had $\mathrm{N}_{1}=\mathrm{N}_{2}$ $=50$ data points. 
Number of replications. Ter replications in each of the conditions were generated. This is the same as the $S$ (subjects) factor in an ANOVA.

Independent variables.

Four independent variables were manipulated in a $2 \times 3 \times 3 \times 3$ (Direction of Dependency x Missing Data Pattern x Percentage of Missing Data $x$ Data Estimation Technique) factorial design. The first factor was a between-subjects manipulation, and the other three factors were within-subjects manipulations.

I. Direction of Dependency. As in study 1, there were two levels of dependency, or $\phi$, in the series for comparison. Half the series had $\phi$ $=0.60$, the other half had $\phi=-0.60$.

II. Missing Data Pattern. Three different missing data patterns were compared. In each of the three cells in this condition, preand post-intervention series had the same missing data pattern.

a. Alternating observations Missing. Series at pre and post intervention were missing data in the following pattern. The earlier section of the series had complete data; the latter section of the series was missing alternating observations. For example, in the $20 \%$ missing condition, observations 1 through 30 were complete; 31 through 50 had even-numbered observations, but odd-numbered observations were missing; observations 51 through 80 were complete; 81 through 100 were missing odd-numbered observations. (Observations 1-50 were "pre-intervention"; 51-100 were "post-intervention.") Missing data in this condition might be similar to patterns that would emerge after a reduction in data collection resources. For 
example, a researcher could decide to sample a behavior every other day, rather than every day. such a pattern could also emerge as a result of attempting to remove the burden on an experimental subject from attending the laboratory every day over an extended period of time. In all cases, the pattern of data collection must be independent of the target behavior.

b. Consecutive Data Missing. In this condition, all missing data were eliminated from a consecutive section of observations in the midale of the series. For example, in the $20 \%$ missing condition, observations 1 through 20 were complete; 21 through 30 were missing; and 31 through 50 were complete; observations 51 through 70 were complete; 71 through 80 were missing; and 81 through 100 were also complete. Data missing in a pattern like this could result from a period of time when data collection is impossible (e.g., due to equipment failure; or due to a temporary absence of other resources, such as the closure of an agency which is responsible for collecting the data). In all cases, the reason for temporarily not collecting data must be independent of the target behavior being measured.

c. Data Missing Completely at Random. Data were eliminated according to a random number generator at both pre- and postintervention. Data missing are a completely random subset of the total data set. This is a stringent condition of missing data not typically met in missing data problems.

III. Percentage of Missing Data. Data were eliminated from the time series in the following proportions: of (complete data, for 
comparison), 20\%, and $40 \%$. This variable was manipulated as a within-groups factor.

IV. Data Estimation Technique. Methods of estimating missing data were compared, as a within-subjects manipulation.

a. ML estimation was performed with the Jones (1980) algorithm available in SAS/ETS. The model specification used was $(1,0,0)$. which was the correct model specification for series in this study. b. ML estimation was also performed with the Jones (1980) algorithm, but with a $(5,0,0)$ model specification.

C. EM estimation was performed with EMCOV2.3 (Graham, 1995). Dependent Variables.

Five hundred forty series (2 levels of autocorrelation x 10 replications of each $x 3$ patterns of missing data $x 3$ percentages of missing data $\times 3$ data estimation techniques) were input to SAS/ETS for time series analysis. Estimates of six dependent variables were obtained, corresponding to parameters of ARIMA (1, 0, 0$)$ models (level, slope, error variance, change in level, change in slope, and phi).

1. Level (L). L estimates were obtained for each series. The criterion value of $\mathrm{L}$ was 0 in all series.

2. Slope (S). Slope was also estimated for each series. The population value of $\mathrm{S}$ was 15 degrees, which was chosen for reasons described above under study 1. Slope will be discussed in the metric of tangent of slope; criterion $=0.27$.

3. Minimum Residual Error Variance. This parameter estimate was obtained from the SAS/ETS analysis, to demonstrate the extent to 
which systematic missing data patterns affect the accuracy of data estimation and subsequent estimates of error variance. The criterion value of error variance was 1.0 .

4. Change in Level (DL). The magnitude of the intervention effect, DL, was 1.5 standard deviations for all simulated series.

5. Change in slope (DS). Change in slope was equal to zero in all series.

6. Dependency Parameter (phi). Phi represents the degree of dependency in the data when the underlying model is autoregressive. The criterion values for phi were 0.60 and -0.60 . Estimates of phi were analyzed separately for each criterion value.

\section{Results}

For each condition, the mean and standard deviation of the ten replications were calculated for estimates of level, slope, error variance, change in level, change in slope, and phi. Five separate 2 $\times 3 \times 3 \times 3$ (2 directions of dependency $\times 3$ missing data patterns $\times 3$ proportions of missing data $\times 3$ data estimation techniques) analyses of variance were used to examine mean differences for the first five dependent variables. Phi ( $\phi$ ) was analyzed in two separate $3 \times 3 \times 3$ analyses of variance, one for each direction of dependency. Significant effects were followed up with simple effects tests and Tukey tests. Follow-up tests were not performed for any analysis for which the overall F-ratio was nonsignificant. Source tables summarizing all ANovAs performed for study 2 are presented in Appendices M through S. 
Level: Overview.

A $2 \times 3 \times 3 \times 3$ (Direction of Dependency $\times$ Pattern $\times$ Technique $x$ Percent Missing) ANOVA was used to compare estimates of level. Direction of Dependency was a between-subjects factor; Pattern, Technique, and Percent Missing were within-subjects factors. The means and standard deviations for level are presented in Tables 14 and 15 .

Significant overall effects. There were significant main effects for Percent Missing $(\underline{F}(2,36)=48.86, \mathrm{p}<.001)$, Technique (E $(2,36)=277.91, \underline{p}<.001)$, and Pattern of missing data $(\underline{F}$ (2, $36)=51.39, \mathrm{p}<.001)$. There were three significant 2 -way interaction effects, all at the $\mathrm{p}<.001$ level of significance: Percent Missing by Technique $(\underline{F}(4,72)=14.12)$; Percent Missing by Pattern $(\underline{F}(4,72)=41.67)$; and Technique by Pattern $(\underline{F}(4,72)=$ 228.35). Finally, there was a significant 3-way interaction between Percent Missing, Technique, and Pattern $(\underline{F}(8,144)=12.06)$. Simple effects tests were used to examine the nature of the interaction between Percent Missing, Technique, and Pattern. These tests determined that the interaction between Pattern and Technique was significant at the .001 level when either $20 \%$ or $40 \%$ of the data were missing. Values for $\underline{F}(4,144)$ were 157.69 and 90.71 respectively.

Simple simple effects tests were used to follow up the significant simple effects tests; results of these tests are presented in Appendix $T$. These tests indicated that when $40 \%$ of the data were missing, there was a significant effect for missing data 
Table 14

Means and Standard Deviations of Estimated Level.

Criterion $=0$.

Part I. Positive Dependency

\begin{tabular}{|c|c|c|c|c|c|}
\hline $\begin{array}{l}\text { Missing Data } \\
\text { Pattern }\end{array}$ & $\begin{array}{l}\text { Perc } \\
\text { Miss }\end{array}$ & & $\begin{array}{l}\text { EM } \\
\text { Algorithm }\end{array}$ & $\frac{M L}{(1,0,0)}$ & $\begin{array}{l}\text { ML } \\
(5,0,0)\end{array}$ \\
\hline \multirow[t]{6}{*}{ Random } & 08 & M & -.273 & -.167 & -.200 \\
\hline & & $S D$ & .902 & .496 & .708 \\
\hline & 208 & M & 2.936 & -.152 & -.285 \\
\hline & & $\mathrm{SD}$ & 2.049 & .551 & .686 \\
\hline & 408 & $\mathrm{M}$ & 4.977 & -.186 & -.295 \\
\hline & & SD & 1.563 & .532 & .679 \\
\hline \multirow[t]{6}{*}{ Consecutive } & 0.8 & $\mathbf{M}$ & -.273 & -.167 & -.200 \\
\hline & & SD & .902 & .496 & .708 \\
\hline & 208 & M & 1.440 & -.071 & -.012 \\
\hline & & SD & 1.053 & .541 & .940 \\
\hline & 408 & M & 2.689 & -.120 & .127 \\
\hline & & SD & .712 & .487 & 1.002 \\
\hline \multirow[t]{6}{*}{ Alternating } & 08 & $M$ & -.273 & -.167 & -.200 \\
\hline & & $S D$ & .902 & .496 & .708 \\
\hline & 208 & $\mathbf{M}$ & -.376 & -.173 & -.216 \\
\hline & & SD & 1.116 & .526 & .729 \\
\hline & 408 & M & 2.488 & -.144 & -.248 \\
\hline & & SD & 1.628 & .539 & .867 \\
\hline
\end{tabular}


Table 15

Means and Standard Deviations of Estimated Level.

Criterion $=0$.

Part II. Negative Dependency

\begin{tabular}{|c|c|c|c|c|c|}
\hline $\begin{array}{c}\text { Missing Data } \\
\text { Pattern }\end{array}$ & $\begin{array}{l}\text { Perc } \\
\text { Miss }\end{array}$ & & $\begin{array}{l}\text { EM } \\
\text { Algorithm }\end{array}$ & $\frac{M L}{(1,0,0)}$ & $\frac{M L}{(5,0,0)}$ \\
\hline \multirow[t]{6}{*}{ Random } & 08 & $\mathbf{M}$ & .101 & .093 & .135 \\
\hline & & SD & .196 & .173 & .240 \\
\hline & 208 & $\mathbf{M}$ & 2.844 & .125 & .225 \\
\hline & & SD & 1.995 & .204 & .252 \\
\hline & 408 & $M$ & 5.104 & .130 & .171 \\
\hline & & SD & 1.672 & .306 & .353 \\
\hline \multirow[t]{6}{*}{ Consecutive } & 08 & $\mathbf{M}$ & .101 & .093 & .135 \\
\hline & & SD & .196 & .173 & .240 \\
\hline & 208 & $\mathbf{M}$ & 1.373 & .088 & .136 \\
\hline & & SD & .566 & .193 & .220 \\
\hline & 408 & $M$ & 3.607 & .101 & .167 \\
\hline & & SD & 1.088 & .224 & .224 \\
\hline \multirow[t]{6}{*}{ Alternating } & $0 ㅇ$ & $M$ & .101 & .093 & .135 \\
\hline & & SD & .196 & .173 & .240 \\
\hline & 208 & $\mathbf{M}$ & -.209 & .088 & .088 \\
\hline & & $S D$ & .503 & .227 & .290 \\
\hline & 408 & $M$ & 3.365 & .110 & .106 \\
\hline & & SD & 1.163 & .235 & .355 \\
\hline
\end{tabular}


estimation Technique regardless of the pattern of missing data. However, when only 208 of data were missing, the effect for Technique was nonsignificant when data were missing in the alternating pattern. The effect for Technique was significant when data were either randomly missing or missing in a consecutive pattern. Tukey tests were used to follow up these significant effects. The critical value of mean difference was equal to 0.608 .

Major findings. Tukey tests indicated that, at both 208 and 408 missing data, use of the EM algorithm resulted in significant overestimates of baseline level of the series. The exception to this was when $20 \%$ of the data were missing in an alternating pattern; under these circumstances, all data estimation approaches resulted in equal estimates of level. The ML estimates were accurate and did not differ from each other regardless of the different model specifications used, i.e., $(1,0,0)$ or $(5,0,0)$ or percent of data missing. These results are depicted in Figure 9. Slope: Overview.

A $2 \times 3 \times 3 \times 3 \times 2$ (Direction of Dependency $x$ Pattern $x$ Technique $x$ Percent Missing) ANovA was used to compare estimates of slope. Direction of Dependency was a between-subjects factor; Pattern, Technique, and Percent Missing were within-subjects factors. The means and standard deviations for slope are presented in Tables 16 and 17.

Significant overall effects. There were three significant main effects in the analysis, all at the $\mathrm{p}<.001$ level: Percent Missing $(\underline{F}(2,36)=32.03) ;$ Technique $(\underline{F}(2,36)=22.36) ;$ and Pattern $(\underline{F}$ 
Figure 9 . Technique by Percent Missing by Pattern interaction for Level

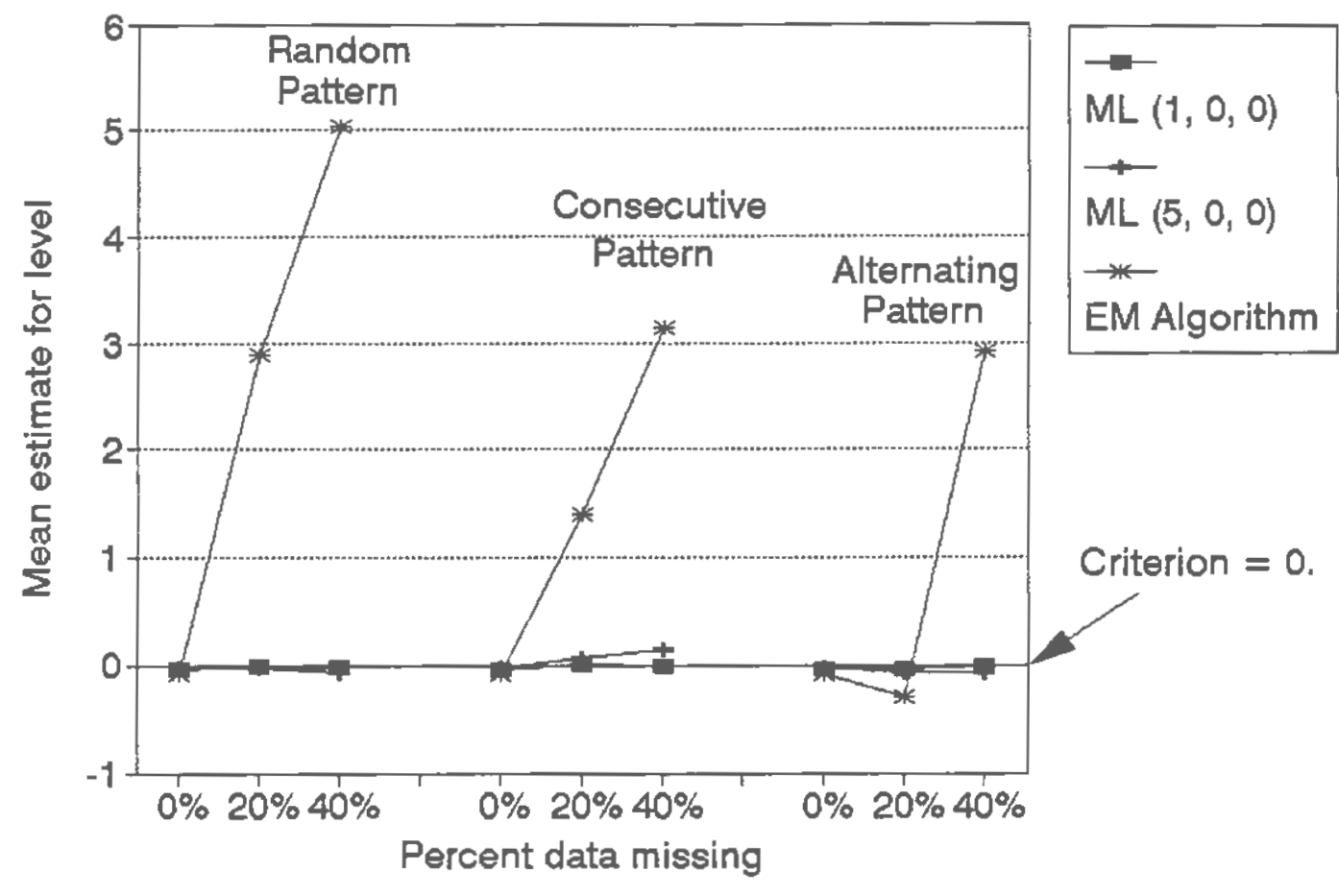


Table 16

Means and Standard Deviations of Estimated Slope.

Criterion $=0.27$.

Part I. Positive Dependency

\begin{tabular}{|c|c|c|c|c|c|}
\hline $\begin{array}{l}\text { Missing Data } \\
\text { Pattern }\end{array}$ & $\begin{array}{l}\text { Perc } \\
\text { Miss }\end{array}$ & & $\begin{array}{l}\text { EM } \\
\text { Algorithm }\end{array}$ & $\begin{array}{l}M L \\
(1,0,0)\end{array}$ & $\frac{M L}{(5,0,0)}$ \\
\hline \multirow[t]{6}{*}{ Random } & 08 & $\mathbf{M}$ & .264 & .260 & .262 \\
\hline & & SD & .030 & .016 & .031 \\
\hline & 208 & $M$ & .197 & .260 & .271 \\
\hline & & SD & .064 & .018 & .023 \\
\hline & 408 & $M$ & .152 & .261 & .270 \\
\hline & & SD & .037 & .016 & .024 \\
\hline \multirow[t]{6}{*}{ Consecutive } & 08 & $M$ & .264 & .260 & .262 \\
\hline & & SD & .030 & .016 & .031 \\
\hline & 208 & $\mathbf{M}$ & .255 & .259 & .269 \\
\hline & & SD & .027 & .016 & .030 \\
\hline & 408 & $\mathbf{M}$ & .236 & .262 & .265 \\
\hline & & SD & .022 & .017 & .033 \\
\hline \multirow[t]{6}{*}{ Alternating } & 08 & $M$ & .264 & .260 & .262 \\
\hline & & SD & .030 & .016 & .031 \\
\hline & $20 \%$ & $M$ & .280 & .262 & .272 \\
\hline & & SD & .060 & .018 & .029 \\
\hline & 408 & M & .246 & .261 & .272 \\
\hline & & SD & .044 & .018 & .032 \\
\hline
\end{tabular}


Table 17

Means and Standard Deviations of Estimated Tangent of Slope.

Criterion $=0.27$.

Part II. Negative Dependency

\begin{tabular}{|c|c|c|c|c|c|}
\hline $\begin{array}{l}\text { Missing Data } \\
\text { Pattern }\end{array}$ & $\begin{array}{l}\text { Perc } \\
\text { Miss }\end{array}$ & & $\begin{array}{l}\text { EM } \\
\text { Algorithm }\end{array}$ & $\begin{array}{l}M L \\
(1,0,0)\end{array}$ & $\frac{M L}{(5,0,0)}$ \\
\hline \multirow[t]{6}{*}{ Random } & 08 & $\mathbf{M}$ & .267 & .269 & .265 \\
\hline & & $\mathrm{SD}$ & .007 & .006 & .010 \\
\hline & 208 & $\mathbf{M}$ & .216 & .269 & .263 \\
\hline & & SD & .055 & .009 & .009 \\
\hline & 408 & $\mathrm{M}$ & .194 & .266 & .265 \\
\hline & & SD & .057 & .016 & .015 \\
\hline \multirow[t]{6}{*}{ Consecutive } & 08 & M & .267 & .269 & .265 \\
\hline & & SD & .007 & .006 & .010 \\
\hline & 208 & $\mathrm{M}$ & .260 & .268 & .265 \\
\hline & & SD & .016 & .007 & .009 \\
\hline & 40 용 & $\mathbf{M}$ & .242 & .269 & .265 \\
\hline & & SD & .014 & .007 & .010 \\
\hline \multirow[t]{6}{*}{ Alternating } & 08 & $\mathbf{M}$ & .267 & .269 & .265 \\
\hline & & SD & .007 & .006 & .010 \\
\hline & 208 & $\mathbf{M}$ & .292 & .269 & .270 \\
\hline & & $S D$ & .040 & .014 & .015 \\
\hline & 408 & $\mathbf{M}$ & .218 & .265 & .271 \\
\hline & & SD & .040 & .013 & .015 \\
\hline
\end{tabular}


$(2,36)=10.15)$. In addition, there were three significant 2 -way interaction effects: Percent Missing by Technique $(\underline{F}(4,72)=$ $11.48, \mathrm{p}<.001)$; Percent Missing by Pattern $(\underline{F}(4,72)=27.15, \underline{\mathrm{p}}$ $.001)$; and Technique by Pattern $(\underline{F}\langle 4,72)=24.52, \underline{p}<.001$. The $3-$ way interaction between Percent Missing, Pattern, and Technique was also significant $(\underline{\mathrm{F}}(8,144)=9.21, \underline{\mathrm{P}}<.001)$.

simple effects tests were used to examine the nature of the interaction between Percent Missing, Technique, and Pattern. These tests determined that the interaction between Pattern and Technique was significant at the .001 level when either 208 or 408 of the data were missing. Values for $\underline{F}(4,144)$ were 114.29 and 85.71 respectively.

simple simple effects tests were used to follow up the significant simple effects tests; results of these tests are presented in Appendix U. These tests indicated that when data were missing in a random pattern, the effect for Technique was significant at both levels of missing data (20\% and 40\%). When data were missing in either a consecutive pattern or an alternating pattern, the effect for Technique was only significant when 40 of the data were missing. Tukey tests were used to follow up these significant effects. The critical value of mean difference was equal to 0.020 .

Major findings. Tukey tests indicated that all significant effects for Technique could be described by the following pattern. Use of the EM algorithm resulted in significant underestimates of the slope of the series, compared with both types of ML estimates which 
were accurate and did not differ from each other regardless of the pattern of missing data. These results are depicted in Figure 10. Error Variance: overview.

A $2 \times 3 \times 3 \times 3 \times 2$ (Direction of Dependency $x$ Pattern $x$ Technique $\mathrm{x}$ Percent Missing) ANOVA was used to compare estimates of error variance. Direction of Dependency was a between-subjects factor; Pattern, Technique, and Percent Missing were within-subjects factors. The means and standard deviations for error variance are presented in Tables 18 and 19.

Significant overall effects. There were three significant main effects in the analysis: Percent Missing $\{\underline{F}(2,36)=8.28, \underline{p}<$ $.01)$; Technique $(\underline{F}(2,36)=1343.66, \underline{\underline{p}}<.001)$; and Pattern $(\underline{F}$ (2, $36)=3712.07, \underline{p}<.001)$. In addition, there were two significant 2way interaction effects: Percent Missing by Pattern $(\underline{F}(4,72)=$ $7.81, \underline{p}<.001)$; and Technique by Pattern $(\underline{F}(4,72)=1308.83, \underline{\mathrm{p}}<$ .001 . The 3-way interaction between Percent Missing, Technique, and Pattern was also significant $(\underline{F}(8,144)=2.52, \underline{p}<.01)$. No other effects in the analysis were significant.

simple effects tests were used to examine the interaction between Technique and Pattern at each level of missing data. These tests determined that this interaction effect was significant when 208 of the data were missing $(\underline{F}\langle 4,144\rangle=31.82, \underline{\mathrm{p}}<.001)$ and when $40 \%$ of the data were missing $(\underline{F}(4,144)=25.34, p<.001)$. simple simple effects tests were used to follow up the significant simple effects tests; results of these tests are presented in Appendix $V$. These tests indicated that the effect for 
Figure 10. Technique by Percent Missing by Pattern Interaction for Slope

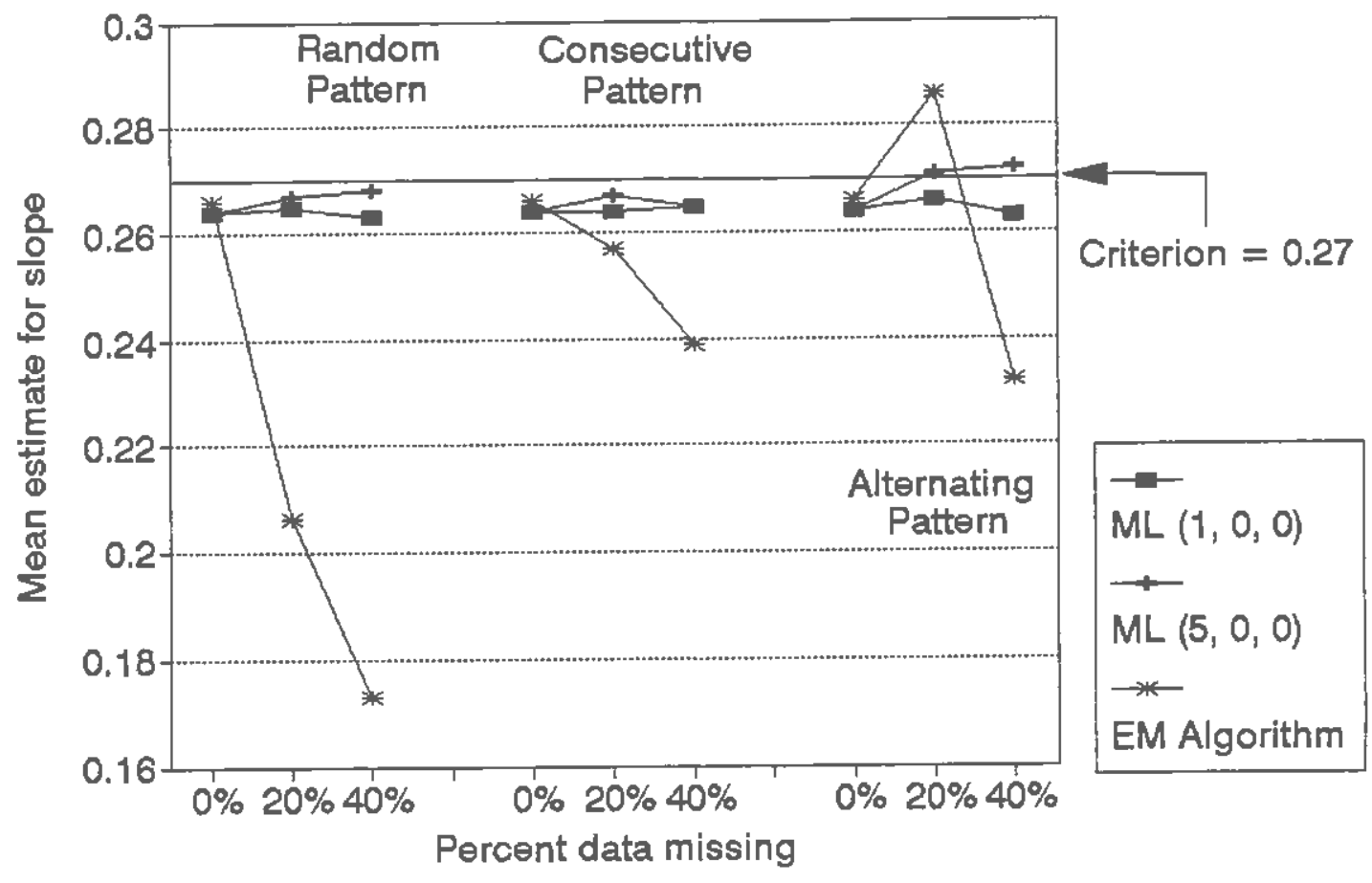


Table 18

Means and Standard Devietions of Estimeted Variance.

Criterion $=1.0$.

Part I. Positive Dependency

\begin{tabular}{|c|c|c|c|c|c|}
\hline $\begin{array}{l}\text { Missing Data } \\
\text { Pattern }\end{array}$ & $\begin{array}{l}\text { Perc } \\
\text { Miss }\end{array}$ & & $\begin{array}{l}\text { EM } \\
\text { Algorithm }\end{array}$ & $\begin{array}{l}M I \\
(1,0,0)\end{array}$ & $\frac{M L}{(5,0,0)}$ \\
\hline \multirow[t]{6}{*}{ Random } & 08 & $\mathbf{M}$ & .972 & .914 & .853 \\
\hline & & SD & .149 & .114 & .090 \\
\hline & 208 & $\mathbf{M}$ & 27.217 & .982 & .911 \\
\hline & & SD & 5.115 & .146 & .119 \\
\hline & 408 & $\mathbf{M}$ & 44.493 & 1.009 & .952 \\
\hline & & SD & 8.174 & .156 & .233 \\
\hline \multirow[t]{6}{*}{ Consecutive } & 08 & $M$ & .972 & .914 & .853 \\
\hline & & SD & .149 & .114 & .090 \\
\hline & 208 & $\mathbf{M}$ & $21 \cdot 114$ & .897 & .819 \\
\hline & & SD & 4.446 & .105 & .126 \\
\hline & 408 & $\mathbf{M}$ & 42.084 & .881 & .763 \\
\hline & & SD & 7.674 & .135 & .110 \\
\hline \multirow[t]{6}{*}{ Alternating } & 08 & M & .972 & .914 & .853 \\
\hline & & SD & .149 & .114 & .090 \\
\hline & 208 & $M$ & 23.746 & .976 & .912 \\
\hline & & SD & 3.322 & .159 & .165 \\
\hline & 408 & $\mathbf{M}$ & 41.168 & 1.058 & .979 \\
\hline & & SD & 5.352 & .200 & .210 \\
\hline
\end{tabular}


Table 19

Means and Standard Deviations of Estimated Variance.

Criterion $=1.0$.

Part II. Negative Dependency

\begin{tabular}{|c|c|c|c|c|c|}
\hline $\begin{array}{l}\text { Missing Data } \\
\text { Pattern }\end{array}$ & $\begin{array}{l}\text { Perc } \\
\text { Mies }\end{array}$ & & $\begin{array}{l}\text { EM } \\
\text { Algorithm }\end{array}$ & $\begin{array}{l}\mathrm{ML} \\
(1,0,0)\end{array}$ & $\frac{M L}{(5,0,0)}$ \\
\hline \multirow[t]{6}{*}{ Random } & 08 & $\mathbf{M}$ & .963 & .967 & .886 \\
\hline & & SD & .124 & .124 & .093 \\
\hline & 208 & $\mathbf{M}$ & 26.534 & .997 & .925 \\
\hline & & SD & 2.713 & .076 & .118 \\
\hline & 408 & $\mathbf{M}$ & 45.459 & 1.220 & 1.022 \\
\hline & & SD & 7.127 & .499 & .172 \\
\hline \multirow[t]{6}{*}{ Consecutive } & 0 & $M$ & .997 & .967 & .886 \\
\hline & & SD & .076 & .124 & .093 \\
\hline & 208 & M & 23.204 & .953 & .872 \\
\hline & & $S D$ & 4.438 & .150 & .097 \\
\hline & 408 & $\mathbf{M}$ & 41.627 & .958 & .832 \\
\hline & & SD & 8.135 & .202 & .127 \\
\hline \multirow[t]{6}{*}{ Alternating } & 08 & $\mathbf{M}$ & .925 & .967 & .886 \\
\hline & & SD & .118 & .124 & .093 \\
\hline & 208 & $\mathbf{M}$ & 19.376 & 1.027 & .909 \\
\hline & & $\mathrm{SD}$ & 3.455 & .133 & .152 \\
\hline & $40 \%$ & $M$ & 38.433 & 1.135 & .942 \\
\hline & & SD & 4.852 & .201 & .158 \\
\hline
\end{tabular}


Technique was significant at both levels of missing data (20\% and 408), regardless of the pattern in which data were missing (e.9., random, consecutive, or alternating). Tukey tests were used to follow up these significant effects. The critical value of mean difference was equal to 2.569 .

Major findings. Tukey tests indicated that all significant effects for Technique could be described by the following pattern. Use of the EM algorithm resulted in significant overestimates of the error variance of the series, compared with both types of ML estimates which were accurate and did not differ from each other regardless of the pattern of missing data. The magnitude of overestimation by EM was approximately twịce as large at 40 o missing as at 20 of missing. Although the critical value for significant group mean differences was substantial at 2.569 (note that the criterion value for variance was 1.0), the largest difference between ML $(1,0,0)$ and ML $(5,0,0)$ was only 0.130 . These results are presented in Figure 11.

Change in Level: Overview.

A $2 \times 3 \times 3 \times 3$ (Direction of Dependency $x$ Pattern $\times$ Technique $x$ Percent Missing) ANOVA was used to compare estimates of change in level. Direction of Dependency was a between-subjects factor; Pattern, Technique, and Percent Missing were within-subjects factors. The means and standard deviations for change in level are presented in Tables 20 and 21.

Significant overall effects. There were three significant main effects in the analysis, all at the $p<.001$ level: Percent Missing 
Figure 11. Technique by Percent Missing by Pattern Interaction for Variance

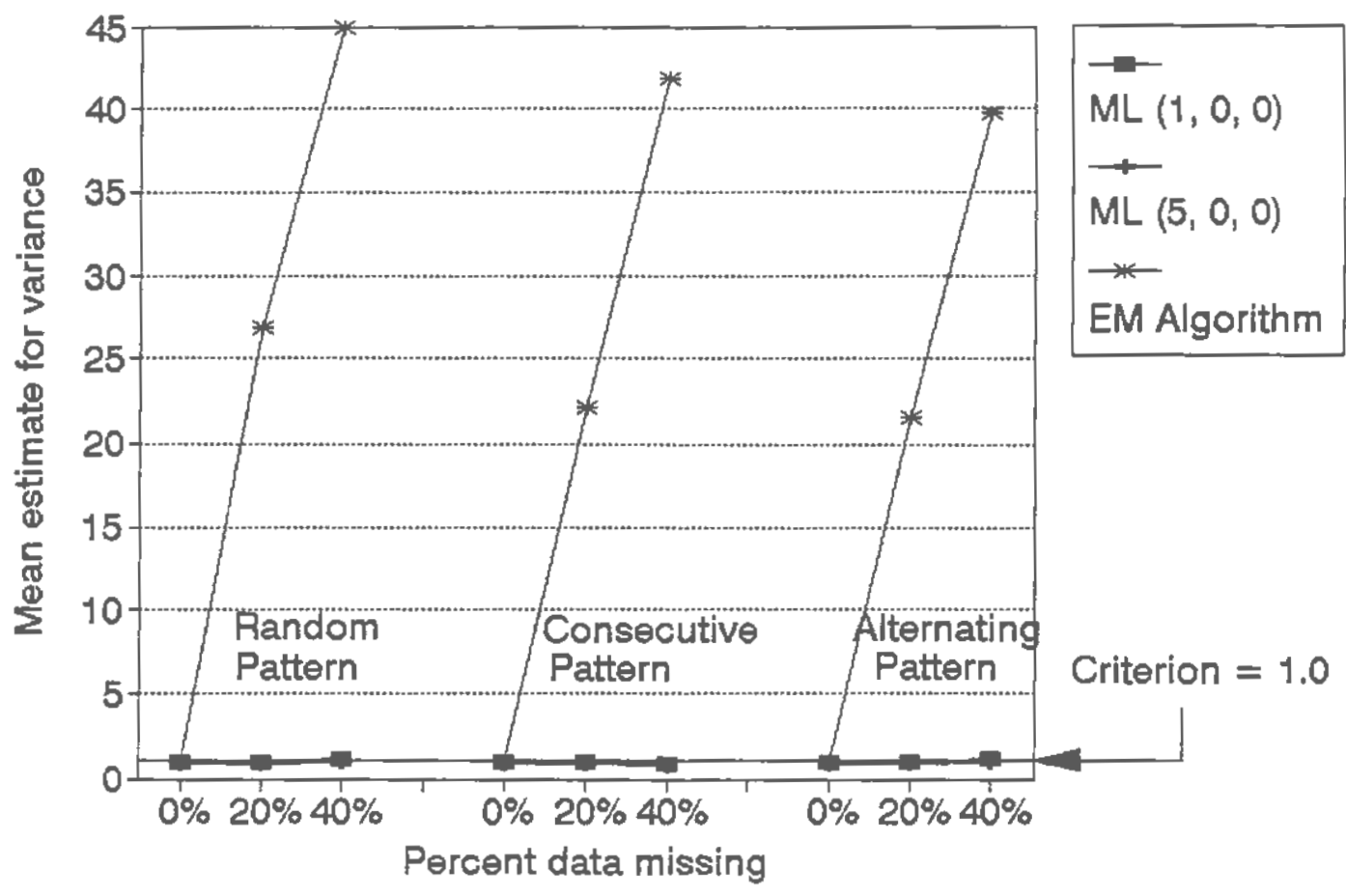


Table 20

Means and Standard Deviations of Estimated Change in Level.

Criterion $=1.5$.

Part I. Positive Dependency

\begin{tabular}{|c|c|c|c|c|c|}
\hline $\begin{array}{c}\text { Missing Data } \\
\text { Pattern }\end{array}$ & $\begin{array}{l}\text { Perc } \\
\text { Miss }\end{array}$ & & $\begin{array}{l}\text { EM } \\
\text { Algorithm }\end{array}$ & $\begin{array}{l}M L \\
(1,0,0)\end{array}$ & $\frac{M I}{(5,0,0)}$ \\
\hline \multirow[t]{6}{*}{ Random } & 08 & $M$ & 1.391 & 1.959 & .858 \\
\hline & & $\mathrm{SD}$ & .922 & .937 & .980 \\
\hline & $20 ㅇ ㅜ ㅇ$ & $\mathbf{M}$ & 1.537 & 1.894 & 1.032 \\
\hline & & SD & 2.132 & 1.083 & .819 \\
\hline & 408 & $\mathbf{M}$ & 1.869 & 1.822 & 1.085 \\
\hline & & SD & 2.743 & 1.100 & .745 \\
\hline \multirow[t]{6}{*}{ Consecutive } & 0 용 & $\mathbf{M}$ & 1.391 & 1.959 & .858 \\
\hline & & $\mathrm{SD}$ & .922 & .937 & .980 \\
\hline & 208 & $\mathbf{M}$ & -1.112 & 1.869 & .801 \\
\hline & & SD & .983 & .945 & 1.157 \\
\hline & 408 & $\mathbf{M}$ & -2.974 & 1.801 & .873 \\
\hline & & SD & .985 & .975 & 1.303 \\
\hline \multirow[t]{6}{*}{ Alternating } & 0.8 & $\mathbf{M}$ & 1.391 & 1.959 & .858 \\
\hline & & $\mathrm{SD}$ & .922 & .937 & .980 \\
\hline & 208 & $\mathbf{M}$ & 3.083 & 1.838 & .802 \\
\hline & & SD & 2.189 & .880 & 1.063 \\
\hline & 408 & $\mathbf{M}$ & -.280 & 1.840 & .726 \\
\hline & & $\mathrm{SD}$ & 1.956 & .875 & .998 \\
\hline
\end{tabular}


Table 21

Means and Standard Deviations of Estimated Change in Level.

Criterion $=1.5$.

Part II. Negative Dependency

\begin{tabular}{|c|c|c|c|c|c|}
\hline $\begin{array}{c}\text { Missing Data } \\
\text { Pattern }\end{array}$ & $\begin{array}{l}\text { Perc } \\
\text { Miss }\end{array}$ & & $\begin{array}{l}\text { EM } \\
\text { Algorithm }\end{array}$ & $\begin{array}{l}\mathrm{MI} \\
(1,0,0)\end{array}$ & $\begin{array}{l}\text { MI } \\
(5,0,0)\end{array}$ \\
\hline \multirow[t]{6}{*}{ Random } & 0 용 & $\mathbf{M}$ & 1.573 & 1.494 & 1.660 \\
\hline & & $\mathrm{SD}$ & .338 & .381 & .472 \\
\hline & 208 & $\mathbf{M}$ & .077 & 1.501 & 1.662 \\
\hline & & $\mathrm{SD}$ & 1.906 & .504 & .426 \\
\hline & 408 & $\mathbf{M}$ & -.648 & 1.511 & 1.609 \\
\hline & & SD & 2.602 & .729 & .429 \\
\hline \multirow[t]{6}{*}{ Consecutive } & 08 & $\mathbf{M}$ & 1.573 & 1.494 & 1.660 \\
\hline & & $\mathrm{SD}$ & .338 & .381 & .472 \\
\hline & 208 & $\mathbf{M}$ & -.717 & 1.502 & 1.630 \\
\hline & & $\mathrm{SD}$ & .904 & .375 & .452 \\
\hline & 408 & $\mathbf{M}$ & -3.145 & 1.491 & 1.601 \\
\hline & & SD & 1.753 & .316 & .451 \\
\hline \multirow[t]{6}{*}{ Alternating } & 08 & $\mathbf{M}$ & 1.573 & 1.494 & 1.660 \\
\hline & & SD & .338 & .381 & .472 \\
\hline & 208 & M & 2.596 & 1.451 & 1.457 \\
\hline & & SD & 1.606 & .655 & .698 \\
\hline & 40 용 & $\mathbf{M}$ & .215 & 1.635 & 1.406 \\
\hline & & $\mathrm{SD}$ & 1.629 & .711 & .635 \\
\hline
\end{tabular}


$(\underline{F}(2,36)=37.26) ;$ Technique $(\underline{F}(2,36)=35.49) ;$ and Pattern $(\underline{F}$ $(2,36)=12.17)$. In addition, there were three significant 2-way interaction effects: Percent Missing by Technique $(\underline{F}(4,72)=$ $11.82, \underline{p}<.001)$; Percent Missing by Pattern $(\underline{F}(4,72)=38.27, \mathrm{p}<$ $.001)$; and Technique by Pattern $(\underline{F}(4,72)=34.06, \underline{p}<.001$. The three way interaction between Percent Missing, Pattern, and Technique was also significant $(\underline{F}(8,144)=11.96, \underline{p}<.001)$.

Simple effects tests were used to examine the nature of the interaction between Percent Missing, Techrique, and Pattern. These tests determined that the interaction between Pattern and Technique was significant at the .001 level when either $20 \%$ or $40 \%$ of the data were missing. Values for $\underline{F}(4,144)$ were 111.23 and 115.34 respectively.

simple simple effects tests were used to follow up the significant simple effects tests; results of these tests are presented in Appendix $w$. These tests indicated that the effect for Technique was significant at every combination of Percent Missing data and Pattern of missing data, at the $p<.001$ level. Tukey tests were used to follow up these significant effects. The critical value of mean difference was equal to 0.913 .

Major findings. Tukey test results were a bit complicated. Generally, use of the EM algorithm resulted in an underestimate of change in level. This was particularly problematic when data were missing in a consecutive pattern; these conditions produced estimates of change in level that indicated a decrease in level rather than the criterion increase. When data were missing in an alternating 
pattern, the EM algorithm overestimated change in level when $20 \%$ of the data were missing, and underestimated when $40 \%$ of the data were missing. When data were randomly missing and only $20 \%$ were missing, there were no significant differences across conditions in estimates of change in level. Both types of $\mathrm{ML}$ estimation were reasonably accurate and did not significantly differ from each other regardless of the pattern of missing data or the amount of missing data.

Although there was a consistent pattern across conditions of ML $(1,0,0)$ estimates being slightly high and ML $(5,0,0)$ estimates being slightly low, this trend did not reach the level of statistical significance. These results are depicted in Figure 12. Change in slope: Overview.

A $2 \times 3 \times 3 \times 3$ (Direction of Dependency $x$ Pattern $x$ Technique $x$ Percent Missing) ANOVA was used to compare estimates of change in slope. Direction of Dependency was a between-subjects factor; Pattern, Technique, and Percent Missing were within-subjects factors. The means and standard deviations for change in slope are presented in Tables 22 and 23.

Significant overall effects. There were three significant main effects in the analysis, all at the $\underline{p}<.001$ level: Percent Missing $(\underline{F}(2,36)=53.88) ;$ Technique $(\underline{F}(2,36)=23.92) ;$ and Pattern $(\underline{F}$ $(2,36)=12.22)$. In addition, there were three significant 2-way interaction effects: Percent Missing by Technique $(\underline{F}(4,72)=$ 21.92, $\mathrm{P}<.001)$; Percent Missing by Pattern $(\underline{F}(4,72)=61.51, \mathrm{P}<$ $.001)$; and Technique by Pattern $(\underline{F}(4,72)=20.53, P<.001$. The $3-$ 
Figure 12. Technique by Percent Missing by Pattern Interaction: Change in Level

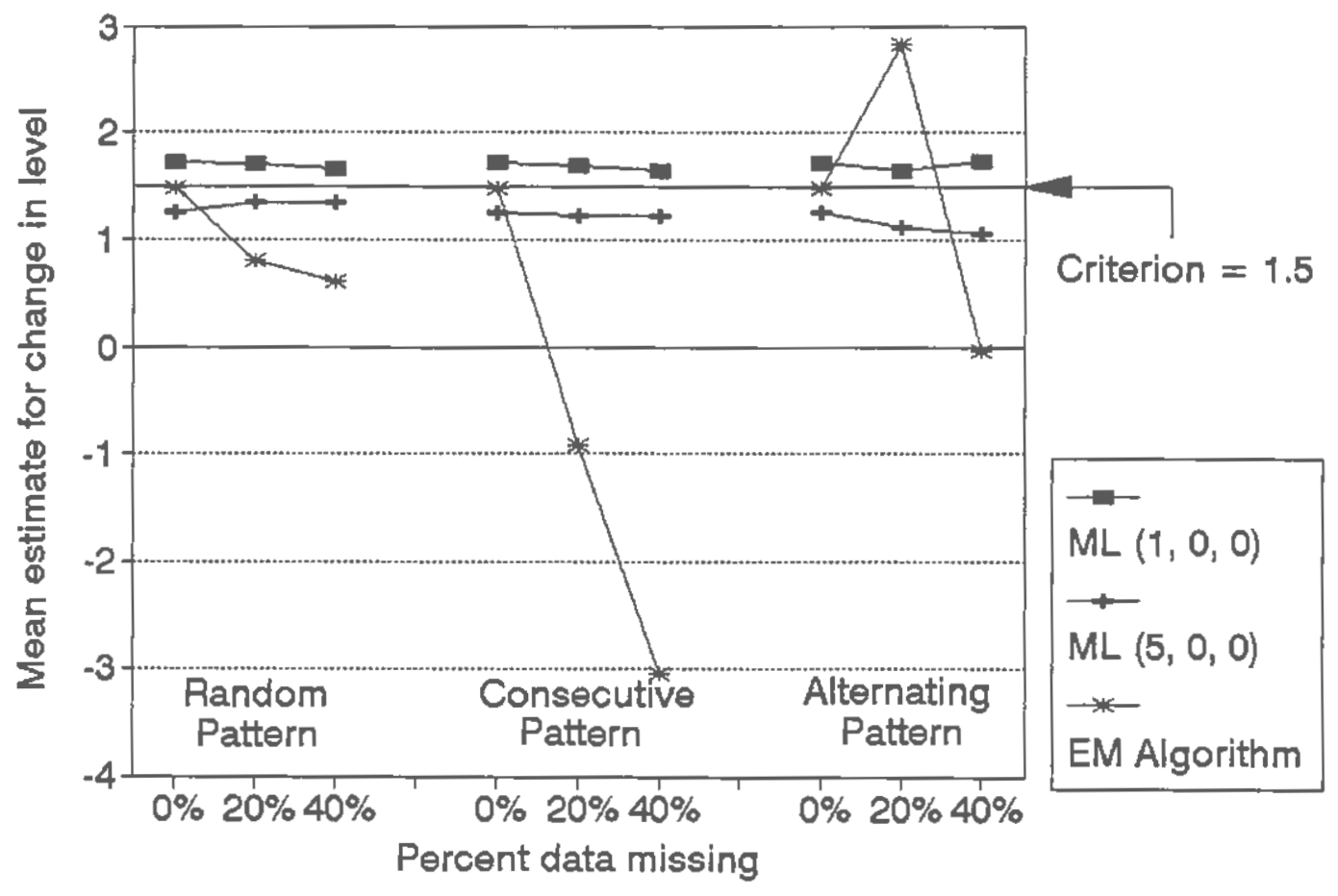


Table 22

Means and Standard Deviations of Estimated Change in Slope.

Criterion $=0$.

Part I. Positive Dependency

\begin{tabular}{|c|c|c|c|c|c|}
\hline $\begin{array}{c}\text { Missing Data } \\
\text { Pattern }\end{array}$ & $\begin{array}{l}\text { Perc } \\
\text { Miss }\end{array}$ & & $\begin{array}{l}\text { EM } \\
\text { Algorithm }\end{array}$ & $\frac{M L}{(1,0,0)}$ & $\begin{array}{l}\text { ML } \\
(5,0,0)\end{array}$ \\
\hline \multirow[t]{6}{*}{ Random } & 08 & $\mathbf{M}$ & .013 & .009 & .006 \\
\hline & & SD & .042 & .030 & .034 \\
\hline & 208 & $\mathbf{M}$ & .018 & .011 & .003 \\
\hline & & $S D$ & .058 & .030 & .028 \\
\hline & 408 & $M$ & -.007 & .012 & .004 \\
\hline & & $\mathrm{SD}$ & .065 & .035 & .034 \\
\hline \multirow[t]{6}{*}{ Consecutive } & 08 & $\mathbf{M}$ & .013 & .009 & .006 \\
\hline & & SD & .042 & .030 & .034 \\
\hline & 208 & $\mathbf{M}$ & .011 & .011 & .007 \\
\hline & & SD & .038 & .031 & .035 \\
\hline & 408 & $\mathbf{M}$ & .010 & .013 & .012 \\
\hline & & SD & .035 & .027 & .047 \\
\hline \multirow[t]{6}{*}{ Alternating } & 08 & $\mathrm{M}$ & .013 & .009 & .006 \\
\hline & & SD & .042 & .030 & .034 \\
\hline & 208 & $\mathbf{M}$ & -.190 & .010 & .006 \\
\hline & & SD & .127 & .032 & .034 \\
\hline & $40 \%$ & $\mathbf{M}$ & -.146 & .009 & .008 \\
\hline & & $\mathrm{SD}$ & .080 & .033 & .038 \\
\hline
\end{tabular}


Table 23

Means and Standard Deviations of Estimated Change in slope.

Criterion $=0$.

Part II. Negative Dependency

\begin{tabular}{|c|c|c|c|c|c|}
\hline $\begin{array}{l}\text { Missing Data } \\
\text { Pattern }\end{array}$ & $\begin{array}{l}\text { Perc } \\
\text { Miss }\end{array}$ & & $\begin{array}{l}\text { EM } \\
\text { Algorithm }\end{array}$ & $\frac{M \pi}{(1,0,0)}$ & $\frac{M L}{(5,0,0)}$ \\
\hline \multirow[t]{6}{*}{ Random } & 08 & $M$ & -.002 & -.001 & .000 \\
\hline & & SD & .008 & .008 & .012 \\
\hline & 208 & $\mathbf{M}$ & .017 & -.030 & .000 \\
\hline & & $S D$ & .095 & .087 & .012 \\
\hline & 408 & $M$ & -.022 & .004 & .001 \\
\hline & & SD & .093 & .017 & .020 \\
\hline \multirow[t]{6}{*}{ Consecutive } & 08 & $\mathbf{M}$ & -.002 & -.001 & .000 \\
\hline & & SD & .008 & .008 & .012 \\
\hline & 208 & $M$ & -.002 & -.001 & .000 \\
\hline & & SD & .010 & .008 & .012 \\
\hline & 408 & $M$ & .001 & -.001 & .000 \\
\hline & & SD & .017 & .009 & .012 \\
\hline \multirow[t]{6}{*}{ Alternating } & 0 웅 & $M$ & -.002 & -.001 & .000 \\
\hline & & SD & .008 & .008 & .012 \\
\hline & 208 & $\mathbf{M}$ & -.210 & -.001 & -.005 \\
\hline & & SD & .061 & .012 & .026 \\
\hline & 408 & $M$ & -.097 & .007 & -.008 \\
\hline & & SD & .077 & .016 & .030 \\
\hline
\end{tabular}


way interaction between Percent Missing, Pattern, and Technique was also significant $(\underline{F}(8,144)=22.93, \underline{P}<.001)$.

Simple effects tests were used to examine the nature of the interaction between Percent Missing, Technique, and Pattern. These tests determined that the interaction between Pattern and Technique was significant at the .001 level when either $20 \%$ or 408 of the data were missing. Values for $\underline{F}(4,144)$ were 372.73 and 109.09 respectively.

Simple simple effects tests were used to follow up the significant simple effects tests; results of these tests are presented in Appendix $x$. These tests indicated that when data were missing in a random or alternating pattern, the effect for Technique was significant at both levels of missing data $(208$ and 400$)$. When data were missing in a consecutive pattern, the effect for Technique was nonsignificant. Tukey tests were used to follow up the significant effects for random and alternating patterns of missing data. The critical value of mean difference was equal to 0.033 .

Major findings: Although simple simple effects tests had been significant for random missing data conditions, none of the group means were significantly different at either $20 \%$ or $40 \%$ missing data. When data were missing in an alternating pattern, use of the EM algorithm resulted in significant underestimates of change in slope of the series. In all other cases, estimates of change in slope were accurate and did not differ significantly from each other. This is the first case in which EM performed worse for a non-random missing 
data pattern than for a random missing data pattern. These results are presented in Figure 13.

Phi: Overview.

Because Direction of Dependency was also an independent variable in this design, estimates of $\phi$ were analyzed in two separate ANOVA's, one for each criterion value of $\phi$. Analysis of $\phi$ was performed using two separate $3 \times 3 \times 3$ (missing data Pattern $x$ missing data estimation Technique x Percent Missing) ANova's. All factors in these analyses were within-subjects factors. The means and standard deviations for $\phi$ are presented in Tables 24 and 25. A. Positive Autocorrelation.

Significant overall effects. All of the effects in this analysis were significant at the $\mathrm{p}<.001$ level. The three main effects were: Percent Missing $(\underline{F}(2,18)=28.83)$; Technique $(\underline{F}(2$, $18)=113.48) ;$ and pattern $(\underline{F}(2,18)=47.84)$. The three 2 -way interaction effects were: Percent Missing by Technique $(\underline{F}(4,36)=$ 9.71); Percent Missing by Pattern $(\underline{F}(4,36)=47.18)$; and Technique by pattern $(\underline{F}(4,36)=111.09)$. The 3-way interaction between Percent Missing, Pattern, and Technique was also significant ( $F$ ( 8 , $72)=21.65, \underline{\mathrm{p}}<.001)$.

simple effects tests were used to examine the nature of the interaction between Percent Missing, Technique, and Pattern. These tests determined that the interaction between Pattern and Technique was significant at the .001 level when either $20 \%$ or 40 \% of the data were missing. Both values for $\underline{F}(4,72)$ were 250.82 (the sum of 
Figure 13. Technique by Percent Missing by Pattern Interaction: Change in Slope

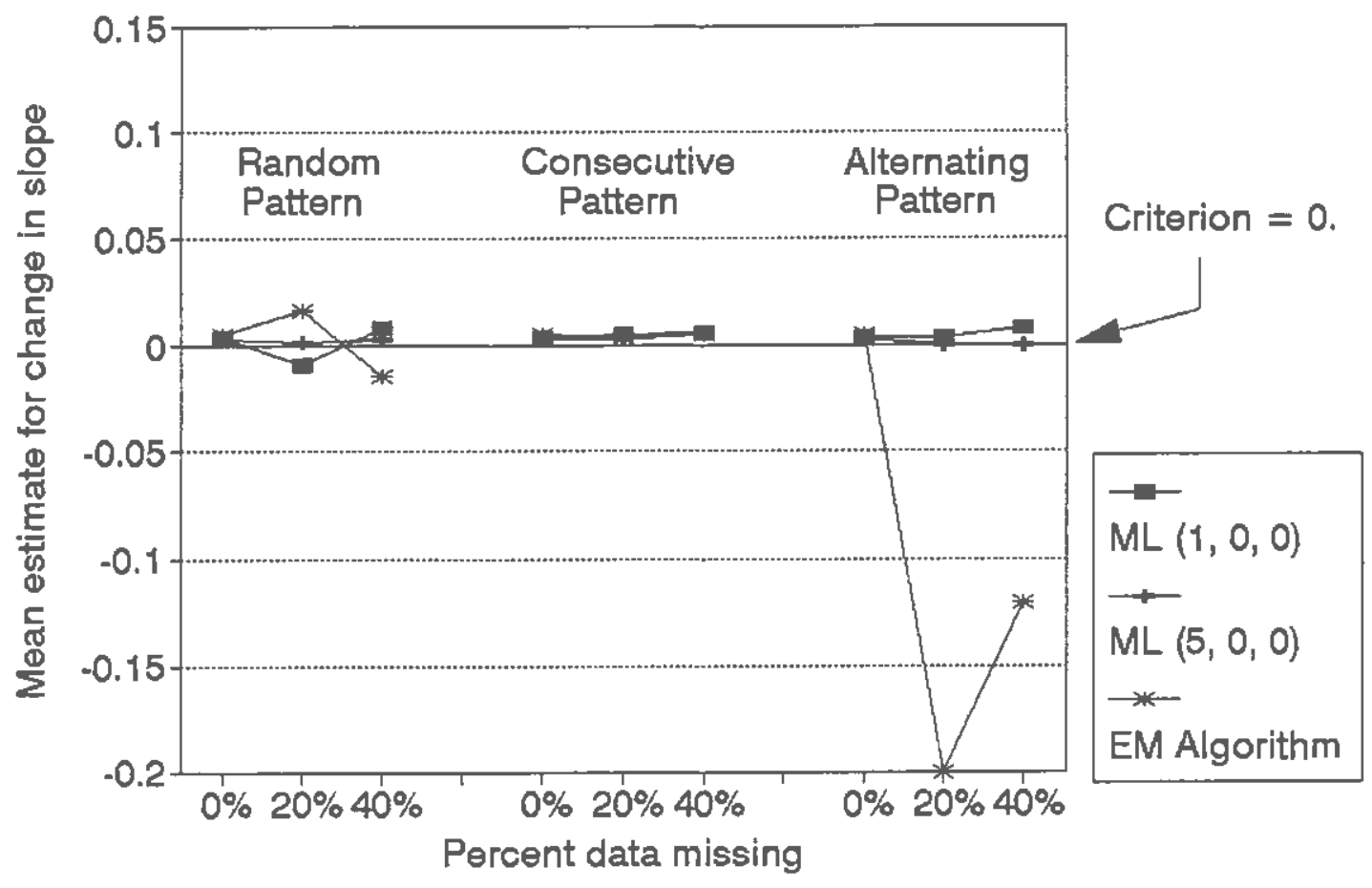


Table 24

Means and Standard Deviations of Estimated Positive Phi.

Criterion $=0.60$.

\begin{tabular}{|c|c|c|c|c|c|}
\hline $\begin{array}{l}\text { Missing Data } \\
\text { Pattern }\end{array}$ & $\begin{array}{l}\text { Perc } \\
\text { Miss }\end{array}$ & & $\begin{array}{l}\text { EM } \\
\text { Algorithm }\end{array}$ & $\begin{array}{l}\mathrm{ML} \\
(1,0,0)\end{array}$ & $\begin{array}{l}\mathrm{ML} \\
(5,0,0)\end{array}$ \\
\hline \multirow[t]{6}{*}{ Random } & 08 & $\mathbf{M}$ & .497 & .513 & .578 \\
\hline & & SD & .101 & .102 & .119 \\
\hline & 208 & $\mathbf{M}$ & .008 & .511 & .585 \\
\hline & & SD & .078 & .108 & .187 \\
\hline & 408 & $\mathbf{M}$ & -.025 & .479 & .551 \\
\hline & & SD & .107 & .165 & .147 \\
\hline \multirow[t]{6}{*}{ Consecutive } & 08 & M & .497 & .513 & .578 \\
\hline & & SD & .101 & .102 & .119 \\
\hline & 208 & $M$ & .340 & .482 & .596 \\
\hline & & $\mathrm{SD}$ & .128 & .122 & .165 \\
\hline & 408 & $\mathbf{M}$ & .228 & .462 & .590 \\
\hline & & $\mathrm{SD}$ & .080 & .131 & .211 \\
\hline \multirow[t]{6}{*}{ Alternating } & 08 & $M$ & .497 & .513 & .578 \\
\hline & & $\mathrm{SD}$ & .101 & .102 & .119 \\
\hline & 208 & $M$ & -.331 & .478 & .611 \\
\hline & & $\mathrm{SD}$ & .095 & .134 & .131 \\
\hline & 408 & $M$ & -.324 & .447 & .767 \\
\hline & & $\mathrm{SD}$ & .072 & .169 & .292 \\
\hline
\end{tabular}


Table 25

Means and Standard Deviations of Estimated Negative Phi.

Criterion $=-0.60$.

\begin{tabular}{|c|c|c|c|c|c|}
\hline $\begin{array}{l}\text { Missing Data } \\
\text { Pattern }\end{array}$ & $\begin{array}{l}\text { Per } \\
\text { Mis: }\end{array}$ & & $\begin{array}{l}\text { EM } \\
\text { Algorithm }\end{array}$ & $\begin{array}{l}\text { ML } \\
(1,0,0)\end{array}$ & $\frac{M L}{(5,0,0)}$ \\
\hline \multirow[t]{6}{*}{ Random } & 08 & $M$ & -.580 & -.619 & -.564 \\
\hline & & SD & .063 & .081 & .129 \\
\hline & 208 & $\mathbf{M}$ & .009 & -.495 & -.593 \\
\hline & & $S D$ & .158 & .381 & .142 \\
\hline & 408 & $\mathbf{M}$ & -.044 & -.597 & -.446 \\
\hline & & $S D$ & .093 & .162 & .229 \\
\hline \multirow[t]{6}{*}{ Consecutive } & 08 & M & -.580 & -.619 & -.564 \\
\hline & & SD & .063 & .081 & .129 \\
\hline & 208 & $M$ & .182 & -.619 & -.634 \\
\hline & & SD & .135 & .106 & .153 \\
\hline & 408 & $\mathbf{M}$ & .285 & -.630 & -.668 \\
\hline & & SD & .171 & .095 & .154 \\
\hline \multirow[t]{6}{*}{ Alternating } & 08 & $M$ & -.580 & -.619 & -.564 \\
\hline & & SD & .063 & .081 & .129 \\
\hline & 208 & $M$ & -.319 & -.598 & -.582 \\
\hline & & SD & .113 & .095 & .206 \\
\hline & 408 & $M$ & -.298 & -.564 & -.755 \\
\hline & & SD & .061 & .076 & .555 \\
\hline
\end{tabular}


squares for the interaction effect was the same at both levels of missing data).

Simple simple effects tests were used to follow up the significant simple effects tests; results of these tests are presented in Appendix $Y$. These tests indicated that the effect for technique was significant at every combination of missing data Pattern and Percent Missing data (all p's <.001). Tukey tests were used to follow up these significant effects. The critical value of mean difference was equal to 0.116 .

Major findings. In ali conditions, use of the EM algorithm resulted in significant underestimates of positive $\phi$. EM was most accurate when data were missing in a consecutive pattern; under these conditions, $\phi$ was estimated to be moderately positive. Wher data were missing in a random pattern, use of $\mathrm{EM}$ resulted in $\phi$ estimates around zero. The worst condition was the alternating pattern of missing data, for which EM resulted in moderately regative estimates of $\phi$.

When data were randomly missing, performance of ML with a $(5,0,0)$ specification did not differ significantly from that of $M L$ with a $(1,0,0)$ specification. When $20 \%$ of the data were consecutively missing, these approaches again yielded similar results. When $40 \%$ of the data were consecutively missing, the $(1,0,0)$ estimate of phi was significantly lower (and farther from criterion) than the $(5,0,0)$ estimate, which was very close to the criterion value of 0.60 . When data were missing in an alternating pattern, at either $20 \%$ or 40 o missing, the $(1,0,0)$ estimate of $\phi$ was 
again significantly lower than the $(5,0,0)$ estimate. At $20 \%$ missing, the higher order model specification was close to the criterion of 0.60 ; at 408 missing, both approaches were equally far from criterion, with the $(1,0,0)$ model specification resulting in underestimated phi (close to 0.40$)$, and the $(5,0,0)$ model resulting in an overestimation of phi (close to 0.80 ).

The 3-way interaction effect for positive $\phi$ estimates is shown in Figure 14.

B. Negative Autocorrelation.

Significant overall effects. All of the effects in this analysis were significant. The three main effects were: Percent Missing $(\underline{F}(2,18)=14.49, \underline{\mathrm{p}}(.001) ;$ Technique $\{\underline{F}(2,18)=41.40$, $\mathrm{p}<.001)$; and Patterr $(\underline{\mathrm{F}}(2,18)=30.03, \underline{\mathrm{P}}<.001)$. The three $2-$ way interaction effects were: Percent Missing by Technique ( $\underline{F}$ ( 4 , $36)=5.84, \underline{p}<.01)$; Percent Missing by Pattern $(\underline{F}(4,36)=16.97$, $\mathrm{p}<.001)$; and Technique by Pattern $(\underline{\mathrm{F}}(4,36)=36.66, \mathrm{p}<.001)$. The 3-way interaction between Percent Missing, Pattern, and Technique was also significant $(\underline{\mathrm{F}}(8,72)=7.80, \underline{\mathrm{p}}<.001)$.

Simple effects tests were used to examine the nature of the interaction between Percent Missing, Technique, and Pattern. These tests determined that the interaction between Pattern and Technique was significant at the .001 level when either $20 \%$ or $40 \%$ of the data were missing. Values for $\underline{F}(4,72)$ were 50.00 and 75.50 , respectively.

Simple simple effects tests were used to follow up the significant simple effects tests; results of these tests are 
Figure 14. Technique by Percent Missing by Pattern Interaction: Positive Phi

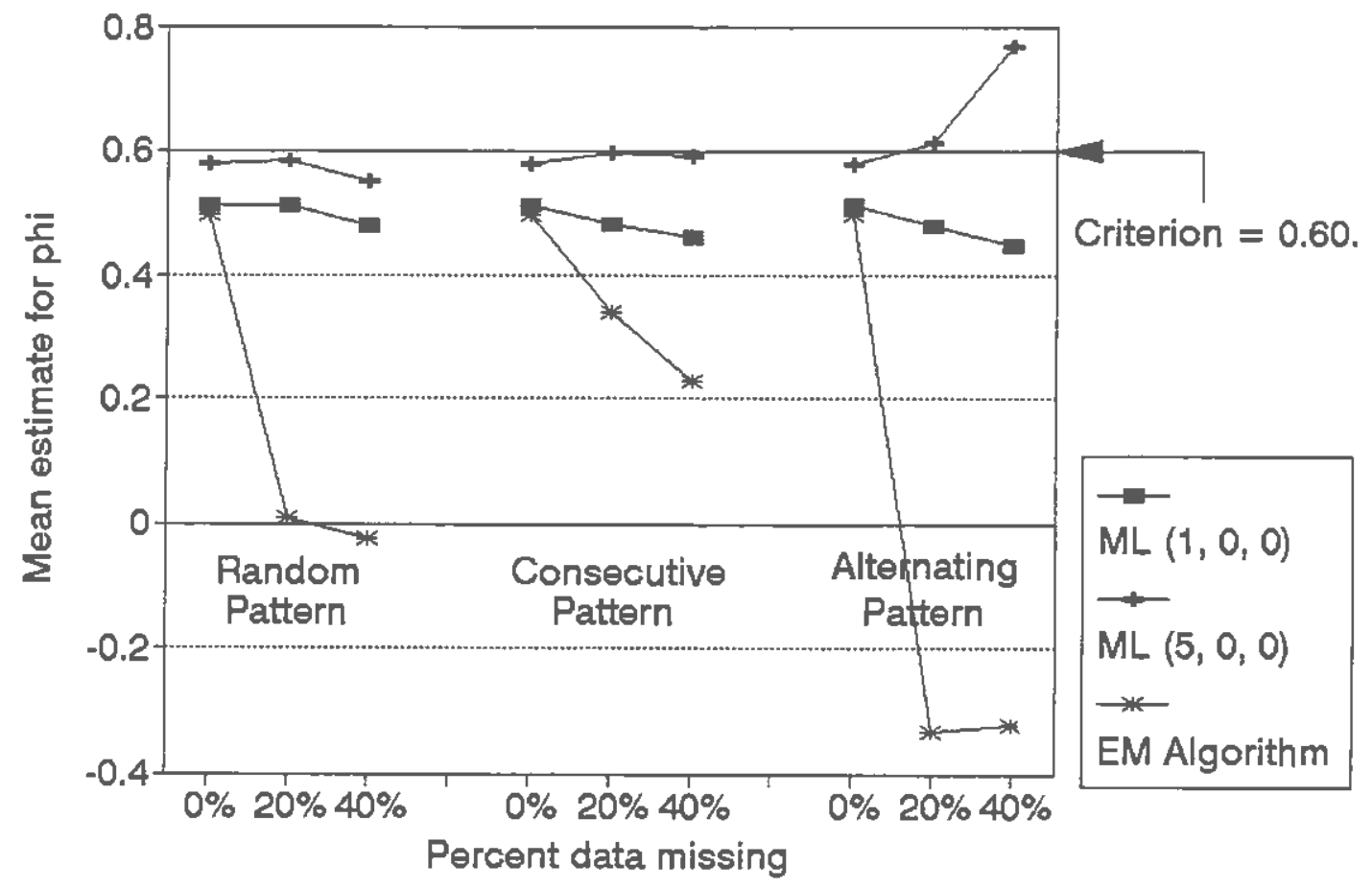


presented in Appendix $z$. These tests indicated that the effect for Technique was significant at every combination of Pattern and Percent Missing (all $\mathrm{p}^{\prime} \mathrm{s}<.001$ ). Tukey tests were used to follow up these significant effects. The critical value of mean difference was equal to 0.202 .

Major findings. Unlike the positive $\phi$ analyses, estimates of negative $\phi$ did not differ significanty for the ML estimates under any condition, regardless of model specification used. The EM algorithm resulted in significant underestimates of negative $\phi$. EM was least accurate when data were missing in a consecutive pattern; under these conditions, $\phi$ was estimated to be moderately positive. When data were missing in a random pattern, use of EM resulted in $\phi$ estimates around zero. EM was most accurate when the pattern of missing data was an alternating pattern, for which EM resulted in moderately negative estimates of $\phi$. The 3 -way interaction effect for negative $\phi$ estimates is shown in Figure 15.

\section{Discussion}

The results of study 2 lend further support to the Jones (1980) ML algorithm, particularly with a $(5,0,0)$ model specification. Use of the two ML approaches led to virtually equivalent estimates of all time series parameters except positive $\phi$. The $(1,0,0)$ specification sometimes resulted in underestimates of $\phi$ when data were missing in an alternating or consecutive pattern. ML with a $(5,0,0)$ specification was consistently the most accurate approach for data estimation. This finding is particularly striking given that $(1,0,0)$ was also the correct model specification in this design. A major 
Figure 15. Technique by Percent Missing by Pattern Interaction: Negative Phi

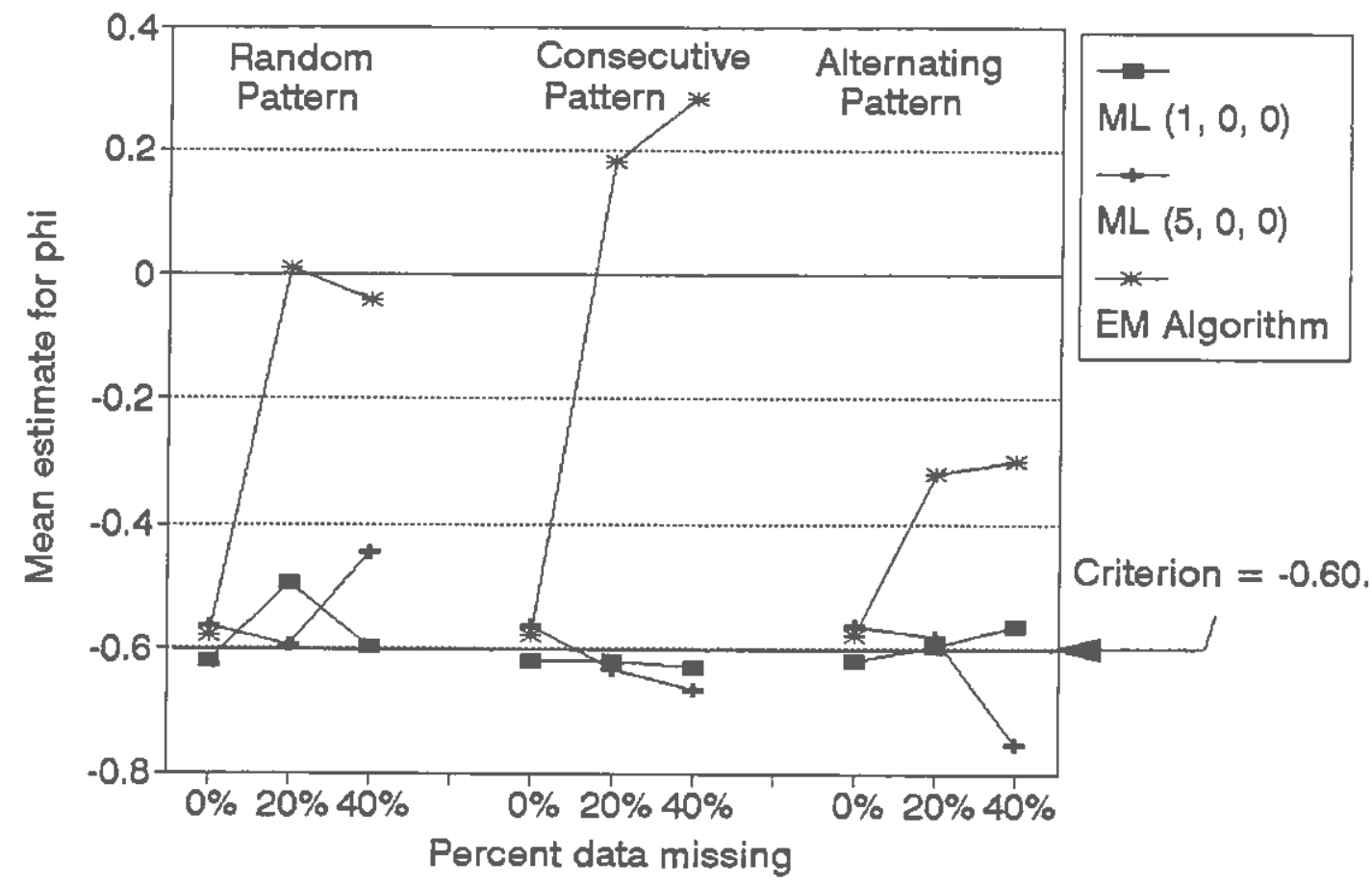


finding of this study is that it provided no evidence that even relatively severe departures from a completely random missing data pattern will have a significant impact on the accuracy of the ML approach with $(5,0,0)$ specification.

Problems detected with EMCOV estimation were consistent with those identified in study 1: overestimates of level and variance, and underestimates of slope, change in level, change in slope, and autocorrelation were generally found. EMCOV's estimates of $\phi$ appeared to be the same regardless of the criterion value (i.e., 0.60 vs. -0.60$)$. In series with a random pattern of missing data, $\phi$ was estimated to be approximately 0 ; when data were eliminated in an alternating pattern, $\phi$ was estimated to be moderately negative; when data were missing in a consecutive pattern, $\phi$ was estimated to be moderately positive. This is an indication that EMCOV does not provide differential estimates of individual observations based on position in the time series. If estimated values tend to be approximately equal and inaccurate at each observation, then estimating alternating observations would result in more of a "sawtooth" pattern, characteristic of negative autocorrelation. Inaccurate but approximately equal estimates for consecutive observations would result in large sections of "smoothed" data in the series, characteristic of positive autocorrelation. The pattern of inaccuracies found in this study supports this interpretation.

There are some limitations in this study which will limit the generalizability of its results. First, only two systematically missing data patterns were compared to completely random data 
elimination. The choice of missing data patterns to include in this study was difficult, since there are such numerous and idiosyncratic patterns of missing data that occur in applied research. Rather than attempt to exactly mimic one or two specific known missing data patterns (e.g., Monday, wednesday, Friday data collection--all other days missing; or Monday through Friday data collection--weekends missing), the decision was made to compare two patterns that differ in the characteristic of distance between observations in the final series.

It is important to note that even though data were eliminated in a systematic pattern, those patterns were unrelated to (independent of) the values of the observations missing (i.e.. data were MAR according to Rubin's 1976 classification). It is often the case in applied research that systematic missing data patterns are related to missing data values(i.e.. "not MAR". In these cases, the reason the data are missing and the values of the missing data are related. Findings from study 2 will not generalize to that case of nonrandomly missing data.

Even with the limitations of this study, investigation of the two patterns of missing data tested uncovered the only circumstances under which $(1,0,0)$ specification of the model resulted in less accurate parameter estimates than the $(5,0,0)$ specification.

overall conclusions of study 2 are: (1) further evidence was provided that EMCOV as currently implemented does not address the time-ordered nature of the data when estimating observations for time series; (2) this shortcoming of EMcov may generalize to other types 
of time-ordered data estimation problems; (3) there exist some conditions of data MAR under which ML with the correct model specification $(1,0,0)$ produced less accurate phi estimates than ML with the $(5,0,0)$ specification; and (4) the Jones (1980) ML algorithm with $(5,0,0)$ model specification was accurate under all conditions tested, and remains the recommended approach to estimating missing time series data. 


\section{Study 3: The effects of nonnormality on the accuracy of missing data estimation in time series.}

\section{Method}

study 3 was an initial exploration of another potential problem for both the ML and EM algorithms: the violation of the assumption of normally distributed data. The practical implications of nonnormality on the accuracy of these algorithms is important to establish, because it is common for behavioral time series data to be nonnormally distributed. It was the aim of study 3 to determine the effects of nonnormal data on the accuracy of both the EM and ML algorithms for estimation of time series data.

Since no previous empirical information is available to guide the design of the study, this initial inquiry is limited in scope. Baseline time series data were generated using a FORTRAN computer program. For this study, all series fit a first order autoregressive model with moderately positive autocorrelation, i.e., $\phi$ equal to 0.60. Given the more limited scope of this third study, it was considered reasonable to restrict inquiry to one ARIMA model and one level of autocorrelation. Time series were generated, drawing from either normal or lognormal data distributions, and then 3 proportions of data were randomly eliminated from each series. Three data estimation techniques were compared. As in study 2, ML with correct (i.e., 1,0,0) specification and $(5,0,0)$ specification were compared with the EM algorithm method. The resulting time series parameter estimates based on SAS/ETS analysis were compared to criterion 
values, and to values based on analyses of the complete simulated series.

Number of observations (N). Generated times series had $N_{1}=N_{2}$ $=50$ data points.

Number of replications. Ten replications in each of the conditions were generated. This is the same as the $s$ (subjects) factor in an ANOVA.

Independent variables.

Three independent variables were manipulated in a $2 \times 3 \times 3$ (Data Distribution x Percent Missing Data x Data Estimation Technique) mixed factorial design. The first factor was a betweensubjects factor, and the other two factors were within-subjects factors.

I. Data Distribution. The time series data simulation program drew observations from either a normal or lognormal distribution. The normal distribution has a mean of zero, a variance equal to 1.0, and skew and kurtosis equal to zero. The lognormal distribution has a mean of 1.5, a variance of 4 , skew equal to 3 , and kurtosis equal to 15. These two conditions were selected in order to contrast ideal conditions with clearly nonnormal conditions, to test the effects of moderately severe nonnormality. These distributions are available as FORTRAN subroutines from the International Mathematical and statistical Libraries (IMSL).

II. Proportion of Missing Data. Data were randomly eliminated from the time series in the following proportions: 0 o (complete data, for comparison), 20\%, and 408 . 
III. Data Estimation Technique. Three methods of estimating missing data were compared, as a within-subjects manipulation.

a. ML estimation was performed with the Jones (1980) algorithm available in SAS/ETS, using $(1,0,0)$ model specification.

b. ML estimation was performed with the Jones (1980) algorithm, using $(5,0,0)$ model specification.

c. EM estimation was performed with EMCOV2.3 (Graham, 1995), as described above.

Dependent Variables.

one hundred eighty series (2 levels of data distribution $\mathrm{x} 10$ replications each $\times 3$ proportions of missing data $x 3$ methods of missing data estimation) were input to sAS/ETS for time series analysis. Six dependent variables were obtained, corresponding to parameters of ARIMA $(1,0,0)$ models (level, slope, error variance, change in level, change in slope, and phi).

1. Level (L). L estimates were obtained for each series. The criterion value of $L$ was 0 in all series.

2. Slope (S). Slope was also obtained for each series. The population value of $s$ was 15 degrees, chosen for reasons described above under study 1 . Results will be reported and discussed in the metric of tangent of slope; criterion $=0.27$.

3. Minimum Residual Error Variance. This parameter estimate was obtained from the SAS/ETS analysis to demonstrate the extent to which nonnormality of the time series data affects the accuracy of data estimation and subsequent estimates of error variance. The criterion value of error variance was 1.0 . 
4. Change in Level (DL). The magnitude of the first intervention effect, DL, was equal to 1.5 standard deviations for all simulated series.

5. Change in slope (DS). The magnitude of the second intervention effect, DS, was equal to 0 for all simulated series.

6. Dependency Parameter (phi). Phi represents the degree of dependency in the data when the underlying model is autoregressive. The criterion value for $\phi$ in all series was 0.60 .

\section{Results}

For each condition, the mean and standard deviation of the ten replications was calculated for all dependent variables. Six separate $2 \times 3 \times 3$ (2 levels of data distribution $\times 3$ proportions of missing data $\times 3$ data estimation techniques) ANOVA's were used to examine mean differences for each dependent variable. Significant effects were followed up with simple effects tests and Tukey tests. Follow-up tests were not performed for any analysis for which the overall F-ratio was non-significant. Source tables summarizing all ANOVA's performed for study 3 are presented in Appendices AA - FF. Leve1: Overview.

A $2 \times 3 \times 3$ (Distribution $\times$ Technique $x$ Percent Missing) ANOVA was used to compare estimates of level. Distribution was a betweensubjects factor; Technique and Percent Missing were within-subjects factors. The means and standard deviations for level are presented in Table 26.

Significant overall effects. There were significant main effects for Distribution $(\underline{F}(1,18)=98.69, \underline{P}<.001)$, Percent 
Table 26

Means and Standard Deviations of Estimated Level.

Criterion $=0$.

\begin{tabular}{|c|c|c|c|c|c|}
\hline $\begin{array}{l}\text { Distribution } \\
\text { of Data }\end{array}$ & $\begin{array}{l}\text { Per } \\
\text { Mis }\end{array}$ & & $\stackrel{\text { EM }}{\text { Algorithm }}$ & $\begin{array}{c}M L \\
(1,0,0)\end{array}$ & $(5,0,0)$ \\
\hline \multirow[t]{6}{*}{ Normal } & 0 웅 & M & -.273 & -.167 & -.200 \\
\hline & & SD & .902 & .496 & .708 \\
\hline & 208 & $M$ & 2.936 & -.152 & -.285 \\
\hline & & SD & 2.049 & .551 & .686 \\
\hline & 408 & M & 4.977 & -.186 & -.295 \\
\hline & & $S D$ & 1.563 & .532 & .679 \\
\hline \multirow[t]{4}{*}{ Lognormal } & 08 & $\mathbf{M}$ & 3.134 & 3.457 & 3.874 \\
\hline & & SD & 1.192 & 1.886 & 1.659 \\
\hline & 208 & $M$ & 6.039 & 3.314 & 4.196 \\
\hline & & $\mathrm{SD}$ & 2.125 & 1.911 & 2.475 \\
\hline & 408 & $M$ & 8.350 & 3.486 & 3.658 \\
\hline & & SD & 2.678 & 1.727 & 2.059 \\
\hline
\end{tabular}


Missing $(\underline{F}(2,36)=41.24, \underline{p}<.001)$, and Technique $(\underline{F}(2,36)=$ 23.25, $\mathrm{p}<.001)$. There was also one significant 2 -way interaction effect: Percent Missing by Technique $(\underline{F}(4,72)=44.93, \underline{P}<.001)$. No other effects in the analysis were significant.

The main effect for Distribution indicated that, collapsed across all other conditions, series with lognormal distributions resulted in estimates of level $\underline{M}=4.39, \underline{S D}=1.11)$ that were significantly higher, and more divergent from the criterion value of zero, than series that were normally distributed $\underline{M}=0.71, \underline{\underline{S D}}=$ 0.39). This finding was to be expected; it is a direct effect of the experimental manipulation of the data distribution.

Simple effects tests were used to examine the nature of the interaction between Percent Missing and Technique. These tests determined that the Technique effect was nonsignificant when no data were missing, but was significant at the .001 level when either $20 \%$ or 40 of the data were missing. Values for $\underline{F}(2,72)$ were 94.32 and 314.21 respectively. Tukey tests were done as a follow up to the significant simple effects tests; the critical value of mean difference was equal to 1.02 .

Major findings. Tukey tests indicated that, at both $20 \%$ and 40\% missing data, use of the EM algorithm resulted in significant overestimates of baseline level of the series. The ML estimates were not significantly different from each other at any level of missing data. However, all level estimates were high, as they were collapsed across both Distribution conditions (i.e., normal and lognormal), since this variable did not interact with the other factors. In 
Figure 16, the Percent Missing by Technique interaction is presented separately for normal and lognormal data, for illustrative purposes. This figure demonstrates the main effect of Distribution on estimates of level, as well as the similar pattern of effects on estimation of level regardless of the distribution type.

\section{Slope: Overview.}

A $2 \times 3 \times 3$ (Distribution $\times$ Technique $x$ Percent Missing) ANOVA was used to compare estimates of slope. Distribution was a betweensubjects factor; Technique and Percent Missing were within-subjects factors. The means and standard deviations for slope are presented in Table 27.

Significant overall effects. There were significant main effects for Percent Missing $(\underline{F}(2,36)=17.13, p<.001)$, and Technique $\{\underline{F}(2,36)=12.42, \mathrm{E}<.001\}$. The interaction between Percent Missing and Technique was also significant $(\underline{F}(4,72)=$ 22.11. $\mathrm{p}<.001)$. No other effects in the analysis were significant. Simple effects tests were used to examine the nature of the interaction between Percent Missing and Technique. These tests determined that the Technique effect was nonsignificant when no data were missing, but was significant at the .001 level when either 20 \% or $40 \%$ of the data were missing. Values for $\underline{F}(2,72)$ were 51.43 and 133.72 respectively. Tukey tests were done as a follow up to the significant simple effects tests; the critical value of mean difference was equal to 0.03 .

Major findings. Tukey tests indicated that, at both $20 \%$ and 40\% missing data, use of the EM algorithm resulted in significant 
Figure 15. Technique by Percent Missing Interaction for Level

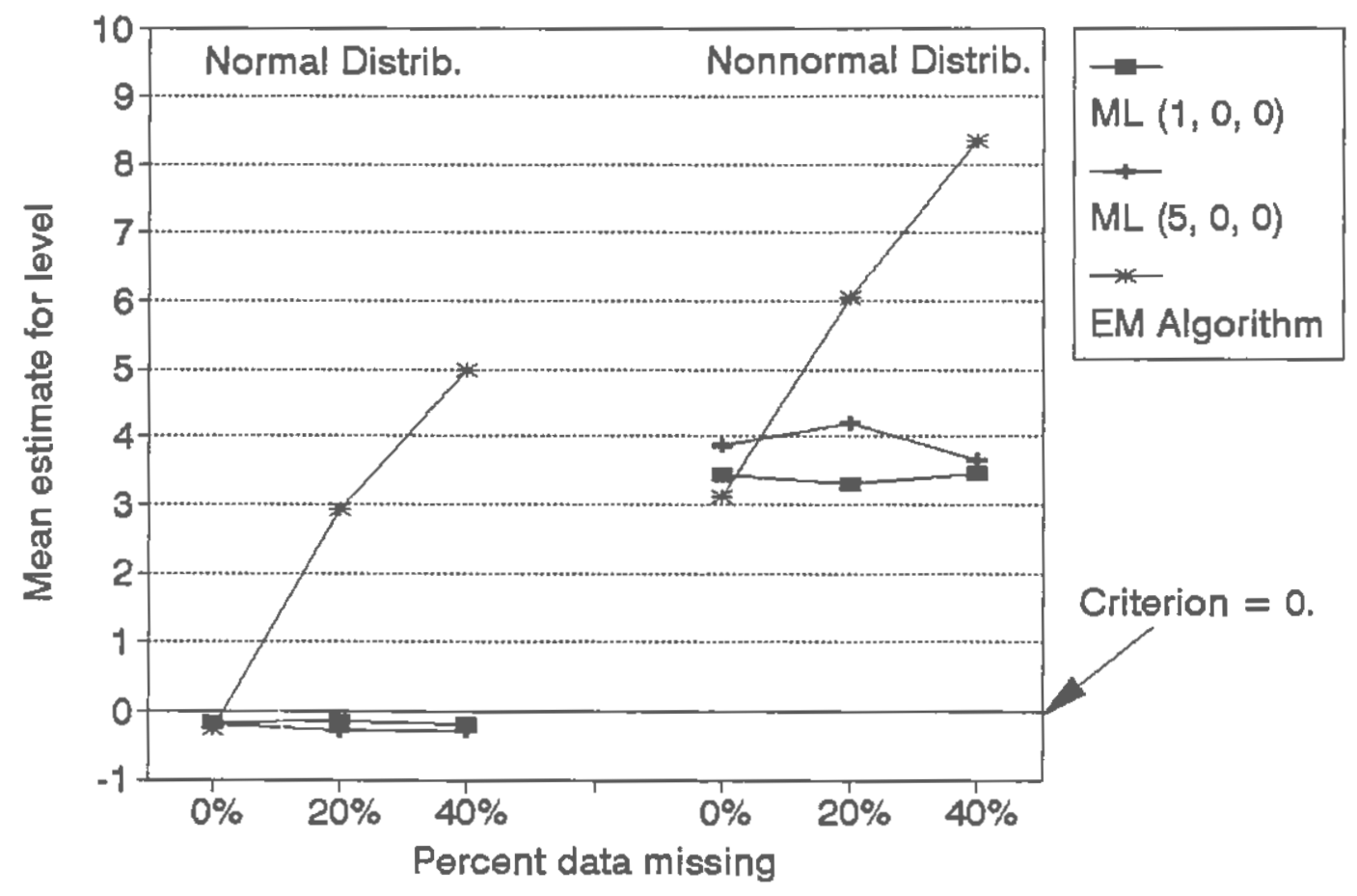


Table 27

Means and Standard Deviations of Estimated Slope.

Criterion $=0.27$.

\begin{tabular}{|c|c|c|c|c|c|}
\hline $\begin{array}{l}\text { Distribution } \\
\text { of Data }\end{array}$ & $\begin{array}{l}\text { Perce } \\
\text { Miss: }\end{array}$ & & $\stackrel{\text { EM }}{\text { Algorithm }}$ & $\begin{array}{c}\mathrm{ML} \\
(1,0,0)\end{array}$ & $\frac{M L}{(5,0,0)}$ \\
\hline \multirow[t]{6}{*}{ Normal } & 08 & $M$ & .264 & .260 & .262 \\
\hline & & $S D$ & .030 & .016 & .031 \\
\hline & 208 & $M$ & .197 & .260 & .271 \\
\hline & & $\mathrm{SD}$ & .064 & .018 & .023 \\
\hline & 408 & $\mathbf{M}$ & .152 & .261 & .270 \\
\hline & & SD & .037 & .016 & .024 \\
\hline \multirow[t]{6}{*}{ Lognormal } & 08 & $\mathbf{M}$ & .294 & .278 & .261 \\
\hline & & SD & .039 & .057 & .037 \\
\hline & 208 & $\mathbf{M}$ & .219 & .278 & .263 \\
\hline & & $S D$ & .065 & .059 & .072 \\
\hline & 408 & $\mathbf{M}$ & .187 & .274 & .263 \\
\hline & & $S D$ & .065 & .053 & .055 \\
\hline
\end{tabular}


underestimates of the slope of the series. The ML estimates were accurate, and were not significantly different from each other at any level of missing data. These results are presented in Figure 17. Again, type of data Distribution did not significantly interact with either Percent Missing or Technique used for data estimation. Error variance: overview.

A $2 \times 3 \times 3$ (Distribution $\times$ Technique $\times$ Percent Missing) ANovA was used to compare estimates of error variance. Distribution was a between-subjects factor; Technique and Percent Missing were withinsubjects factors. The means and standard deviations for variance are presented in Table 28.

Significant overall effects. There were significant main effects for Distribution $(\underline{F}(1,18)=19.80, \underline{p}<.001)$, Percent Missing $(\underline{F} \quad(2,36)=299.90, \underline{p}<.001)$, and Technique $(\underline{F}(2,36)=$ 309.38, $\mathrm{p}<.001)$. There was also one significant 2 -way interaction effect: Percent Missing by Technique $(\underline{F}(4,72)=359.81, p<.001)$. No other effects in the analysis were significant.

The main effect for data distribution indicated that, collapsed across all other conditions, series with lognormal distributions resulted in higher estimates of error variance $(\underline{M}=12.51, \underline{S D}=2.33)$ than series that were normally distributed $(\underline{M}=8.70, \underline{S D}=1.39)$. Simple effects tests were used to examine the nature of the interaction between Percent Missing and Technique. These tests determined that the technique effect was nonsignificant when no data were missing, but was significant at the .001 level when either $20 \%$ or 408 of the data were missing. Values for $\underline{F}(2,72)$ were 906.27 
Figure 17. Technique by Percent Missing Interaction for Slope

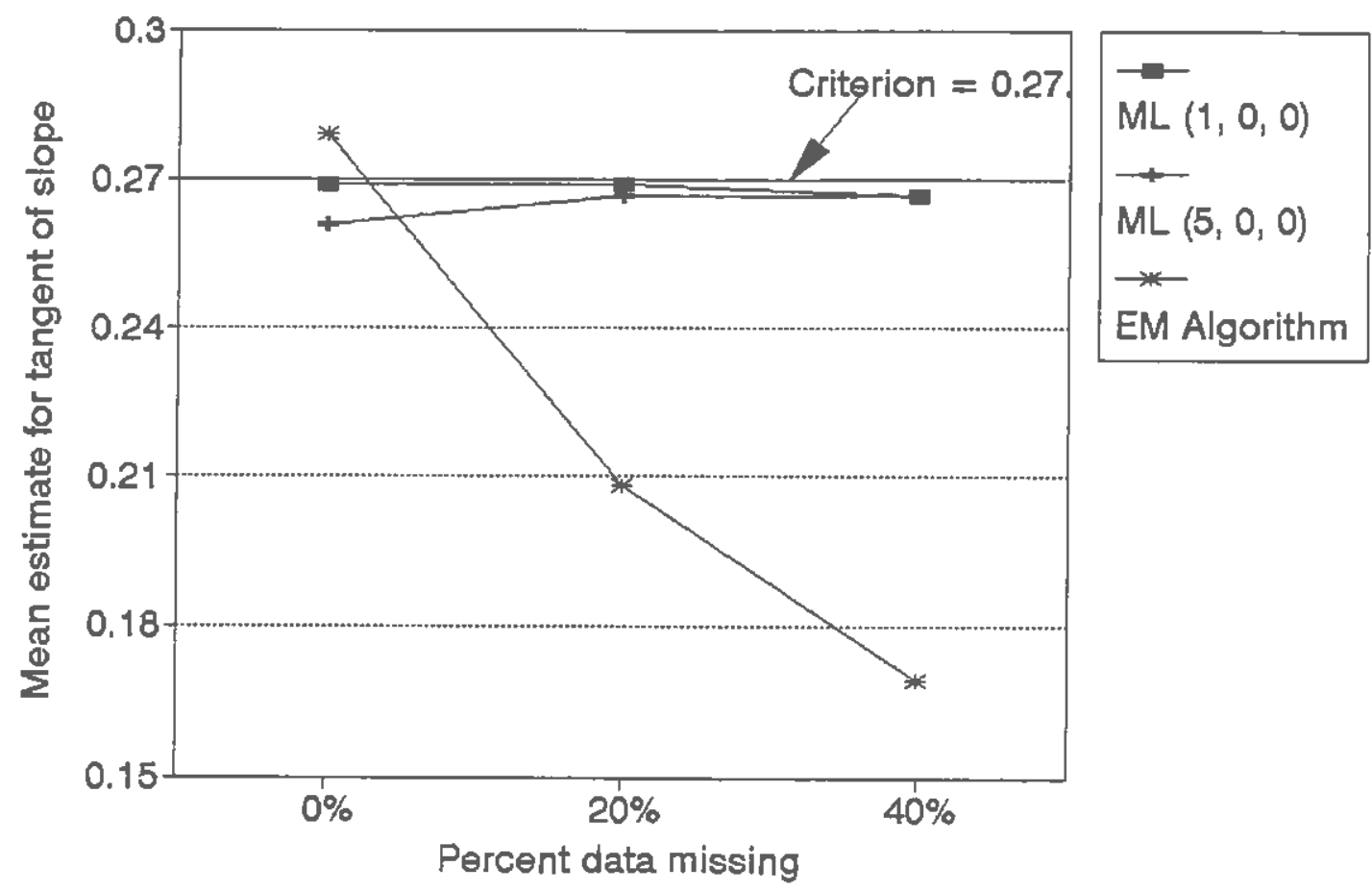


Table 28

Means and Standard Deviations of Estimated Variance.

Criterion $=1.0$.

\begin{tabular}{|c|c|c|c|c|c|}
\hline $\begin{array}{l}\text { Distribution } \\
\text { of Data }\end{array}$ & $\begin{array}{l}\text { Perc } \\
\text { Miss }\end{array}$ & & $\begin{array}{c}\text { EM } \\
\text { Algorithm }\end{array}$ & $\frac{\mathrm{ML}}{(1,0,0)}$ & $\begin{array}{c}M L \\
(5,0,0)\end{array}$ \\
\hline \multirow[t]{6}{*}{ Normal } & 08 & $\mathbf{M}$ & .972 & .914 & .853 \\
\hline & & SD & .149 & .114 & .090 \\
\hline & 208 & $\mathbf{M}$ & 27.217 & .982 & .911 \\
\hline & & $S D$ & 5.115 & .146 & .119 \\
\hline & 408 & $\mathbf{M}$ & 44.493 & 1.009 & .952 \\
\hline & & $S D$ & 8.174 & .156 & .233 \\
\hline \multirow[t]{6}{*}{ Lognormal } & 08 & $\mathbf{M}$ & 4.560 & 3.535 & 5.438 \\
\hline & & $S D$ & 2.235 & 2.771 & 2.817 \\
\hline & 208 & $\mathbf{M}$ & 29.363 & 3.824 & 5.350 \\
\hline & & $S D$ & 8.603 & 3.269 & 2.670 \\
\hline & 408 & $\mathbf{M}$ & 51.782 & 3.792 & 4.945 \\
\hline & & $S D$ & 10.762 & 1.866 & 2.999 \\
\hline
\end{tabular}


and 2873.96 respectively. Tukey tests were done as a follow up to the significant simple effects tests; the critical value of mean difference was equal to 3.05 .

Major findings. Tukey tests indicated that, at both 20 s and 40 of missing data, use of the EM algorithm resulted in significant overestimates of error variance. The ML estimates were not significantly different from each other at any level of missing data. These results are presented in Figure 18. All variance estimates were high, as they were collapsed across both data distribution conditions (i.e., normal and lognormal). Change in Level: Overview.

A $2 \times 3 \times 3$ (Distribution $\times$ Technique $\times$ Percent Missing) ANOVA was used to compare estimates of change in level. Distribution was a between-subjects factor; Technique and Percent Missing were withinsubjects factors. The means and standard deviations for change in level are presented in Table 29.

Significant overall effects. There were no significant effects in the omnibus analysis of variance, suggesting that estimates of this intervention parameter were not significantly affected by Percent Missing, Distribution, or Technique used to estimate missing data. No follow-up tests were performed for this analysis, since no overall effects were significant. Change in slope: overview.

A $2 \times 3 \times 3$ (Distribution $\times$ Technique $x$ Percent Missing) ANOVA was used to compare estimates of change in slope. Distribution was a between-subjects factor; Technique and Percent Missing were within- 
Figure 18. Technique by Percent Missing Interaction for Variance

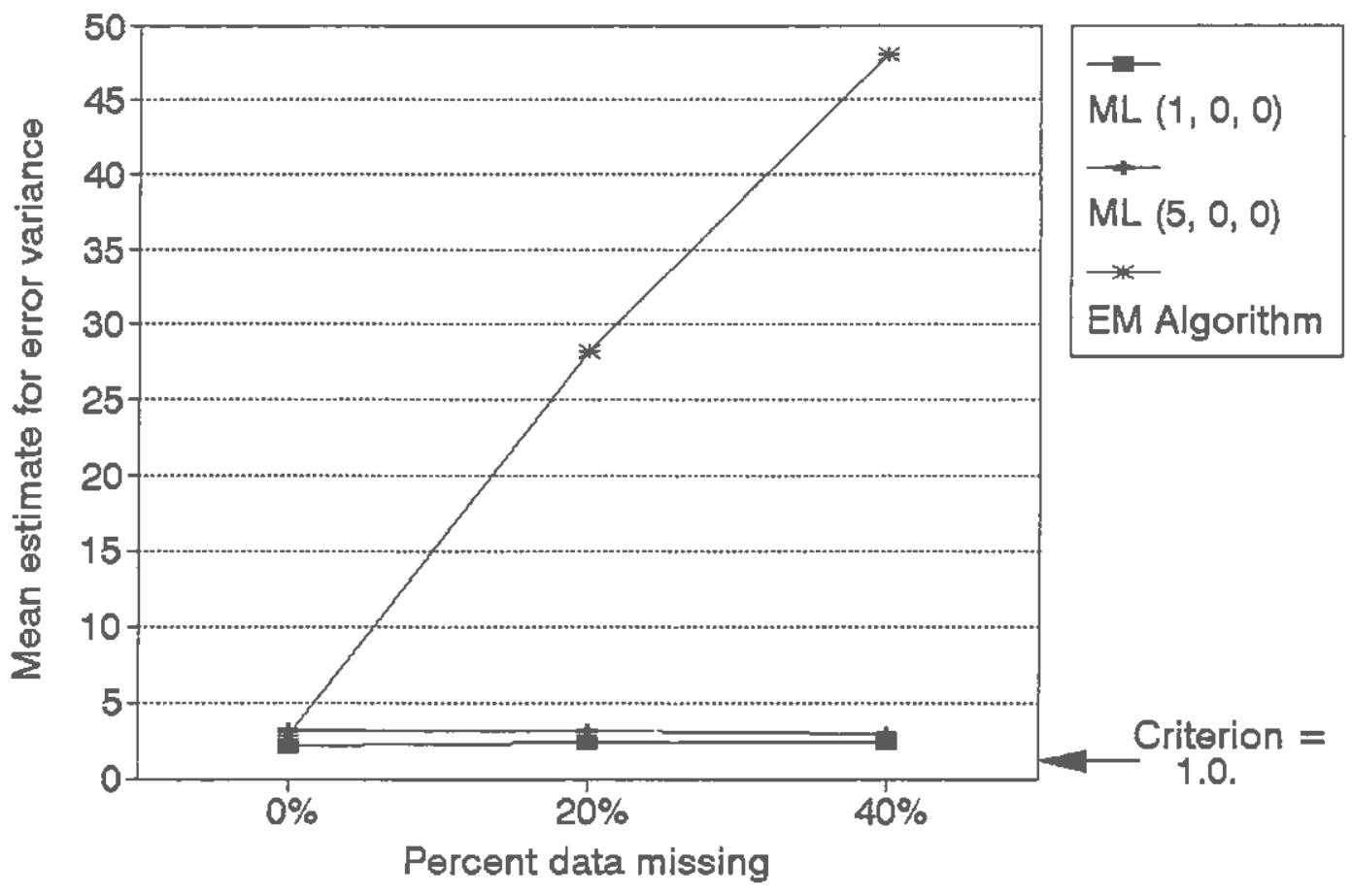


Table 29

Means and Standard Deviations of Estimated Change in Level.

Criterion $=1.5$.

\begin{tabular}{|c|c|c|c|c|c|}
\hline $\begin{array}{l}\text { Distribution } \\
\text { of Data }\end{array}$ & $\begin{array}{l}\text { Perc } \\
\text { Miss }\end{array}$ & & $\stackrel{\text { EM }}{\text { Algorithm }}$ & $\stackrel{\mathrm{ML}}{(1,0,0)}$ & $\begin{array}{c}M L \\
(5,0,0)\end{array}$ \\
\hline \multirow[t]{6}{*}{ Normal } & 08 & $\mathbf{M}$ & 1.391 & 1.959 & .858 \\
\hline & & SD & .922 & .937 & .980 \\
\hline & 208 & $M$ & 1.537 & 1.894 & 1.032 \\
\hline & & $S D$ & 2.132 & 1.083 & .819 \\
\hline & 408 & $M$ & 1.869 & 1.822 & 1.085 \\
\hline & & SD & 2.743 & 1.100 & .745 \\
\hline \multirow[t]{6}{*}{ Lognormal } & 08 & $\mathbf{M}$ & 1.861 & .518 & 2.181 \\
\hline & & SD & 1.051 & .997 & 4.396 \\
\hline & 208 & $\mathbf{M}$ & 1.887 & .756 & 1.140 \\
\hline & & $S D$ & 1.922 & 1.430 & 1.545 \\
\hline & 408 & $\mathbf{M}$ & 1.417 & .853 & 2.337 \\
\hline & & SD & 1.590 & I. 588 & 5.288 \\
\hline
\end{tabular}


subjects factors. The means and standard deviations for change in slope are presented in Table 30.

Significant overall effects. There were no significant effects in the omnibus ANOVA, suggesting that estimates of change in slope were not significantly affected by percent of data missing, data distribution, or technique used to estimate missing data. Estimates were close to zero (the criterion value) in all conditions. No follow-up tests were performed for this analysis, since no overall effects were significant.

Phi: Overview.

A $2 \times 3 \times 3$ (Distribution $x$ Technique $x$ Percent Missing) ANOVA was used to compare estimates of $\phi$. Distribution was a betweensubjects factor; Technique and Percent Missing were within-subjects factors. The means and standard deviations for $\phi$ are presented in Table 31.

Significant overall effects. Significant effects in this analysis were: Percent Missing $(\underline{F}\langle 2,36)=39.79, \underline{p}<.001)$; Technique $(\underline{F}(2,36)=68.00, \underline{P}<.001)$; and their interaction $(F$ (4), $72)=24.64, \underline{p}<.001)$. No other effects in the analysis were significant.

Simple effects tests were used to examine the nature of the interaction between Percent Missing and Technique. These tests determined that the Technique effect was nonsignificant when no data were missing, but was significant at the .001 level when either 208 or 40 of of the data were missing. Values for $\underline{F}(2,72)$ were 140.00 and 208.10 respectively. Tukey tests were done as a follow up to the 
Table 30

Meang and Standard Devietions of Estimated Chenge in slope.

criterion $=0$.

\begin{tabular}{|c|c|c|c|c|c|}
\hline $\begin{array}{c}\text { Distribution } \\
\text { of Data }\end{array}$ & $\begin{array}{l}\text { Perc } \\
\text { Miss }\end{array}$ & & $\underset{\text { Algorithm }}{\text { EM }}$ & $(1,0,0)$ & $\frac{M I}{(5,0,0)}$ \\
\hline \multirow[t]{6}{*}{ Normal } & 08 & $M$ & .013 & .009 & .006 \\
\hline & & $\mathrm{SD}$ & .042 & .030 & .034 \\
\hline & 208 & $\mathbf{M}$ & .018 & .011 & .003 \\
\hline & & SD & .058 & .030 & .028 \\
\hline & 408 & $M$ & -.007 & .012 & .004 \\
\hline & & SD & .065 & .035 & .034 \\
\hline \multirow[t]{6}{*}{ Lognormal } & 08 & $\mathbf{M}$ & -.053 & .009 & .005 \\
\hline & & $S D$ & .068 & .090 & .132 \\
\hline & 208 & $\mathbf{M}$ & -.017 & .005 & .019 \\
\hline & & SD & .087 & .088 & .112 \\
\hline & 408 & $\mathbf{M}$ & -.045 & .013 & .006 \\
\hline & & SD & .109 & .087 & .159 \\
\hline
\end{tabular}


Table 31

Means and Standard Deviations of Estimated Phi.

Criterion $=0.60$.

\begin{tabular}{|c|c|c|c|c|c|}
\hline $\begin{array}{l}\text { Distribution } \\
\text { of Data }\end{array}$ & $\begin{array}{l}\text { Pero } \\
\text { Miss }\end{array}$ & & $\underset{\text { Algorithm }}{\text { EM }}$ & $\frac{M L}{(1,0,0)}$ & $(5,0,0)$ \\
\hline \multirow[t]{6}{*}{ Normal } & 08 & $\mathbf{M}$ & .497 & .513 & .578 \\
\hline & & SD & .101 & .102 & .119 \\
\hline & 208 & $M$ & .008 & .511 & .585 \\
\hline & & SD & .078 & .108 & .187 \\
\hline & 40 옹 & $M$ & -.025 & .479 & .551 \\
\hline & & SD & .107 & .165 & .147 \\
\hline \multirow[t]{6}{*}{ Lognormal } & 0 용 & $\mathbf{M}$ & .514 & .567 & .563 \\
\hline & & SD & .087 & .105 & .137 \\
\hline & 208 & $\mathbf{M}$ & .088 & .553 & .420 \\
\hline & & $\mathrm{SD}$ & .172 & .135 & .279 \\
\hline & 408 & M & -.074 & .526 & .532 \\
\hline & & SD & .082 & .198 & .331 \\
\hline
\end{tabular}


significant simple effects tests; the ciritical value of mean difference was equal to 0.143 .

Major findings. Tukey tests indicated that, at both 208 and 40 o missing data, use of the EM algorithm resulted in significant underestimates of $\phi$; estimates were approximately zero when either 208 or 408 of the data were missing. The ML estimates were accurate (within 0.10 of criterion), and were not significantly different from each other at any level of missing data. These results are presented in Figure 19. Again, Distribution did not significantly interact with either Percent Missing or Technique used for data estimation.

\section{Discussion}

The most important findings in study 3 were the continued support for the Jones (1980) ML algorithm, the consistent problems with EMCOV, and the lack of significant effects attributed to the Distribution variable. Data distribution only had a significant main effect on estimates of level and error variance. In these analyses, the distribution effect only reflected the difference in the original simulated series due to the difference in distribution, i.e., lognormal series had higher levels and greater error variance. However, data distribution did not differentially affect data estimation by technique used; neither EMCOV nor the Jones algorithm performed worse as a function of lognormally-distributed data. All other significant effects were a function of the interaction between percent of data missing and data estimation technique.

The limitations of the EMCov program in estimating time series data were consistent with findings from study 1 and study 2 : level 
Figure 19. Technique by Percent Missing Interaction for Phi

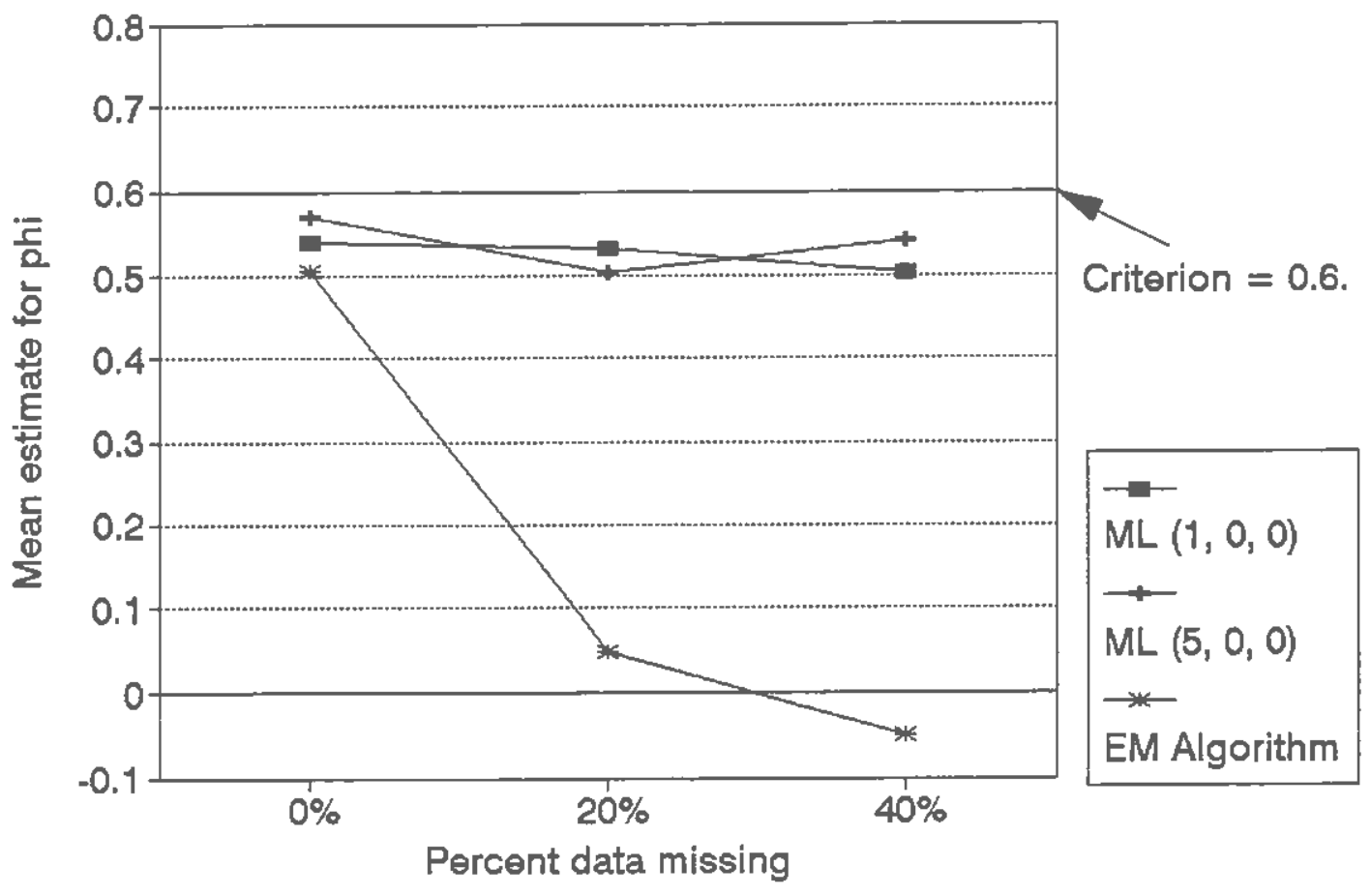


and variance were overestimated, while slope and phi were

underestimated. The good news for EMCOV is that these problems were not exacerbated by nonnormality, at least not under the conditions tested here.

The other major finding of study 3 was the consistent accuracy of the ML (Jones, 1980) algorithm available in SAS/ETS. This algorithm performed well under all conditions tested, regardless of whether a first order or a higher order $(5,0,0)$ autoregressive model was specified.

This study provided an initial exploration into time series data estimation under conditions of nonnormality. It was intended to be a limited probe for problems rather than an exhaustive study of the effects of nonnormality on data estimation for time series data. Future research should test the effects of nonnormality at various series lengths and levels of skew and kurtosis. However, even with the present study's limitations, it stili contributes to the current state of knowledge in this area. 


\section{General Discussion}

This dissertation compared the accuracy of the Jones (1980) maximum likelihood algorithm and the EM algorithm for estimating time series data under various real-world conditions. The Jones (1980) maximum likelihood algorithm in SAS/ETS had previously been found to be remarkably accurate in estimating data under ideal conditions (i.e., when the underlying ARIMA model is a $(1,0,0)$ model, and that underlying model is correctly specified, and data are missing completely at random from the series, and conditions of normality are met) (Colby \& velicer, in submission). The EM algorithm had several potential advantages, including the EM algorithm's established applicability to a broad range of missing data problems, and the fact that its use does not require model specification or normality assumptions.

These two missing data estimation algorithms were tested under commonly-encountered conditions: (1) in the absence of correct model identification; (2) with systematically missing data; and (3) with time series data that are nonnormally distributed. The results lead to several clear recommendations described below.

\section{Major findings.}

This series of studies provides convincing support for the accuracy of the Jones (1980) ML algorithm for estimating time series data. Under a broad set of circumstances, including model misspecification, data missing in various patterns, nonnormality, and different degrees and directions of dependency in the data, this algorithm produced accurate estimates of level, slope, variance, 
change in level, and change in slope, when up to $40 \%$ of data were missing. These results were consistent whether the model specification was $(1,0,0)$ or $(5,0,0)$. Estimation of the autocorrelation parameter highlighted the advantages of specifying a $(5,0,0)$ model regardless of the actual underlying ARIMA model of the data series. These findings support the original recommendation by Velicer and McDonald (1984) to use a higher order autoregressive model specification for all time series models. These encouraging results further extend the utility of time series analysis to applied researchers with similar missing data problems.

Results from these three studies also convincingly demonstrate the inappropriateness of EMCov as currently implemented for timeordered data. EMCOV resulted in severe overestimates of error variance, which would increase the probability of a Type II error in analyses regarding the effect of an intervention in interrupted time series analysis. Additionally, EM resulted in overestimates of level, and underestimates of change in level and slope. Use of the EM algorithm also precluded accurate estimates of autocorrelation. This series of studies clearly supports the use of the Jones (1980) ML algorithm with $(5,0,0)$ model specification as the most accurate method for estimating missing time series data.

It is very likely that the findings of these three studies have direct implications for other time-ordered data designs. The pattern of results found in this research demonstrated that inaccuracies in data estimation could be attributed to a failure to consider the time-ordered nature of the data to be estimated. All time-ordered 
data share the characteristics of potential dependence across multiple observations, and level and slope parameters, whether these are explicitly modeled in an analysis or not. Results described above suggest the importance of incorporating these characteristics explicitly in any longitudinal design for which a researcher is estimating missing data.

Limitations.

This series of studies has some limitations which affect the generalizability of the results. Those that are specific to individual studies have been described in the relevant study's Discussion section above. The following limitations pertain to all three studies.

First, these studies constitute a test of EMCOV2.3, which is one application of the EM algorithm. These studies cannot be said to test the EM algorithm per se. It appears that EMCOV does rot take into consideration the special characteristics of time-ordered data. A.though it was approved for use with time series data (Graham, 1995, personal communication), its accuracy for longitudinal data has not been supported by this research. It is possible that modifying the input data file to EMCOV in order to model all of the aspects of the series, e.g., observation \#, and pre-vs. post-intervention status, could enhance the accuracy of this approach. However, unless the EMCOV program were edited to prompt the user for this information interactively, and to incorporate these design aspects into its data estimation procedure, this would require significantly more work on 
the part of the researcher, particularly when compared with the Jones ML algorithm which already does all of this as part of SAS/ETS.

Second, the extreme poor performance of the EMCov program under some conditions may raise a concern about heterogeneity of variance in this design and the possible masking of significant differences between the ML approaches with various model specifications. Several considerations may moderate concern about possible masked differences between these conditions. First, analysis of variance is known to be robust to violations of homogeneity of variance. Second (and perhaps more to the point) actual differences between data approaches other than EMCOV were small, even when criterion values for significant mean differences were large. (See Discussion section of Study 1 above for additional comments).

Third, the promising results in all three of these studies were based on time series that are longer than those found in typical applied research. All simulated series had 100 data points when complete; after data were eliminated, all series had a minimum of 60 data points with which to estimate the rest of the observations. It has not been established whether the Jones (1980) algorithm would be equally accurate on shorter time series.

Recommendations and future directions.

The results of these studies considered together with the results of colby and Velicer (in submission) suggest that applied researchers should rely on the most empirically supported method to estimate missing data: the Jones (1980) ML algorithm in SAS/ETS with $(5,0,0)$ model specification. Not only has it been found to be 
accurate under all conditions tested here, but it is the easiest method to implement since it is done automatically when incomplete data series are input to SAS/ETS proc ARIMA.

Results to date in this area of research clearly require that applied researchers specify the cechniques they used for replacing missing data in all published research. As demonstrated here and in Colby and Velicer (in submission), different approaches can lead to dramatically different results even at relatively low levels of missing data.

Future research should include the following priorities: explore the effects of systematically missing data that are not MAR on the Jones algorithm; (2) develop methods of handing systematically missing data with the use of multivariate time series designs; (3) investigate the effects of nonnormality on the Jones algorithm more extensively, in order to determine the upper limits of nonnormality and the lower limits on number of observations that can be handled by the Jones algorithm; (4) test the use of the Jones algorithm on shorter time series which are more representative of those typically found in published applied behavioral studies; and (5) test the Jones algorithm on other types of time-ordered data designs, for which it will likely be more accurate than many available estimation techniques currently available.

This research points to the following major conclusions: 1. The Jones (1980) ML algorithm available in SAS/ETS is an accurate method of estimating missing time series data. When used in combination with a $(5,0,0)$ model specification, it results in 
accurate parameter estimation with up to 40 of of data missing at random. Model misspecification, systematic patterns of missing data, and lognormal data distributions did not negatively impact on ML's estimation accuracy.

2. EMcov2.3, in its current form, is inappropriate for estimating time series data. The pattern of inaccuracies suggests that EMCOV is not taking the time-ordered nature of the data into consideration. EMCOV may be reasonably accurate when all time series design parameters are modeled in the data input matrix, but this solution reguires substantially more effort than implementing the Jones (1980) ML algorithm.

3. Given the dramatically differential results of missing data estimation methods, it is critical that applied researchers routinely specify in published research how much missing data they encountered and how they handled it. 
References

Aitken, A. C. (1934). On least squares and lineal combination of observations. Rroceedings of the Royal Society of Edinburgh. 55, $42-47$

Akaike, H. (1974). A new look at the statistical model

identification. IEEE Transactions on Automatic control, 19, $716-723$.

Algina, J., \& Swaminathan, H. A. (1977). A procedure for the analysis of time series designs. Journal of Experimental Education. $45,56-60$.

Algina, J.\& Swaminathan, H. A. (1979). Alternatives to simonton's analysis of the interrupted and multiple-group time series designs. Psvchological Bulletin, 85, 919-926.

Baum, L. E., Petrie, T., Soules, G., \& weiss, N. (1970). A maximization technique occurring in the statistical analysis of probabilistic functions of Markov chains. Annals of Mathematical Statistics, 41, 164-171.

Beale, E. M. L., \& Little, R. J. A. (1975). Missing values in multivariate analysis. Journal of the Royal statistical society, Series B, 37, 129-145.

Beguin, J. M., Courieroux, C., E Monfort, A. (1980). Identification of a mixed autoregressive - moving average process: The corner method. In O. D. Anderson (Ed.), Time series: Proceedings of the International Conference held at Nottingham University, March 1979 (pp. 423-436). Amsterdam: North-Holiand. 
Bhansali, R. J., \& Downham, D. Y. (1977). Some properties of the order of an autoaggressive model selected by a generalization of Akaike's FPE-Criterion. Biometrika, 64, 547-551.

Box, G. E. P., \& Jenkins, G. M. (1976) Time-series analysis: Forecasting and control. San Francisco: Holden-Day.

Box, G. E. P., \& Pierce, W. A. (1970). Distribution of residual autocorrelations in autoregressive-integrated moving average time series models. Jounnal of American Statistical Association, 65, $1509-1526$.

Box, G. E. P., \& Tiao, G. C. (1965). A change in level of nonstationary time series. Bionetrika, 52, 181-192.

Colby, S. M., \& Velicer, W. F. Extending the utility of time series analysis by estimating missing data. Manuscript in submission.

crosbie, J. (1993). Interrupted time-series analysis with brief single-subject data. Journal of consulting and clinical Psychology, 61, 966-974.

Dempster, A. P., Laird, N. M., \& Rubin, D. B. (1977). Maximum likelihood estimation from incomplete data via the EM algorithm. Journal of the Royal statistical society. Series B, 39, 1-38.

Dixon, W. J. (1988). BMDP statistical software. [Computer program manual]. Berkeley: University of California Press.

Djuric, P. M., \& Kay, S. M. (1992). Order selection of autoregressive models. IEEE Transactions on Acoustics, Speech, and Signal Processing, 40, 2829-2833. 
Glass, G. V., Willson, V. L., \& Gottman, J. M. (1975). Design and Analysis of Time Series Experiments. Boulder: Colorado Assoc. Univ. Press.

Gottman, J. M. (1973). N-of-one and N-of-two research in psychotherapy. Psychological Bulletin, 80, 93-105. Gottman, J.M. (1981). Time series analysis: A comprehensive introduction for social scientists. New York: Cambridge University Press.

Gottman, J. M., \& Glass, G. V. (1978). Analysis of interrupted timeseries experiments. In J. Kratochwill (Ed.), Strategies to evaluate change in single subject research. New York: Academic Press.

Graham, J. W. (1995). EMCOV, Version 2.3. Computer Program. Graham, J. W., \& Hofer, S. (1993). Covariance estimation with missing values: An application of the EM algorithm. [EMCOV Reference Manual\}.

Gray, H. L., Kelly, G. D., \& McIntire, D.D. (1978). A new approach to ARIMA modeling. Communications in statistics, B7, 1-77. Hannan, E. J., \& Rissanen, J. (1982). Recursive estimation of mixed autoregressive moving average order. Biometrika, 69, 81-94. Harrop, J. W., E Velicer, W. F. (1985). A comparison of three alternative methods of time series model identification. Multivariate Behavioral Research, 20, 27-44. Harrop, J. W., \& Velicer, W. F. (1990). Computer programs for interrupted time series analysis: II. A quantitative evaluation. Multivariate Behavioral Research, 25, 233-248. 
Hartley, H. O. (1958). Maximum likelihood estimation from incomplete data. Biometrics, 14, 174-194.

Jones, R. H. (1980). Maximum likelihood fitting of ARMA models to time series missing observations. Technometrics, 22, 389-396.

Kashyap, R. L. (1977). A Bayesian comparison of different classes of dynamic models using empirical data. IEEE Transactions on Automatic Control, 22, 715-727.

Laird, N. M. (1988). Missing data in longitudinal studies. Statistics in Medicine, $7,305-315$.

Little, R. J. A., \& Rubin, D. B. (1987). Statistical analysis with missing data. New York: Wiley.

Ljung, G. M. \& Box, G. E. P. (1978). On a measure of lack of fit in time series models. Biometrika, 65, 297-303.

Marsh, J. C., \& Shibano, M. (1984). Issues in the statistical analysis of clinical time-series data. Social Work Research and Abstracts, 20, 7-12.

Mccleary, R., \&e Hay, R. A. Jr. (1980). Applied time series analysis for the social sciences, Beverly Hills, CA: Sage.

Morrison, D. F. (1983). Applied linear statistical methods. Englewood cliffs, NJ: Prentice-Hall. Padia, W. L. (1975). The consequences of model misidentification in the interrupted time-series experiment. Dissertation Abstracts International, 36, 4875A. (University Microfilms No. 76-3938). Parzen, E. (1974). Some recent advances in time series modeling. IEEe Transactions on Automatic Control, 19, 723-729. 
Pukkila, T. M. (1982). On the identification of ARIMA (p,q) models. In O.D. Anderson (ED.), Time Series Adalysis: Theory and Practice I: Proceedings of the International conference held at valencia, Spain June 1981 (pp. 81-103). Amsterdam: North-Holland. Rankin, E. D., \& Marsh. J. C. (1985). Effects of missing data on the statistical analysis of clinical time series. Social work Research and Abstracts, 21, $13-16$.

Revenstorf, D., Kessler, A., Schindler, L., Hahlweg, K., so Bluemner E. (1980). Time series analysis: Clinical applications evaluating intervention effects in diaries. In O. D. Anderson (Ed.). Analyzing Time Series: Proceedings of the International Conference held on Guernsey, Channel Islands, october, 1979 (pp. 291-312). Ansterdam: North-Holland.

Rissanen, J. (1978). Modeling by shortest data description. Automatica, 14, 465-478.

Rissanen, J. (1986a). Stochastic complexity and modeling. Amnals of Statisties, 14, 1080-1100.

Rissanen, J. (1986b) . Order estimation by accumulated prediction errors. Journal of Applied Probability, 23A, 55-61.

Rosel, J., \& Elósegui, E. (1994). Daily and weekly smoking habits: A Box-Jenkins Analysis. Psychological Reports, 75, 1639-1648.

Rubin, D. B. (1976). Inference and missing data. Biometrika, 63, 581592.

SAS Institute Ind. (1988). SAS/ETS user's guide, version 6, first edition. Cary, NC: SAS Institute Inc. 
schwartz, G. (1978). Estimating the dimension of a model. Annals of Statistics, $6,461-469$.

Simonton, D. K. (1977). Cross-sectional time-series experiments: Some suggested statistical analyses. Psychological Bulletin, 84, $489-502$.

Swaminathan, H., be Algina, J. (1977). Analysis of quasi-experimental time-series designs. Multivariate Behavioral Research, 12, 111-131. Tsay, R. S. (1984). Regression models with time series errors. Journal of the American Statistical Association, 79, 118-124. Tsay, R. S., \& Tiao, G. C. (1984). Consistent estimates of autoregressive parameters and extended sample autocorrelation function for stationary and nonstationary ARIMA models. Journal of American Statistical Association, 79, 84-90.

Velicer, W. F., \& Colby, S. M. (in press). Time series analysis for alcohol prevention and treatment research. In $K$. Bryant and $M$. windle (Eds.), New Methodological Approaches to Alcohol Prevention Research. American Psychological Association.

Velicer, W. F., \& Harrop, J. W. (1983). The reliability and accuracy of time series model identification. Evaluation Review, 7 , 551560.

Velicer, W. F., \& McDonald, R. P. (1984). Time series analysis without model identification. Multivariate Behavioral Research, 19. $33-47$.

Velicer, W. F., \& McDonald, R. P. (1991). Cross-sectional time series designs: A general transformation approach. Multivariate Behavioral Research, 26, 247-254. 
Velicer, W. F., Redding, C. A., Richmond, R. L., Greeley, J., \& Swift, W. (1992). A time series investigation of three nicotine regulation models. Addictive Behaviors, 17, 325-345. 
Appendix A: ANOVA Summary Table for Level.

\begin{tabular}{|c|c|c|c|c|}
\hline Source & df & $\underline{\text { SS }}$ & $\underline{F}$ & $\underline{\mathrm{p}}$ \\
\hline $\mathbf{M}$ & 3 & 15.23 & 1.91 & $\mathrm{~ns}$ \\
\hline DD & I & 36.69 & 13.83 & .000 \\
\hline$M \times D D$ & 3 & 13.33 & 1.68 & ns \\
\hline Sub (M $\times$ DD $)$ & 72 & 190.93 & $(\mathrm{MS}=2.65)$ & \\
\hline PM & 2 & 248.13 & 170.70 & .000 \\
\hline$P M \times M$ & 6 & 5.70 & 1.31 & no \\
\hline$P M \quad x \quad D D$ & 2 & 1.30 & 0.90 & ns \\
\hline PM $\quad x \quad M \quad x \quad D D$ & 6 & 2.17 & 0.50 & ns \\
\hline Sub $x \quad P M\left(\begin{array}{lll}M & x & D D\end{array}\right)$ & 144 & 104.66 & $(M S=0.73)$ & \\
\hline T & 3 & 1115.63 & 175.12 & .000 \\
\hline$T \times M$ & 9 & 27.43 & 1.44 & ns \\
\hline$T \times \mathrm{DD}$ & 3 & 1.60 & 0.25 & ns \\
\hline$T \times M \times D D$ & 9 & 14.59 & 0.76 & ns \\
\hline Sub $\times \quad T \quad\left(\begin{array}{lll}M & \times & D D\end{array}\right)$ & 216 & 458.69 & $(M S=2.12)$ & \\
\hline PM $\mathbf{x} \quad T$ & 6 & 739.98 & 170.73 & .000 \\
\hline$P M \times T \times M$ & 18 & 15.97 & 1.23 & ns \\
\hline$P M \times T \times D D$ & 6 & 2.74 & 0.63 & ns \\
\hline PM $\quad \begin{array}{lllllllllllllll} & \mathbf{T} & \mathbf{x} & \mathbf{M} & \mathbf{x} & \mathrm{DD}\end{array}$ & 18 & 7.04 & 0.54 & $\mathrm{~ns}$ \\
\hline Sub $\times P M \times T(M \times D D)$ & 432 & 312.06 & $(M S=0.72)$ & \\
\hline $\begin{array}{l}M=\text { ModeI } \\
D D=\text { Direction of Depe } \\
P M=\text { Percent Missing } \\
T \quad=\text { Technique }\end{array}$ & $y$ & & & \\
\hline
\end{tabular}


Appendix B: ANOVA Surmary Table for slope.

\begin{tabular}{|c|c|c|c|}
\hline Source & df & $\underline{\mathrm{sS}}$ & $\underline{\underline{F}}$ \\
\hline M & 3 & .16 & 22.55 \\
\hline DD & 1 & .08 & 35.67 \\
\hline$M \times D D$ & 3 & .16 & 22.12 \\
\hline sub $(M \times D D)$ & 72 & .17 & $(M S=0.00)$ \\
\hline PM & 2 & .08 & 60.42 \\
\hline $\mathrm{PM} \times \mathrm{M}$ & 6 & .00 & .62 \\
\hline $\mathrm{PM} \times \mathrm{xD}$ & 2 & .00 & .86 \\
\hline $\mathrm{PM} \times \mathrm{M} \times \mathrm{DD}$ & 6 & .00 & .79 \\
\hline Sub $\times P M(M \times D D)$ & 144 & .09 & $(M S=0.00)$ \\
\hline $\mathbf{T}$ & 3 & .42 & 68.86 \\
\hline $\mathbf{T} \times \mathbf{M}$ & 9 & .02 & .84 \\
\hline $\mathbf{T} \mathbf{x} \mathrm{DD}$ & 3 & .00 & .74 \\
\hline$T \times M \times D D$ & 9 & .02 & .84 \\
\hline Sub $\times T(M \times D D)$ & 216 & .43 & $(\mathrm{MS}=0.00)$ \\
\hline PM $x T$ & 6 & .25 & 66.58 \\
\hline 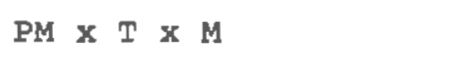 & 18 & .01 & .70 \\
\hline$P M \times T \times D D$ & 6 & .00 & .80 \\
\hline $\mathrm{PM} \times \mathbf{x} \times \mathbf{M} \times \mathrm{DD}$ & 18 & .01 & 1.00 \\
\hline Sub $\times P M \times T(M \times D D)$ & 432 & .27 & $(M S=0.00)$ \\
\hline
\end{tabular}

$M$ = Model

$\mathrm{DD}=$ Direction of Dependency

$\mathrm{PM}=$ Percent Missing

$T=$ Technique 
Appendix C: ANOVA Summary Tablo for Variance.

\begin{tabular}{|c|c|c|c|c|}
\hline Source & df & $\underline{\mathbf{S S}}$ & $\underline{\underline{F}}$ & $\underline{p}$ \\
\hline M & 3 & 35.45 & 1.13 & $\Omega \mathbf{s}$ \\
\hline $\mathrm{DD}$ & 1 & 6.77 & .65 & תs \\
\hline$M \times D D$ & 3 & 14.08 & .45 & ns \\
\hline Sub (M $\mathbf{x} \quad$ DD $)$ & 72 & 755.50 & $(\mathrm{MS}=10.49)$ & \\
\hline PM & 2 & 19229.04 & 1285.65 & .000 \\
\hline$P M \times M$ & 6 & 89.01 & 1.98 & ns \\
\hline$P M \times D D$ & 2 & 3.89 & .26 & ns \\
\hline$P M \times M \times D D$ & 6 & 31.46 & .70 & ns \\
\hline Sub $\times P M\left(\begin{array}{lll}M & \times & D D\end{array}\right)$ & 144 & 1076.88 & $(\mathrm{MS}=7.48)$ & \\
\hline $\mathrm{T}$ & 3 & 92521.17 & 2978.83 & .000 \\
\hline$T \times M$ & 9 & 121.75 & 1.31 & ns \\
\hline$T \times \mathrm{DD}$ & 3 & 26.50 & .85 & ns \\
\hline$T \times M \times D D$ & 9 & 52.63 & .56 & ns \\
\hline Sub $\times \quad T(M \times D D)$ & 216 & 2236.29 & $(M S=10.35)$ & \\
\hline PM $\mathrm{x} T$ & 6 & 56476.86 & 1267.54 & .000 \\
\hline$P M \times T \times M$ & 18 & 262.22 & 1.96 & ns \\
\hline$P M \quad x \quad T \quad x \quad D D$ & 6 & 12.20 & .27 & ns \\
\hline$P M \quad x \quad T \quad x \quad M \quad x \quad D D$ & 18 & 97.85 & .73 & ne \\
\hline Sub $x P M \times T(M \times D D)$ & 432 & 3208.04 & $(M S=7.43)$ & \\
\hline
\end{tabular}

\footnotetext{
$M=$ Model

$\mathrm{DD}=$ Direction of Dependency

PM $=$ Percent Missing

$\mathrm{T}=$ Technique
} 
Appendix D: ANOVA Sumary Table for Change in Level.

\begin{tabular}{|c|c|c|c|c|}
\hline Source & $\underline{\mathrm{df}}$ & $\underline{\text { SS }}$ & $\underline{F}$ & P \\
\hline M & 3 & 25.10 & 3.91 & Is \\
\hline DD & 1 & 9.19 & 4.30 & ns \\
\hline$M \times D D$ & 3 & 4.27 & .67 & ns \\
\hline Sub $(M \times D D)$ & 72 & 153.91 & $(M S=2.14)$ & \\
\hline PM & 2 & 7.43 & 4.01 & ns \\
\hline PM $\times$ M & 6 & 4.68 & .84 & ns \\
\hline$P M \times D D$ & 2 & .93 & .50 & ns \\
\hline$P M \times M \times D D$ & 6 & 6.11 & 1.10 & ns \\
\hline$S u b \times P M(M \times D D)$ & 144 & 133.30 & $(M S=.93)$ & \\
\hline T & 3 & 34.32 & 11.44 & .004 \\
\hline$T \times M$ & 9 & 17.00 & 1.89 & ns \\
\hline T $X \mathrm{DD}$ & 3 & 10.06 & 3.35 & ns \\
\hline$T \times M \times D D$ & 9 & 32.42 & 3.60 & ns \\
\hline Sub $\times \quad T \quad\left(\begin{array}{lll}M & x & D D\end{array}\right)$ & 216 & 531.32 & $\langle M S=2.46\rangle$ & \\
\hline$P M \times T$ & 6 & 31.38 & 5.64 & .000 \\
\hline$P M \times T \times M$ & 18 & 8.60 & .51 & ns \\
\hline$P M \times T \times D D$ & 6 & 4.73 & .85 & ns \\
\hline$P M \times T \times M \times D D$ & 18 & 20.04 & 1.20 & ns \\
\hline Sub $\times \quad P M \quad x \quad T \quad\left(\begin{array}{lll}M & \times & D D\end{array}\right)$ & 432 & 400.96 & $(M S=.93)$ & \\
\hline
\end{tabular}

$M=$ Model

$\mathrm{DD}=$ Direction of Dependency

PM = Percent Missing

$T=$ Technique 
Appendix E: ANOVA Summary Table for Change in slope.

\begin{tabular}{|c|c|c|c|c|}
\hline Source & $\underline{\mathrm{df}}$ & $\underline{\underline{S S}}$ & $\underline{F}$ & $\underline{p}$ \\
\hline$M$ & 3 & .09 & 5.59 & .002 \\
\hline $\mathrm{DD}$ & 1 & .06 & 10.49 & .002 \\
\hline$M \times D D$ & 3 & .12 & 7.20 & .000 \\
\hline Sub $(M \times D D)$ & 72 & .40 & $(\mathrm{MS}=.01)$ & \\
\hline PM & 2 & .01 & 3.09 & ns \\
\hline$P M \quad x \quad M$ & 6 & .00 & .39 & ns \\
\hline$P M \quad x \quad D D$ & 2 & .01 & 1.97 & ns \\
\hline $\mathrm{PM} \times \mathrm{x} \times \mathrm{x}$ DD & 6 & .00 & .27 & ns \\
\hline Sub $\times$ PM $(M \times D D)$ & 144 & .20 & $(M S=.00)$ & \\
\hline $\mathbf{T}$ & 3 & .02 & 1.15 & ns \\
\hline$T \times M$ & 9 & .09 & 1.66 & ns \\
\hline $\mathbf{T} \times \mathrm{DD}$ & 3 & .02 & 1.37 & ns \\
\hline $\mathbf{T} \mathbf{x} \mathbf{M} \mathrm{DD}$ & 9 & .08 & 1.52 & ns \\
\hline Sub $x \quad T \quad\left(\begin{array}{lll}M & \mathbf{x} & \mathrm{DD}\end{array}\right)$ & 216 & 1.25 & $(M S=.01)$ & \\
\hline $\mathbf{P M} \mathbf{x} \quad T$ & 6 & .02 & 2.91 & .009 \\
\hline PM $\quad x \quad T \quad x \quad M$ & 18 & .01 & .50 & ns \\
\hline $\mathrm{PM} \times \mathrm{x} \times \mathrm{DD}$ & 6 & .00 & .48 & ns \\
\hline$P M \times T \times M \times D D$ & 18 & .02 & .90 & ns \\
\hline Sub $\times$ PM $\times T$ (MXDD) & 432 & .55 & $(M S=.00)$ & \\
\hline
\end{tabular}

$M=$ Model

$D D=$ Direction of Dependency

PM = Percent Missing

$T=$ Technique 
Appendix F: ANOVA Sumary Table for Positive Phi. (Autoregressive Models)

\begin{tabular}{|c|c|c|c|c|}
\hline Source & df & SS & $\underline{\underline{F}}$ & p \\
\hline $\mathbf{M}^{2}$ & 2 & .24 & 2.96 & ns \\
\hline Sub (M) & 27 & 1.08 & $(M S=0.12)$ & \\
\hline PM & 2 & 1.07 & 62.40 & .000 \\
\hline $\mathbf{P M} \times \mathbf{M}$ & 4 & .12 & 3.50 & ns \\
\hline $\operatorname{Sub}(P M \times M)$ & 54 & .46 & $(M S=.01)$ & \\
\hline$T$ & 3 & 11.44 & 77.21 & .000 \\
\hline$T \times M$ & 6 & .44 & 1.50 & $s$ \\
\hline Sub $(T \times M)$ & 81 & 4.00 & $(M S=.05)$ & \\
\hline$P M \times T$ & 6 & 5.40 & 105.22 & .000 \\
\hline$P M \times T \times M$ & 12 & .24 & 2.38 & .008 \\
\hline Sub $\times P M(T \times M)$ & 162 & 1.39 & $(M S=.01)$ & \\
\hline
\end{tabular}

${ }^{1} M=$ Model (all models except $(0,0,1)$ model)

PM = Percent Missing

$T=$ Technique 
Appendix G: ANOVA Summary Table for Negative Phi. (Autoregressive Models)

\begin{tabular}{|c|c|c|c|}
\hline Source & df & $\underline{\mathrm{SS}}$ & $\underline{\boldsymbol{F}}$ \\
\hline $\mathbf{M}^{1}$ & 2 & .15 & 3.00 \\
\hline Sub (M) & 27 & .66 & $(M S=.07)$ \\
\hline PM & 2 & 2.37 & 106.55 \\
\hline PM $\times$ M & 4 & .04 & .93 \\
\hline Sub $(P M \times M)$ & 54 & .60 & $(M S=.01)$ \\
\hline$T$ & 3 & 9.00 & 93.17 \\
\hline $\mathrm{T} \times \mathrm{M}$ & 6 & .81 & 4.21 \\
\hline Sub $(T \times M)$ & 81 & 2.61 & $(\mathrm{MS}=.03)$ \\
\hline$P M \times T$ & 6 & 3.96 & 54.77 \\
\hline $\mathrm{PM} \times \mathrm{T} \times \mathrm{M}$ & 12 & .16 & 1.08 \\
\hline Sub $\times P M(T \times M)$ & 162 & 1.95 & (MS $=.01)$ \\
\hline
\end{tabular}

${ }^{1} \mathrm{M}=$ Model (all models except $(0,0,1)$ model)

PM = Percent Missing

$T$ = Technique 
Appendix 8: ANOVA Summary Table for Positive Phi. (Moving Averages Model)

$\begin{array}{lrccc}\text { Source } & \text { df } & \text { SS } & \text { F } & \text { P } \\ \text { PM } & 2 & .01 & 1.10 & \text { ns } \\ \text { Sub (PM) } & 18 & .10 & (\text { MS }=.01) \\ T^{1} & 1 & .62 & 25.13 & .001 \\ \text { Sub (T) } & 9 & .22 & (\text { MS }=.02) & \\ \text { PM x T } & 2 & .02 & 1.12 & \mathrm{~ns} \\ \text { Sub (PM X T) } & 18 & .14 & \text { (MS }=.01) & \end{array}$

PM = Percent Missing

${ }^{1} T$ = Technique (Maximum Likelihood with 1,0,0 vs, 5, 0,0 specification) 
Appendix I: ANOVA Summary Table for Negative Phi. (Moving Averages Model)

\section{Source}

PM

Sub (PM)

$T^{1}$

Sub (T)

PM $\times \mathrm{T}$

Sub (PM $\times$ T) df

2

18

1

9

2

18 $\underline{\text { SS }}$

.09

.14

.13

.21

.00

0.18

.16

$(M S=.00)$

(MS $=.01$ )

5.37

$($ MS $=.02)$ e

ns

ns

ns

PM = Percent Missing

${ }^{2} T$ = Technique (Maximum Likelihood with $1,0,0$ vs. 5, 0,0 specification) 
Appendix J: ANOVA Summary Table for Positive Theta.

\begin{tabular}{lrrrr} 
Source & df & SS & $\underline{F}$ & P \\
PM & 2 & 2.13 & 49.15 & .000 \\
Sub (PM) & 18 & .39 & $(M S=.02)$ & \\
$T^{1}$ & 1 & & & .000 \\
Sub (T) & 9 & 1.85 & 227.41 & .000 \\
PM X T & 2 & .07 & $(M S=.01)$ & \\
Sub (PM X T) & 18 & 1.50 & 28.83 & \\
& & .47 & $(M S=.03)$ & \\
\hline
\end{tabular}

$P M=$ Percent Missing

${ }^{2} T$ = Technique (Maximum Iikelihood with $0,0,1$ specification vs. EM Algorithm) 
Appendix K: ANOVA Summary Table for Negativa Theta.

Source

PM

Sub (PM)

$T^{2}$

Sub (T)

PM $\times T$

Sub (PM $\times$ T) $\underline{\text { df }}$

2

18

1

9

2

18
$\underline{S S}$

2.08

.18

1.85

.18

1.02

.25
$\underline{F}$

모

101.69

.000

(MS $=.01$ )

92.60

.000

$(M S=.02)$

37.14

.000

PM = Percent Missing

${ }^{1} T$ = Technique (Maximum Likelihood with $0,0,1$ specification vs. EM Algorithm) 
Appendix L: Follow up of $T \times M \times$ PM interaction in the estimation of positive phi. (simple simple effects tests).

Effects of

Technique at:
Model

$(1,0,0)$

20 웅

$(2,0,0)$

$(3,0,0)$
408

Percent

Missing

08

208

408

0 용

208

40 영
$\underline{E}(3,243)$

$$
2.70
$$

104.95 * *

$98 \cdot 20 * *$

5.41 *

119.82 * *

202.70 *

$4.50 *$

$104.50 *$ *

147.30 * *

\# $\mathrm{P}<.01 \quad \mathrm{P}<.001$ 
Appendix M: ANOVA Summary Table for Level.

\begin{tabular}{|c|c|c|c|c|}
\hline Source & $\underline{d f}$ & $\underline{\underline{S S}}$ & $\underline{F}$ & p \\
\hline DD & 1 & 12.31 & 7.83 & ns \\
\hline Sub (DD) & 18 & 28.28 & $(\mathrm{MS}=1.57)$ & \\
\hline PM & 2 & 32.08 & 48.86 & .001 \\
\hline$P M \quad x \quad D D$ & 2 & 0.19 & 0.28 & ns \\
\hline Sub $(P M \quad x \quad D D)$ & 36 & 12.59 & $(M S=0.35)$ & \\
\hline $\mathrm{T}$ & 2 & 150.82 & 277.91 & .001 \\
\hline $\mathrm{T} \times \mathrm{DD}$ & 2 & 1.04 & 1.92 & $\mathrm{~ns}$ \\
\hline Sub $(T \times D D)$ & 36 & 9.77 & $(M S=0.27)$ & \\
\hline $\mathbf{P}$ & 2 & 334.48 & 51.39 & .001 \\
\hline$P \times D D$ & 2 & 0.18 & 0.03 & ns \\
\hline Sub $(P \times D D)$ & 36 & 117.17 & $(M S=3.25)$ & \\
\hline $\mathbf{T} \times \mathbf{P M}$ & 4 & 19.84 & 14.12 & .001 \\
\hline$T \times P M \times D D$ & 4 & 0.33 & 0.24 & ns \\
\hline Sub $\times T(P M \times D D)$ & 72 & 25.29 & $(M S=.35)$ & \\
\hline$P M \times P$ & 4 & 64.26 & 41.67 & .001 \\
\hline$P M \times P \quad x \quad D D$ & 4 & 1.33 & 0.86 & ns \\
\hline Sub $\times P M(P \times D D)$ & 72 & 27.76 & $(M S=.39)$ & \\
\hline$T \times P$ & 4 & 289.37 & 228.35 & .001 \\
\hline$T \times P \times D D$ & 4 & 2.07 & 1.63 & ns \\
\hline Sub $\times T(P \times D D)$ & 72 & 22.81 & $(M S=.32)$ & \\
\hline$T \times P \times P M$ & 8 & 40.06 & 12.06 & .001 \\
\hline$T \times P \times P M \times D D$ & 8 & 1.22 & 0.37 & ns \\
\hline Sub $x$ T $\times P(P M \times D D)$ & 144 & 59.79 & $(M S=.42)$ & \\
\hline
\end{tabular}

\footnotetext{
$\mathrm{DD}=$ Direction of Dependency

$P M=$ Percent Missing

$T$ = Technigue

$P$ = Pattern of Missing Data
} 
Appendix N: ANOVA Summary Table for slope.

\begin{tabular}{|c|c|c|c|c|}
\hline Source & gf & $\underline{S S}$ & $\underline{\mathbf{F}}$ & P \\
\hline$D D$ & 1 & 0.00 & 1.10 & ns \\
\hline Sub (DD) & 18 & 0.04 & $(M S=.00)$ & \\
\hline PM & 2 & 0.03 & 32.03 & .001 \\
\hline PM $\mathbf{x} \quad \mathrm{DD}$ & 2 & 0.00 & 1.62 & ns \\
\hline Sub (PM $\times \quad D D)$ & 36 & 0.01 & $(M S=.00)$ & \\
\hline $\mathbf{T}$ & 2 & 0.02 & 22.36 & .001 \\
\hline $\mathrm{T} \times \mathrm{DD}$ & 2 & 0.00 & 0.12 & ns \\
\hline Sub $(T \times$ DD $)$ & 36 & 0.02 & $\{M S=.00)$ & \\
\hline $\mathbf{P}$ & 2 & 0.06 & 10.15 & .001 \\
\hline$P \quad \mathbf{x} \quad \mathrm{DD}$ & 2 & 0.00 & 0.37 & ns \\
\hline Sub $(P \quad x \quad D D)$ & 36 & 0.10 & $(\mathrm{MS}=.00)$ & \\
\hline$T \times P M$ & 4 & 0.02 & 11.48 & .001 \\
\hline$T \times P M \times D D$ & 4 & 0.00 & 1.89 & ns \\
\hline$S u b \times T(P M \times D D)$ & 72 & 0.02 & $(\mathrm{MS}=.00)$ & \\
\hline$P M \times P$ & 4 & 0.05 & 27.15 & .001 \\
\hline $\mathrm{PM} \times \mathbf{P} \times \mathrm{xD}$ & 4 & 0.00 & 2.20 & ns \\
\hline Sub $\times P M(P \quad x \quad D D)$ & 72 & 0.03 & $(M S=.00)$ & \\
\hline $\mathrm{T} \times \mathrm{P}$ & 4 & 0.06 & 24.52 & .001 \\
\hline $\mathbf{T} \mathbf{x} \mathbf{P} \times \mathrm{DD}$ & 4 & 0.00 & 0.47 & ns \\
\hline Sub $\times T(P \times D D)$ & 72 & 0.04 & $(M S=.00)$ & \\
\hline$T \times P \times P M$ & 8 & 0.03 & 9.21 & .001 \\
\hline $\mathrm{T} \times \mathrm{P} \times \mathrm{PM} \times \mathrm{DD}$ & 8 & 0.01 & 1.69 & ns \\
\hline Sub $\times T \times P(P M \times D D)$ & 144 & 0.05 & $\{M S=.00\}$ & \\
\hline
\end{tabular}

$\mathrm{DD}=$ Direction of Dependency

PM = Percent Missing

$T=$ Technique

P = Pattern of Missing Data 
Appendix 0: ANOVA Summary Table for Variance.

\begin{tabular}{|c|c|c|c|c|}
\hline Source & $\underline{\mathrm{df}}$ & $\underline{\text { sS }}$ & $\underline{\underline{F}}$ & E \\
\hline $\mathrm{DD}$ & 1 & 3.44 & 0.41 & ns \\
\hline Sub (DD) & 18 & 149.38 & $(M S=8.30)$ & \\
\hline PM & 2 & 137.38 & 8.28 & .01 \\
\hline$P M \times D D$ & 2 & 25.73 & 1.55 & ns \\
\hline Sub $(P M \times D D)$ & 36 & 298.64 & $(M S=8.30)$ & \\
\hline $\mathbf{T}$ & 2 & 17181.60 & 1343.66 & .001 \\
\hline$T \quad \mathbf{x} D$ & 2 & 2.60 & 0.20 & ns \\
\hline Sub ( $T \times D D)$ & 36 & 230.17 & $(M S=6.39)$ & \\
\hline $\mathbf{P}$ & 2 & 54433.46 & 3712.07 & .001 \\
\hline $\mathbf{P} \times \mathrm{DD}$ & 2 & 11.95 & 0.82 & ns \\
\hline Sub $(P \times D D)$ & 36 & 263.95 & $(M S=7.33)$ & \\
\hline $\mathrm{T} \times \mathrm{PM}$ & 4 & 72.48 & 2.58 & ns \\
\hline$T \times P M \times D D$ & 4 & 23.05 & 0.82 & ns \\
\hline sub $\times$ T $(P M \times D D)$ & 72 & 505.93 & $(M S=7.03)$ & \\
\hline$P M \times P$ & 4 & 259.84 & 7.81 & .001 \\
\hline$P M \quad x \quad P \quad x \quad D D$ & 4 & 48.06 & 1.44 & ns \\
\hline $\operatorname{Sub} \times \mathrm{PM}\left(\begin{array}{lll}P & \mathrm{DD}\end{array}\right)$ & 72 & 598.80 & $(M S=8.32)$ & \\
\hline$T \times P$ & 4 & 33999.48 & 1308.83 & .001 \\
\hline$T \times P \times D D$ & 4 & 5.23 & 0.20 & $\mathrm{~ns}$ \\
\hline Sub $\times \quad T \quad\left(\begin{array}{lll}P & x & D D\end{array}\right)$ & 72 & 467.58 & $(M S=6.49)$ & \\
\hline$T \times P \times P M$ & 8 & 141.93 & 2.52 & .01 \\
\hline$T \times P \times P M \times D D$ & 8 & 43.15 & 0.77 & ns \\
\hline Sub $\times T \times P(P M \times D D)$ & 144 & 1012.51 & $(\mathrm{MS}=7.03)$ & \\
\hline
\end{tabular}

$\mathrm{DD}=$ Direction of Dependency

PM = Percent Missing

$T=$ Technique

$\stackrel{P}{P}=$ Pattern of Missing Data 
Appendix P: ANOVA Summary Table for Change in Level.

\section{Source}

DD

Sub (DD)

PM

PM $x$ DD

$S u b(P M \times D D)$

T

T $\mathbf{x}$ DD

Sub ( $\mathrm{T} \times \mathrm{DD})$

P

$P \times D D$

Sub $(P \quad x \quad D D)$

T $x$ PM

$T \times \mathrm{PM} \times \mathrm{DD}$

Sub $x$ T (PM $X$ DD)

$P M \times P$

PM $x$ P $\times$ DD
Sub $\times$ PM ( $P \times D D)$

PM $x$ P $\times$ DD
Sub $\times$ PM ( $P \times D D)$

T $\mathbf{x}$

$T \times P \times D D$

Sub $x \quad T(P \times D D)$

$T \times P \times P M$

T $x \quad P \quad P M \times D D$

$S u b \times T \times P(P M \times D D)$ $\underline{\mathrm{df}}$

1

18

2

2

36

2

2

36

2

2

36

4

4

72

4

72

4

4

72

8

8

144

\section{$\underline{\text { SS }}$}

0.00

60.86

56.42

7.38

27.26

61.36

2.19

31.12

125.86

35.11

186.17

40.48

6.09

61.63

115.49

I 1.42

54.32

112.39

5.11

59.39

83.90

9.03
126.24

$\underline{E}$

0.00

D

ns

(MS $=3.38$ )

$\begin{array}{rl}37.26 & .001 \\ 4.88 & \mathrm{~ns}\end{array}$

(MS $=.76$ )

$$
35.49
$$

1.27

.001

(MS $=.86$ )

$$
12.17
$$

3.39

.001

(MS=5.17)

11.82

.001

1.78

(MS $=.86$ )

ns ns

ns

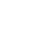

144

126.24

$\begin{array}{cc}38.27 & .001 \\ 3.78 & \mathrm{~ns} \\ (\mathrm{MS}=.75) & \end{array}$

$\begin{array}{cc}34.06 & .001 \\ 1.55 & \text { ns } \\ (\mathrm{MS}=.82) & \end{array}$

$\begin{array}{cc}11.96 & .001 \\ 1.29 & \mathrm{ng} \\ (\mathrm{MS}=.88) & \end{array}$

$\mathrm{DD}=$ Direction of Dependency

PM = Percent Missing

$T=$ Technique

$P$ = Pattern of Missing Data 
Appendix Q: ANOVA Summary Table for Change in slope.

\section{Source}

DD

Sub (DD)

PM

PM $\mathrm{x}$ DD

Sub (PM $\times$ DD)

$\mathbf{T}$

T $\times$ DD

Sub ( $\mathrm{x}$ DD)

$\mathbf{P}$

$P \times$ DD

Sub ( $P$ x DD)

T $\times$ PM

$T \times P M \quad D D$

Sub $x$ T $(P M \quad x \quad D D)$

PM $X$

$P M \times P \times D D$

$S u b \times P M(P \quad x \quad D D)$

$T \times P$

$T \times P \times D D$

Sub $\quad x \quad T \quad\left(\begin{array}{llll}P & \mathbf{x} & \mathrm{DD}\end{array}\right)$

T X P X PM

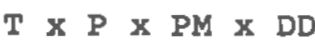

Sub $\times$ T $\times P$ (PM $X$ DD)

\section{df}

1

18

2

2

36

2

36

2

2

36

4

4

72

4

4

72

4
4
72

8

8

144

\section{$\underline{s S}$}

0.01

0.15

0.16

0.00

0.05

0.05

0.00

0.04

0.15

0.00

0.23

0.10

0.00

0.08

0.32

0.00

0.09

0.09

0.00

0.08

0.21

0.01

0.16
$\underline{\underline{F}}$

F

p

1.36 ns

(MS=.01)

$$
53.88
$$

0.42

ns

(MS $=.00$ )

$\begin{array}{rr}23.92 & .001 \\ 1.07 & 05\end{array}$

(MS $=.00)$

$\begin{array}{cc}12.22 & .001 \\ 0.10 & \mathrm{~ns} \\ (\mathrm{MS}=.01) & \end{array}$

$\begin{array}{cc}21.92 & .001 \\ 0.69 & \mathrm{~ns} \\ (\mathrm{MS}=.00) & \end{array}$

$\begin{array}{rl}61.51 & .001 \\ 0.54 & \text { ns }\end{array}$

(MS $=.00$ )

$\begin{array}{rl}20.53 & .001 \\ 0.94 & \mathrm{~ns}\end{array}$

$(M S=.00)$

$\begin{array}{rl}22.93 & .001 \\ 1.12 & \text { ns }\end{array}$

(MS $=.00$ )

$\mathrm{DD}=$ Direction of Dependency

$\mathrm{PM}=$ Percent Missing

$\mathrm{T}=\mathrm{Technique}$

$\mathbf{P}$ = Pattern of Missing Data 
Appendix R: ANOVA Sumary Table for Positive Phi.

\begin{tabular}{|c|c|c|c|c|}
\hline Source & $\underline{d f}$ & $\underline{\mathrm{SS}}$ & $\underline{\mathbf{F}}$ & p \\
\hline PM & 2 & 0.62 & 28.83 & .001 \\
\hline Sub (PM) & 18 & 0.19 & $(M S=.01)$ & \\
\hline $\mathbf{T}$ & 2 & 1.75 & 113.48 & .001 \\
\hline Sub $\{T\rangle$ & 18 & 0.14 & (MS $=.01)$ & \\
\hline $\mathbf{P}$ & 2 & 9.82 & 47.84 & .001 \\
\hline Sub (P) & 18 & 1.85 & $(M S=.10)$ & \\
\hline $\mathbf{T} \times \mathbf{P M}$ & 4 & 0.38 & 9.71 & .001 \\
\hline Sub (T X PM) & 36 & 0.35 & $(\mathrm{MS}=.01)$ & \\
\hline PM $\mathrm{x} P$ & 4 & 2.00 & 47.18 & .001 \\
\hline Sub $(P M \times P)$ & 36 & 0.38 & $\langle M S=.01\}$ & \\
\hline $\mathbf{T} \times \mathbf{P}$ & 4 & 3.66 & 111.09 & .001 \\
\hline Sub $\left(\begin{array}{lll}T & \mathbf{P}\end{array}\right)$ & 36 & 0.30 & $(M S=.01)$ & \\
\hline $\mathrm{T} \times \mathrm{P} \times \mathrm{PM}$ & 8 & 1.07 & 21.65 & .001 \\
\hline Sub $x T(P \quad x \quad P M)$ & 72 & 0.44 & $(M S=.01)$ & \\
\hline
\end{tabular}

$\mathrm{DD}=$ Direction of Dependency

PM = Percent Missing

$T=$ Technique

$P$ = Pattern of Missing Data 
Appendix S: ANOVA Sumary Table for Negative Phi.

\begin{tabular}{|c|c|c|c|c|}
\hline Source & $\underline{d f}$ & $\underline{\underline{s}}$ & $\underline{\mathbf{F}}$ & $\underline{p}$ \\
\hline PM & 2 & 0.73 & 14.49 & .001 \\
\hline Sub (PM) & 18 & 0.45 & $(M S=.03)$ & \\
\hline $\mathbf{T}$ & 2 & 1.91 & 41.40 & .001 \\
\hline Sub $(T)$ & 18 & 0.42 & $(M S=.02)$ & \\
\hline$P$ & 2 & 8.77 & 30.03 & .001 \\
\hline sub (P) & 18 & 2.63 & $(M S=.15)$ & \\
\hline$T \times P M$ & 4 & 0.39 & 5.84 & .01 \\
\hline Sub $(T \times P M)$ & 36 & 0.60 & $(M S=.02)$ & \\
\hline$P M \times P$ & 4 & 1.45 & 16.97 & .001 \\
\hline Sub (PM $\times$ P $P$ ) & 36 & 0.77 & $(M S=.02)$ & \\
\hline$T \times P$ & 4 & 4.22 & 36.66 & .001 \\
\hline $\operatorname{Sub}(T \times P)$ & 36 & 1.04 & $(M S=.03)$ & \\
\hline$T \times P \times P M$ & 8 & 1.06 & 7.80 & .001 \\
\hline Sub $x \quad T(P \times P M)$ & 72 & 1.23 & $(\mathrm{MS}=.02)$ & \\
\hline
\end{tabular}

\footnotetext{
$D D=$ Direction of Dependency

$\mathrm{PM}=$ Percent Missing

$T=$ Technique

$P$ = Pattern of Missing Data
} 
Appendix $T$ : Follow up of $T$ X P X PM interaction in the estimation of level. (Simple simple effects tests).

\begin{tabular}{|c|c|c|c|}
\hline $\begin{array}{l}\text { Effects of } \\
\text { Technique at: }\end{array}$ & $\begin{array}{c}\text { Missing Data } \\
\text { Pattern }\end{array}$ & $\begin{array}{l}\text { Percent } \\
\text { Missing }\end{array}$ & $\underline{E}(2,216$ \\
\hline & Random & 208 & $295.89 \star \star$ \\
\hline & Consecutive & 208 & $65.71 *$ \\
\hline & Alternating & 208 & 2.02 \\
\hline & Random & 408 & $902.75 * \pi$ \\
\hline & Consecutive & 408 & $331.54 *$ \\
\hline & Alterneting & 408 & $308.06 * *$ \\
\hline
\end{tabular}

\# $\underline{\underline{p}<.001}$ 
Appendix U: Follow up of T X P X PM interaction in the estimation of slope. (Simple simple effects tests).

$\begin{array}{lccc}\begin{array}{l}\text { Effects of } \\ \text { Technique at: }\end{array} & \begin{array}{c}\text { Missing Data } \\ \text { Pattern }\end{array} & \begin{array}{c}\text { Percent } \\ \text { Missing }\end{array} & \text { F (2, 216) } \\ & \text { Random } & 208 & 119.05 * \\ \text { Consecutive } & 208 & 0.95 \\ \text { Alternating } & 208 & 2.38 \\ \text { Random } & 408 & 261.90 * \text { * } \\ \text { Consecutive } & 408 & 23.81 \text { * } \\ \text { Alternating } & 408 & 47.62 \text { * }\end{array}$

* $\mathrm{p}<.001$ 
Appendix V: Follow up of T X P X PM interaction in the estimation of variance. (Simple simple effects tests).

Missing Data Pattern

Random

Consecutive

Alternating

Random

Consecutive

Alternating
208

208

20 웅

40 응

408

408
$\underline{F}(2,216)$

$1315.60 *$

886.11 *

831.25 **

$3777.64 * *$

3290.77 * *

2943.32 **

$\star \star \quad \mathrm{P}<.001$ 
Appendix W: Follow up of T X P X PM interaction in the estimation of change in level. (Simple simple effects tests).

$\begin{array}{lccr}\begin{array}{l}\text { Effects of } \\ \text { Technique at: }\end{array} & \begin{array}{c}\text { Missing Data } \\ \text { Pattern }\end{array} & \begin{array}{c}\text { Percent } \\ \text { Missing }\end{array} & \text { F }(2,216) \\ & & & \\ \text { Random } & 208 & 9.37 * \\ \text { Consecutive } & 208 & 89.27 \text { * } \\ \text { Alternating } & 208 & 35.79 * \text { * } \\ \text { Random } & 408 & 13.64 \text { * } \\ \text { Consecutive } & 408 & 316.05^{*} \\ \text { Alternating } & 408 & 37.14 *\end{array}$

$\star \mathrm{p}<.001$ 
Appendix X: Follow up of T X P X PM interaction in the estimation of change in slope. (Simple simple effects tests).

\begin{tabular}{|c|c|c|c|}
\hline $\begin{array}{l}\text { Effects of } \\
\text { Technique at: }\end{array}$ & $\begin{array}{c}\text { Missing Data } \\
\text { Pattern }\end{array}$ & $\begin{array}{l}\text { Percent } \\
\text { Missing }\end{array}$ & $\underline{E}(2,216$ \\
\hline & Random & $20 \%$ & $9.09 *$ \\
\hline & Consecutive & 208 & 0.02 \\
\hline & Alternating & 208 & $495.50 \%$ \\
\hline & Random & 408 & $9.09 * \pi$ \\
\hline & Consecutive & 408 & 0.01 \\
\hline & Alternating & 408 & $190.91 *$ \\
\hline
\end{tabular}

$\# \quad \underline{\mathrm{e}<.001}$ 
Appendix Y: Follow up of $T$ X P X PM interaction in the estimation of positive phi. (Simple simple effects tests).

Effects of

Technique at:
Missing Data

Pattern

Random

Consecutive

Alternating

Random

Consecutive

Alternating
208

208

208

408

408

408
$F(2,108)$

285.51 **

$47.83 *$ *

753.62**

$285.51 *$ *

97.10 **

$911.59 * *$

$\$$ t $<<.001$ 
Appendix Z: Follow up of T X P X PM interaction in the estimation of negative phi. (simple simple effects tests).

\begin{tabular}{|c|c|c|c|}
\hline $\begin{array}{l}\text { Effects of } \\
\text { Technique at: }\end{array}$ & $\begin{array}{c}\text { Missing Data } \\
\text { Pattern }\end{array}$ & $\begin{array}{l}\text { Percent } \\
\text { Missing }\end{array}$ & $\underline{E}(2,108$ \\
\hline & Random & 208 & $99.52 \star \star$ \\
\hline & Consecutive & 208 & $207.62 * \star$ \\
\hline & Alternating & $20 \%$ & $23.33 * *$ \\
\hline & Random & 408 & $77.62 * \star$ \\
\hline & Consecutive & 408 & $277.14 * *$ \\
\hline & Alternating & 408 & $50.00 * *$ \\
\hline
\end{tabular}

** $\mathrm{p}<.001$ 
Appendix AA: ANOVA Summary Table for Level.

\begin{tabular}{|c|c|c|c|}
\hline Source & $\mathrm{df}$ & $\underline{\mathbf{S S}}$ & $\underline{\underline{F}}$ \\
\hline $\mathrm{D}$ & 1 & 610.73 & 98.69 \\
\hline Sub (D) & 18 & 111.40 & $(\mathrm{MS}=6.19)$ \\
\hline PM & 2 & 87.55 & 41.24 \\
\hline$P M \times D$ & 2 & .01 & 0.00 \\
\hline Sub $\left(\begin{array}{lll}P M & \times & D\end{array}\right)$ & 36 & 38.21 & $(M S=1.06)$ \\
\hline$T$ & 2 & 244.99 & 23.25 \\
\hline$T \times D$ & 2 & 5.96 & 0.57 \\
\hline Sub $\left(\begin{array}{lll}T & \mathbf{x} & \mathrm{D}\end{array}\right)$ & 36 & 189.65 & $(M S=5.27)$ \\
\hline $\mathrm{PM} \times \mathrm{T}$ & 4 & 189.71 & 44.93 \\
\hline PM $\times \quad T \times D$ & 4 & 1.15 & 0.27 \\
\hline Sub $\times$ PM $(T \times D)$ & 72 & 76.00 & $(\mathrm{MS}=1.06)$ \\
\hline
\end{tabular}

\footnotetext{
$\mathrm{D}$ = Distribution

$\mathrm{PM}=$ Percent Missing

$T=$ Technique
} 
Appendix BB: ANOVA Summary Table for Slope.

\begin{tabular}{|c|c|c|c|}
\hline Source & df & $\underline{\text { ss }}$ & $\underline{\underline{F}}$ \\
\hline D & 1 & 0.01 & 1.39 \\
\hline Sub (D) & 18 & 0.10 & $(M S=.01)$ \\
\hline PM & 2 & 0.04 & 17.13 \\
\hline$P M \times D$ & 2 & 0.00 & 0.10 \\
\hline Sub $(P M \quad x \quad D)$ & 36 & 0.04 & $(M S=.00)$ \\
\hline$T$ & 2 & 0.09 & 12.42 \\
\hline$T \times D$ & 2 & 0.01 & 1.21 \\
\hline Sub $\left(\begin{array}{lll}T & \times & D\end{array}\right)$ & 36 & 0.13 & $(M S=.00)$ \\
\hline$P M \times T$ & 4 & 0.09 & 22.11 \\
\hline$P M \times T \times D$ & 4 & 0.00 & 0.12 \\
\hline Sub $x$ PM $\left(\begin{array}{lll}T & \times & D\end{array}\right)$ & 72 & 0.07 & $(M S=.00)$ \\
\hline
\end{tabular}

\footnotetext{
$\mathrm{D}$ = Distribution

$\mathrm{PM}=$ Percent Missing

$T=$ Technique
} 
Appendix CC: ANOVA Summery Table for Variance.

\begin{tabular}{|c|c|c|c|c|}
\hline Source & $\mathrm{d} f$ & $\underline{\text { s }}$ & $\underline{\underline{F}}$ & P \\
\hline D & 1 & 653.12 & 19.80 & .001 \\
\hline Sub (D) & 18 & 593.85 & $(\mathrm{MS}=32.99)$ & \\
\hline PM & 2 & 6895.64 & 299.90 & .001 \\
\hline $\mathrm{PM} \times \mathrm{D}$ & 2 & 18.94 & 0.82 & $\mathrm{~ns}$ \\
\hline Sub $(P M \times D)$ & 36 & 413.87 & $(M S=11.50)$ & \\
\hline$T$ & 2 & 22462.84 & 309.38 & .001 \\
\hline$T \times D$ & 2 & 25.32 & 0.35 & ns \\
\hline Sub $\left(\begin{array}{lll}T & x & D\end{array}\right)$ & 36 & 1306.92 & $(M S=36.30)$ & \\
\hline$P M \times T$ & 4 & 13798.16 & 359.81 & .001 \\
\hline $\mathrm{PM} \times \mathrm{T} \times \mathrm{D}$ & 4 & 52.52 & 1.37 & ns \\
\hline Sub $\times P M(T \times D)$ & 72 & 690.27 & (MS $=9.59$ ) & \\
\hline
\end{tabular}

\footnotetext{
$\mathrm{D}=$ Distribution

PM = Percent Missing

$T=$ Technique
} 
Appendix DD: ANOva Sumary Table for Change in Level.

\begin{tabular}{|c|c|c|c|}
\hline Source & df & $\underline{\mathrm{SS}}$ & $\underline{E}$ \\
\hline D & 1 & 0.14 & 0.02 \\
\hline Sub (D) & 18 & 129.33 & $(M S=7.18)$ \\
\hline PM & 2 & 1.08 & 0.17 \\
\hline$P M \times D$ & 2 & 0.89 & 0.14 \\
\hline Sub $(P M \times D)$ & 36 & 111.66 & $(M S=3.10)$ \\
\hline $\mathbf{T}$ & 2 & 3.96 & 0.22 \\
\hline$T \times D$ & 2 & 33.06 & 1.84 \\
\hline Sub $(T \times D)$ & 36 & 324.03 & $(M S=9.00)$ \\
\hline$P M \times T$ & 4 & 3.23 & 0.36 \\
\hline $\mathrm{PM} \times \mathrm{T} \times \mathrm{D}$ & 4 & 6.85 & 0.75 \\
\hline Sub $\times P M(T \times D)$ & 72 & 163.40 & $(\mathrm{MS}=2.27)$ \\
\hline
\end{tabular}

\footnotetext{
$\mathrm{D}=$ Distribution

$\mathrm{PM}=$ Percent Missing

$T=$ Technigue
} 
Appendix EE: ANOVA Summary Table for change in slope.

\begin{tabular}{|c|c|c|c|}
\hline Source & $\underline{\mathrm{d} f}$ & $\underline{\text { sS }}$ & $\underline{F}$ \\
\hline $\mathrm{D}$ & 1 & 0.01 & 0.50 \\
\hline Sub (D) & 18 & 0.32 & $(\mathrm{MS}=.02)$ \\
\hline PM & 2 & 0.00 & 1.71 \\
\hline$P M \quad \mathrm{x} D$ & 2 & 0.00 & 0.86 \\
\hline Sub $(P M \quad x \quad D)$ & 36 & 0.03 & $(\mathrm{MS}=.00)$ \\
\hline$T$ & 2 & 0.02 & 0.64 \\
\hline$T \times D$ & 2 & 0.02 & 0.65 \\
\hline$S u b\left(\begin{array}{lll}T & \times\end{array}\right)$ & 36 & 0.64 & $(\mathrm{MS}=.02)$ \\
\hline$P M \times T$ & 4 & 0.01 & 1.43 \\
\hline$P M \times T \times D$ & 4 & 0.00 & 0.59 \\
\hline Sub $\times P M(T \times D)$ & 72 & 0.07 & $(M S=.00)$ \\
\hline
\end{tabular}

\footnotetext{
$D=$ Distribution

PM = Percent Missing

$\mathrm{T}=$ Technique
} 
Appendix FF: ANOVA Sumnary Table for Phi.

\begin{tabular}{|c|c|c|c|}
\hline Source & $\underline{\mathrm{df}}$ & $\underline{\text { ss }}$ & $\underline{E}$ \\
\hline $\mathrm{D}$ & 1 & 0.00 & 0.00 \\
\hline Sub (D) & 18 & 0.60 & $(M S=.03)$ \\
\hline PM & 2 & 1.51 & 39.79 \\
\hline$P M \times D$ & 2 & 0.01 & 0.24 \\
\hline Sub $\left(\begin{array}{lll}P M & \times & D\end{array}\right)$ & 36 & 0.68 & $(M S=.02)$ \\
\hline$T$ & 2 & 5.29 & 68.00 \\
\hline$T \times D$ & 2 & 0.10 & 1.34 \\
\hline Sub $(T \times D)$ & 36 & 1.40 & $(M S=.04)$ \\
\hline $\mathrm{PM} \times \mathrm{T}$ & 4 & 2.07 & 24.64 \\
\hline $\mathrm{PM} \quad \mathrm{x} \quad \mathrm{T} \quad \mathrm{x} \quad \mathrm{D}$ & 4 & 0.11 & 1.26 \\
\hline Sub $x$ PM $(T \times D)$ & 72 & 1.51 & (MS $=.02$ ) \\
\hline
\end{tabular}

\footnotetext{
$D=$ Distribution

PM = Percent Missing

$\mathrm{T}=$ Technigue
} 
Bibliography

Aitken, A. C. (1934). On least squares and lineal combination of observations. Proceedings of the Royal Society of Edinburgh, 55 , $42-47$

Akaike, H. (1974). A new look at the statistical model

identification. IEEE Transactions on Automatic Control, 19. $716-723$.

Algina, J., \& Swaminathan, H. A. (1977). A procedure for the analysis of time series designs. Journal of Experimental Education, 45, $56-60$.

Algina, J. \& Swaminathan, H. A. (1979). Alternatives to Simonton's analysis of the interrupted and multiple-group time series designs. Psychological Bulletin, 86, 919-926.

Baum, L. E., Petrie, T., soules, G., \& Weiss, N. (1970). A maximization technique occurring in the statistical analysis of probabilistic functions of Markov chains. Annals of Mathematical Statistics, 41, 164-171.

Beale, E. M. L., \& Little, R. J. A. (1975). Missing values in multivariate analysis. Journal of the Royal statistical society, Series $\mathrm{B}, \underline{37}, 129-145$.

Beguin, J. M., Courieroux, C., \& Monfort, A. (1980). Identification of a mixed autoregressive - moving average process: The corner method. In O. D. Anderson (Ed.), Time Series: Proceedings of the International Conference held at Nottingham University. March 1979 (pp. 423-436). Amsterdam: North-Holland. 
Bhansali, R. J., \& Downham, D. Y. (1977). Some properties of the order of an autoaggressive model selected by a generalization of Akaike's FPE-Criterion. Biometrika, 64, 547-551.

Box, G. E. P., \& Jenkins, G. M. (1976) Time-series analysis: Forecasting and control. San Francisco: Holden-Day.

Box, G. E. P., \& Pierce, W. A. (1970). Distribution of residual autocorrelations in autoregressive-integrated moving average time series models. Journal of American Statistical Association, 65, $1509-1526$

Box, G. E. P., \& Tiao, G. C. (1965). A change in level of nonstationary time series. Biometrika, 52, 181-192.

Colby, S. M., se velicer, W. F. Extending the utility of time series analysis by estimating missing data. Manuscript in submission.

crosbie, J. (1993). Interrupted time-series analysis with brief single-subject data. Journal of consulting and Clinical Psychology, 61, 966-974.

Dempster, A. P., Laird, N. M., \& Rubin, D. B. (1977). Maximum likelihood estimation from incomplete data via the EM algorithm. Journal of the Royal statistical society, Series B, 39, 1-38.

Dixon, W. J. (1988). BMDP statistical software. [Computer program manual]. Berkeley: University of California Press.

Djuric, P. M. \& Kay, S. M. (1992). Order selection of autoregressive models. IEEE Transactions on Acoustics, Speech, and Signal Processing, $\underline{40}, 2829-2833$. 
Glass, G. V., Willson, V. L. \& \& Gottman, J. M. (1975). Design and Analysis of Time Series Experiments. Boulder: Colorado Assoc. Univ. Press.

Gottman, J. M. (1973). N-of-one and N-of-two research in psychotherapy. Psychological Bulletin, 80, 93-105.

Gottman, J. M. (1981). Time series analysis: A comprehensive introduction for social scientists. New York: Cambridge University Press.

Gottman, J. M. \& \& Glass, G. V. (1978). Analysis of interrupted timeseries experiments. In J. Kratochwill (Ed.), Strategies to evaluate change in single subject research. New York: Academic Press.

Graham, J. W. (1995). EMCov, Version 2.3. Computer Program. Graham, J. W., \& Hofer, S. (1993). Covariance estimation with missing values: An application of the EM algorithm. [EMCOV Reference Manua1].

Gray, H. L., Kelly, G. D., \& McIntire, D.D. (1978). A new approach to ARIMA modeling. Communications in statistics, B7, 1-77.

Hannan, E. J., \& Rissanen, J. (1982). Recursive estimation of mixed autoregressive moving average order. Biometrika, 69, 81-94. Harrop, J. W., \& Velicer, W. F. (1985). A comparison of three alternative methods of time series model identification. Multivariate Behavioral Research, 20, 27-44. Harrop, J.W., \& Velicer, W. F. (1990). Computer programs for interrupted time series analysis: II. A quantitative evaluation. Multivariate Behavioral Research, 25, 233-248. 
Hartley, H. O. (1958). Maximum likelihood estimation from incomplete data. Biometrics, 14, 174-194.

Jones, R. H. (1980). Maximum likelihood fitting of ARMA models to time series missing observations. Technometrics, 22, 389-396.

Kashyap, R. L. (1977). A Bayesian comparison of different classes of dynamic models using empirical data. IEEE Transactions on Automatic Control, 22, 715-727.

Laird, N. M. (1988). Missing data in longitudinal studies. Statistics in Medicine, 7, 305-315.

Little, R. J. A., \& Rubin, D. B. (1987). Statistical analysis with missing data. New York: Wiley.

Ljung, G. M., \& Box, G. E. P. (1978). On a measure of lack of fit in time series models. Biometrika, 65, 297-303.

Marsh, J. C., \& Shibano, M. (1984). Issues in the statistical analysis of clinical time-series data. Social work Research and Abstracts, 20, 7-12.

Mccleary, R., \& Hay, R. A. Jr. (1980). Applied time series analysis for the social sciences. Beverly Hills, CA: Sage.

Morrison, D. F. (1983). Applied linear statistical methods.

Englewood cliffs, NJ: Prentice-Hall.

Padia, W. L. (1975). The consequences of model misidentification in

the interrupted time-series experiment. Dissertation Abstracts

International, 36, 4875A. (University Microfilms No. 76-3938).

Parzen, E. (1974). Some recent advances in time series modeling. IEEE Transactions on Automatic control, 19, 723-729. 
Pukkila, T. M. (1982). On the identification of ARIMA ( $p, q)$ models. In O.D. Anderson (ED.), Time Series Analysis: Theory and Practice I: Proceedings of the International conference held at valencia. Spain. June 1981 (pp. 81-103). Amsterdam: North-Holland. Rankin, E. D., \& Marsh, J. C. (1985). Effects of missing data on the statistical analysis of clinical time series. Social Work Research and Abstracts, 21, 13-16.

Revenstorf, D., Kessler, A., Schindler, L., Hahlweg, K., \& Bluemner E. (1980). Time series analysis: Clinical applications evaluating intervention effects in diaries. In O. D. Anderson (Ed.). Analyzing Time Series: Proceedings of the International Conference held on Guernsey. Channel Islands, October, 1979 (pp. 291-312). Amsterdam: North-Holland.

Rissanen, J. (1978). Modeling by shortest data description. Automatica, 14, 465-478.

Rissanen, J. (1986a). Stochastic complexity and modeling. Annals of Statistics, 14, 1080-1100.

Rissanen, J. (1986b). Order estimation by accumulated prediction errors. Journal of Applied Probability, 23A, 55-61.

Rosel, J., Ex Elósegui, E. (1994). Daily and weekly smoking habits: A Box-Jenkins Analysis. Psychological Reports, 75, $1639-1648$. Rubin, D. B. (1976). Inference and missing data. Biometrika, 63, 581592.

SAS Institute Ine. (1988). SAS/ETS user's guide, version 6, first edition. Cary, NC: SAS Institute Ine. 
Schwartz, G. (1978). Estimating the dimension of a model. Annals of Statistics, $\underline{6}, 461-469$.

Simonton, D. K. (1977). Cross-sectional time-series experiments: Some suggested statistical analyses. Psychological Bulletin, 84, $489-502$.

Swaminathan, H., \& Algina, J. (1977). Analysis of quasi-experimental time-series designs. Multivariate Behavioral Resegrch, 12, 111-131. Tsay, R. S. (1984). Regression models with time series errors. Journal of the American Statistical Association, 79, 118-124. Tsay, R. S., \& Tiao, G. C. (1984). Consistent estimates of autoregressive parameters and extended sample autocorrelation function for stationary and nonstationary ARIMA models. Journal of American Statistical Association, 79, 84-90.

Velicer, W. F., \& colby, S. M. (in press). Time series analysis for alcohol prevention and treatment research. In $K$. Bryant and $M$. Windle (Eds.), New Methodological Approaches to Alcohol Prevention Research. American Psychological Association.

Velicer, W. F., \& Harrop, J.W. (1983). The reliability and accuracy of time series model identification. Evaluation Review, 7, 551560.

Velicer, W. F., \& McDonald, R. P. (1984). Time series analysis without model identification. Multivariate Behavioral Research, $19,33-47$.

Velicer, W. F., \& McDonald, R. P. (1991). Cross-sectional time series designs: A general transformation approach. Multivariate Behavioral Research, 26, 247-254. 
Velicer, W. F., Redding, C. A., Richmond, R. L., Greeley, J., \&x Swift, w. (1992). A time series investigation of three nicotine regulation models. Addictive Behaviors, 17, 325-345. 